\section{D) Check for updates}

Cite this: Mater. Adv., 2021, 2, 5006

Received 3rd June 2021,

Accepted 24th June 2021

DOI: $10.1039 / \mathrm{d} 1 \mathrm{ma} 00490 \mathrm{e}$

rsc.li/materials-advances

\title{
The rational design of inorganic and organic material based nanocomposite hybrids as $\mathrm{Na}$-ion battery electrodes
}

\author{
Rangaswamy Puttaswamy, ${ }^{a}$ Nataraj Sanna Kotrappanavar (D *ab and \\ Debasis Ghosh iD *a
}

\begin{abstract}
The past decade has witnessed significant research interest in rechargeable Na-ion batteries (SIBs). Compared to Li-ion batteries (LIBs), SIBs promise to be much more cost-effective, thanks to the high abundance of sodium, and they are capable of providing energy densities close to LIBs when the cost is normalized. However, although promising, conventional SIB electrodes suffer from low capacities/poor rate capabilities due to slow $\mathrm{Na}^{+}$diffusion kinetics and inferior cycle lives due to structural and phase instability. To mitigate these issues, much effort has been devoted towards designing composite electrodes, where the components can synergistically boost the capacities, rate capabilities, and cycling stabilities. While the rational design of electrodes has been able to overcome certain hurdles relating to SIB technology, summarizing coherent approaches for addressing issues in this field is important in order to direct the future sustainable and economic development of commercially viable high-performance electrodes. In this review, we have summarized recent advances relating to the rational design of carbonaceous and noncarbonaceous nanocomposites involving different inorganic and organic materials for SIB applications. Synthesis strategies, synergistic interactions, and electrochemical performance data are summarized. Existing issues are covered and potential solutions for designing better electrodes are also proposed.
\end{abstract}

${ }^{a}$ Centre for Nano \& Material Sciences, Jain University, Jain Global Campus, Bangalore 562112, India. E-mail: g.debasis@jainuniversity.ac.in, debasisghosh88@gmail.com, sk.nataraj@jainuniversity.ac.in

${ }^{b}$ IMDEA Water Institute, Avenida Punto Com, 2. Parque Científico Tecnológico de la Universidad de Alcalá, Alcalá de Henares, 28805 Madrid, Spain

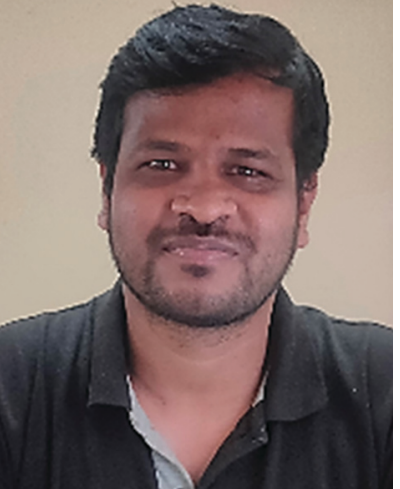

Rangaswamy Puttaswamy
Rangaswamy $P$ completed his doctoral work in chemistry at Kuvempu University, India in 2020. His doctoral research was focused on the synthesis and electrochemical studies of electrode materials for energy storage applications, such as lithium- and sodium-ion batteries. Currently he is working as a Senior Research Associate at the Centre for Nano and Materials Science, Jain University, India. His current research is focused on electrode materials for aqueous metal ion batteries.

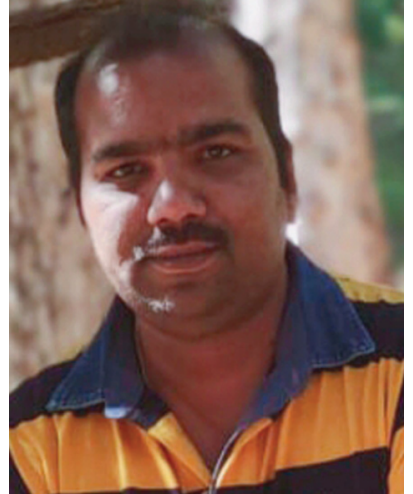

Nataraj Sanna Kotrappanavar
Dr S. K. Nataraj is currently working as a Professor at the Centre for Nano and Material Sciences (CNMS), Jain University, Bangalore, India. $\mathrm{He}$ obtained his $P h D$ in 2008 in polymer science from Karnatak University, Dharwad, India. Immediately after the completion of his PhD, he pursued three Postdoctoral Associate assignments at Chonnam National University, South Korea (2007-2009), the Institute of Atomic Molecular Sciences, Academia Sinica (2009-10), Taiwan, and Cavendish Laboratory, University of Cambridge, UK (2010-2013). He was awarded the DST-INSPIRE Faculty Award (2013-2015) at CSIR-CSMCRI, Bhavnagar. His main area of interest is the development of sustainable materials and processes for energy and environmental applications, including water treatment. 


\section{Introduction}

In a world of ever-more innovative and sophisticated gadgets that are used to simplify human efforts, energy sockets are constantly changing shape, size, and design to accommodate new energy storage sources. At present, rechargeable Li-ion batteries (LIBs) are the most reliable power source for many gadgets, owing to their high energy densities, high durability, lack of memory effects, and low self-discharge rates. ${ }^{1-4}$ Ever since the first commercial example in 1991, LIBs have been exploited to extract maximum output performance from the component materials involved. Over the years, innovation in the field of LIBs has led to the extraction of performances close to the maximum capabilities. However, the limited availability of $\mathrm{Li}$ in the face of ever-increasing energy demands is the biggest concern relating to the sustainability of this technology, and this is forcing researchers and technologists to investigate alternative monovalent and multivalent metal-ion batteries, moving "beyond Li ions". ${ }^{-10}$ Among the limited alternative emerging possibilities available for adoption, rechargeable sodium-ion batteries (SIBs) stand out as the most promising technology owing to the high theoretical capacity of sodium (1166 $\mathrm{mA} \mathrm{h} \mathrm{g}^{-1}$ ), its high abundance (it is practically inexhaustible and less susceptible to supply risk), ${ }^{11-13}$ its environmental friendliness, and low battery management costs. Most significantly, the abundance of $\mathrm{Na}$ in comparison to Li makes SIBS economically viable, and they are easy to process ${ }^{14}$ and safer to package into devices.

Despite the promising features, the practical use of SIBs is restricted by several factors, ${ }^{11,14,15}$ such as poor capacities, low initial Coulombic efficiencies, poor rate capabilities, inferior cycle lives, etc. The poor electrochemical performance of SIBs arises mainly due to the much larger radius of $\mathrm{Na}^{+}(1.02 \AA)$ compare to $\mathrm{Li}^{+}$ion, resulting in poor intercalation kinetics, ${ }^{16,17}$ with rigid inner inorganic frameworks imposing significant challenges when it comes to designing suitable hosts to accommodate $\mathrm{Na}^{+}$. Although

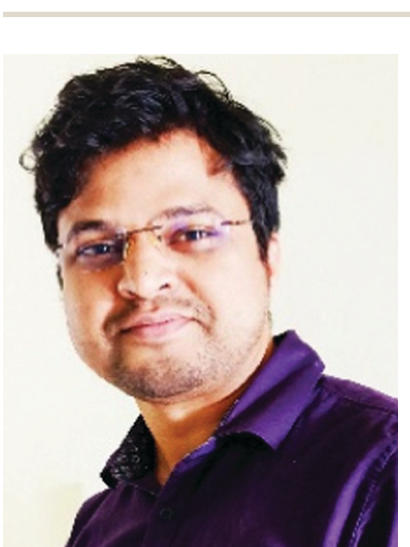

Debasis Ghosh
Dr Debasis Ghosh (PhD, IIT Kharagpur, 2014) has been working on electrochemical energy storage for the last 10 years. Before joining the Centre for Nano and Material Sciences, Jain University, Bangalore in 2017 as an Assistant Professor, he was appointed as a postdoctoral fellow at KAIST in South Korea and at the University of Waterloo, Canada. The current research interests of his research group include rechargeable batteries (metal-ion, metal-sulfur, and metal-air), supercapacitors,

and the design of multifunctional electrocatalysts for OER/ORR/HER applications. conversion-type or alloyed electrode (Table 1) materials exhibit higher initial capacities, the high structural strain caused by pulverization and phase changes causes degradation of the active materials, resulting in poor cycle lives. ${ }^{18}$ On the other hand, electrodes based on organic materials, although offering high theoretical capacities and facile $\mathrm{Na}^{+}$insertion paths due to tuneable structural design abilities, are plagued with electrolyte solubility issues. ${ }^{19,20}$ Furthermore, both conventional organic and inorganic material based electrodes suffer from poor electronic conductivity, ${ }^{21-23}$ which restricts charge transfer and results in poor electrochemical performance, especially at high charge/discharge rates.

Therefore, developments in the field of SIBs have been hindered as the search for combinations of highly electrochemically active materials and rational designs continues. Researchers are particularly looking for nanomaterial-based engineered composite electrodes with higher numbers of storage sites, improved conductivities, and flexible architectures, which can directly influence the capacities, rate capabilities, and cycling stabilities. ${ }^{24-28}$ Cutting the size of the active material down to few nanometers accompanied by rational design in terms of nanocomposite formation, with controlled structural features and architectures, has been found to be an effective strategy to mitigate the aforementioned problems of limited achievable capacities, poor rate capabilities, and inferior cycling stabilities related to SIBs. Nanostructured active materials with 0D, 1D, and 2D architectures offer large electroactive surfaces for charge storage and accelerate the reaction kinetics via significantly reducing the diffusion path lengths for $\mathrm{Na}^{+}$ions/electrons. In addition, 3D architectures are beneficial for maintaining structural integrity. Suitably designed nanoarchitectures with interior void spaces $^{29}$ not only offer highly active surfaces with reduced diffusion path lengths for $\mathrm{Na}^{+}$ions but there is also room for volume expansion, thus enhancing the cycling stability. ${ }^{30-32}$

The rational design of nanocomposite electrodes often involves: (i) directing the heterogeneous growth of a nanostructured active material on a conducting flexible carbon support, such as structurally modified graphene, carbon nanotubes (CNTs), carbon fibers (CFs), etc.; (ii) the in situ modification/confinement of active materials with an appropriate conducting matrix; or (iii) adopting multi-functional nanocomposite hybrids of two or more active materials (carbonaceous or non-carbonaceous), which can synergistically enhance the electrochemical performance of the electrode. The task-specific design of nanocomposite electrodes comprising one or more active materials with or without a conducting carbonaceous support offers several advantages over the use of bare active materials, owing to a synergistic effect from each component reducing the limitations of SIBs. For example, nanocomposites of active materials with carbonaceous supports allow the nanostructures to be connected through a conductive network, ensuring easy charge propagation and improving the electrode kinetics. In addition, the hierarchical porous nature of a conductive matrix in a nanocomposite can significantly enhance the penetration of electrolyte ions, ease ion diffusion, and influence the chargestorage kinetics with an enhanced capacitive contribution. ${ }^{33,34}$ 
Table 1 Examples of cathode and anode materials that use different sodium-ion storage mechanisms

Electrode materials for sodium-ion batteries

Intercalation-type mechanism

Conversion-type mechanism

Alloy-based mechanisms

Intercalation- and conversion-based mechanism

Conversion- and alloy-based

mechanism

Intercalation-, conversion- and

alloy-based mechanism

Displacement reaction

\author{
$\mathrm{Na}_{x} \mathrm{Mo}_{2} \mathrm{O}_{4}, \mathrm{Na}_{4} \mathrm{Ti}_{5} \mathrm{O}_{12}, \mathrm{NaFePO}_{4}, \mathrm{NaTi}_{2}\left(\mathrm{PO}_{4}\right)_{3}, \mathrm{NaVPO}_{4} \mathrm{~F}, \mathrm{Na}_{3} \mathrm{~V}_{2}\left(\mathrm{PO}_{4}\right)_{3}, \mathrm{Na}_{3} \mathrm{~V}_{2}\left(\mathrm{PO}_{4}\right)_{2} \mathrm{~F}_{3}, \mathrm{Na}_{3} \mathrm{~V}_{2}\left(\mathrm{PO}_{4}\right)_{2} \mathrm{FO}_{2}$, \\ $\mathrm{Na}_{2} \mathrm{Fe}_{2}\left(\mathrm{SO}_{4}\right)_{3}, \mathrm{Na}_{2+2 x} \mathrm{Fe}_{2-x}\left(\mathrm{SO}_{4}\right)_{3}, \mathrm{~V}_{2} \mathrm{O}_{5}, \mathrm{VO}_{2}, \mathrm{Na}_{2 / 3} \mathrm{Ni}_{1 / 3} \mathrm{Mn}_{2 / 3} \mathrm{O}_{2}, \mathrm{Na}_{2} \mathrm{Ti}_{3} \mathrm{O}_{7}, \mathrm{NaMO}_{2}$ (M = Ti, V, Cr, Ni, Fe, Co, \\ $\mathrm{Mn}), \mathrm{NaMnO}_{2}, \mathrm{NaMPO}_{4}(\mathrm{M}=\mathrm{Mn}, \mathrm{Fe}, \mathrm{Co}, \mathrm{Ni}), \mathrm{Na}_{2} \mathrm{FePO}_{4}, \mathrm{NaNi}_{0.5} \mathrm{Ti}_{0.5} \mathrm{O}_{2}, \mathrm{Na}_{2} \mathrm{FePO}_{4} \mathrm{~F}, \mathrm{Nb}_{2} \mathrm{O}_{5}$, MXenes, \\ $\mathrm{NaTiO}_{2}, \mathrm{NaMnPO}_{4}, \mathrm{NaNiO}_{2}, \mathrm{NaFeSO}_{4} \mathrm{~F}, \mathrm{NaFeO}_{2}, \mathrm{NaCrO}_{2}, \mathrm{Na}_{x} \mathrm{NiO}_{2}, \mathrm{Na}_{x} \mathrm{CoO}_{2}, \mathrm{Na}_{2 / 3}\left(\mathrm{Ni}_{1 / 3} \mathrm{Fe}_{1 / 3} \mathrm{Mn}_{2 / 3}\right) \mathrm{O}_{2}$, \\ $\mathrm{Na}\left[\mathrm{Mn}_{1 / 2} \mathrm{Fe}_{1 / 2}\right] \mathrm{O}_{2}, \mathrm{Na}_{2 / 3}\left[\mathrm{Fe}_{1 / 2} \mathrm{Mn}_{1 / 2}\right] \mathrm{O}_{2}, \mathrm{NaMn}_{1 / 2} \mathrm{Fe}_{1 / 2} \mathrm{O}_{2}, \mathrm{Na}_{2 / 3} \mathrm{Mn}_{1 / 2} \mathrm{Fe}_{1 / 2} \mathrm{O}_{2}, \mathrm{P} 2-\mathrm{Na}_{2 / 3}\left(\mathrm{Fe}_{1 / 2} \mathrm{Mn}_{1 / 2}\right) \mathrm{O}_{2}$, \\ $\mathrm{NaMn}_{3} \mathrm{O}_{5}, \mathrm{Na}_{2 / 3} \mathrm{Co}_{1 / 3} \mathrm{Ti}_{2 / 3} \mathrm{O}_{2}, \mathrm{Na}_{1 / 2} \mathrm{Co}_{2 / 3} \mathrm{Mn}_{1 / 3} \mathrm{O}_{2}, \mathrm{P} 2-\mathrm{Na}_{1 / 3} \mathrm{Ni}_{1 / 3} \mathrm{Mn}_{2 / 3} \mathrm{O}_{2}, \mathrm{NaNi}_{1 / 3} \mathrm{Mn}_{1 / 3} \mathrm{Fe}_{1 / 3} \mathrm{O}_{2}$, \\ $\mathrm{Na}_{2 / 3} \mathrm{Fe}_{1 / 2} \mathrm{Mn}_{1 / 2} \mathrm{O}_{2}, \mathrm{Na}_{2 / 3}\left[\mathrm{Ni}_{1 / 3} \mathrm{Mn}_{2 / 3}\right] \mathrm{O}_{2}, \mathrm{Na}_{2} \mathrm{Ti}_{6} \mathrm{O}_{13}, \mathrm{Na}_{2} \mathrm{Ti}_{2} \mathrm{O}_{5}, \mathrm{Fe}_{2}\left(\mathrm{MoO}_{4}\right)_{3}, \mathrm{Na}_{2} \mathrm{FeP}_{2} \mathrm{O}_{7}, \mathrm{Na}_{4} \mathrm{Fe}(\mathrm{CN})_{6}$, \\ $\mathrm{Na}_{2} \mathrm{Ti}_{7} \mathrm{O}_{15}, \mathrm{Na}_{2} \mathrm{Ti}_{2} \mathrm{O}_{4}(\mathrm{OH})_{2}, \mathrm{Na}_{0.85} \mathrm{Li}_{0.17} \mathrm{Ni}_{0.21} \mathrm{Mn}_{0.64} \mathrm{O}_{2}, \mathrm{Na}_{2} \mathrm{FeP}_{2} \mathrm{O}_{7}, \mathrm{Na}_{4} \mathrm{Mn}_{9} \mathrm{O}_{18}$, CuHCF, Na $\mathrm{M}\left[\mathrm{Fe}(\mathrm{CN})_{6}\right]$ \\ $(\mathrm{M}=\mathrm{Mn}, \mathrm{Fe}, \mathrm{Co}, \mathrm{Ni}, \mathrm{Cu}), \mathrm{Na}_{4} \mathrm{Mn}_{4} \mathrm{Ti}_{5} \mathrm{O}_{18}$ \\ $\mathrm{Fe}_{2} \mathrm{~S}, \mathrm{MoO}_{2}, \mathrm{FeSe}_{2}, \mathrm{NiS}_{2}, \mathrm{ZnSe}, \mathrm{MoO}_{3}, \mathrm{CuS}, \mathrm{Cu}_{2} \mathrm{P}_{2} \mathrm{O}_{7}, \mathrm{MnFe}_{2} \mathrm{O}_{4}, \mathrm{MgFe}_{2} \mathrm{O}_{4}, \mathrm{NiP}_{3}, \mathrm{CuF}_{2}, \mathrm{CoF}_{2}, \mathrm{MnF}_{2}, \mathrm{FeF}_{2}$, \\ $\mathrm{MnS}, \mathrm{CoO}, \mathrm{MnO}$, CuNCN, $\mathrm{ZnNCN}, \mathrm{CaV}_{4} \mathrm{O}_{9}, \mathrm{CoFe}_{2} \mathrm{O}_{4}$ \\ $\mathrm{Sb}$ @Co $(\mathrm{OH})_{2}, \mathrm{Sn}-\mathrm{Ge}, \mathrm{Co}-\mathrm{Sn}, \mathrm{Sn}-\mathrm{Fe}, \mathrm{Sn}-\mathrm{Cu}, \mathrm{Sn}-\mathrm{Ni}, \mathrm{Co}_{3} \mathrm{Sn}_{2}, \mathrm{Mo}_{3} \mathrm{Sb}_{7}, \mathrm{Bi}-\mathrm{Sb}, \mathrm{Sn}-\mathrm{P}, \mathrm{Bi}_{0.94} \mathrm{Sb}_{1.06} \mathrm{~S}_{3}, \mathrm{Bi}_{2} \mathrm{~S}_{3}$, \\ $\mathrm{Bi}_{2} \mathrm{O}_{3}, \mathrm{Sn}_{50} \mathrm{Ge}_{25} \mathrm{Sb}_{25}, \mathrm{Sn}_{10} \mathrm{Bi}_{10} \mathrm{Sb}_{80}, \mathrm{Zn}_{4} \mathrm{Sb}_{3}, \mathrm{FeSb}_{2}$ \\ $\mathrm{Co}_{9} \mathrm{~S}_{8}, \mathrm{MoS}_{2}, \mathrm{~V}_{2} \mathrm{O}_{3}, \mathrm{Co}_{0.8} \mathrm{Se}, \mathrm{Cu}_{2} \mathrm{~S} @ \mathrm{MOS}_{2}, \mathrm{Ni}_{3} \mathrm{~S}_{2}-\mathrm{Co}_{9} \mathrm{~S}_{8}, \mathrm{TiO}_{2} @ \mathrm{MoS}_{2}, \mathrm{VS}_{2}, \mathrm{WS}_{2}, \mathrm{FeF}_{3} \cdot 0.5 \mathrm{H}_{2} \mathrm{O}, \mathrm{Fe}_{2} \mathrm{~F}_{5} \cdot \mathrm{H}_{2} \mathrm{O}$, \\ $\mathrm{FeO}_{x} \mathrm{~F}_{2-x}, \mathrm{MF}_{3}$ (M = Ti, V, Mn, Fe, and Co), $\mathrm{FeF}_{x}, \mathrm{NaFeF}_{3}, \mathrm{FeO}_{0.7} \mathrm{~F}_{1.3}, \mathrm{Cu}_{3}\left(\mathrm{PO}_{4}\right)_{2}, \mathrm{FeV}_{2} \mathrm{O}_{4}, \mathrm{NiSe}_{2}, \mathrm{Ni}_{3} \mathrm{~V}_{2} \mathrm{O}_{8}$ \\ $\mathrm{Si}, \mathrm{P}, \mathrm{Pb}, \mathrm{Ge}, \mathrm{Sb}, \mathrm{SnS}, \mathrm{Sb}_{2} \mathrm{O}_{3}, \mathrm{Fe}_{3} \mathrm{O}_{4}, \mathrm{Sb}_{2} \mathrm{~S}_{3}, \mathrm{SnO}_{2}, \mathrm{CuO}, \mathrm{Co}_{9} \mathrm{Se}_{8}, \mathrm{SnSe}_{2}, \mathrm{GeS}_{2}, \mathrm{SnS}-\mathrm{ZnS}, \mathrm{Co}_{9} \mathrm{~S}_{8}-\mathrm{ZnS}$, \\ $\mathrm{Ni}_{2} \mathrm{P}-\mathrm{ZnP}_{4}, \mathrm{Sn}_{4} \mathrm{P}_{3}, \mathrm{Se}_{4} \mathrm{P}_{4}, \mathrm{CuP}_{2}, \mathrm{CoP}_{4}, \mathrm{MoP}, \mathrm{FeP}_{4}, \mathrm{CoSe}_{2}, \mathrm{CoS}_{2}, \mathrm{FeS}_{2}, \mathrm{MOSe}_{2}, \mathrm{Sb}_{2} \mathrm{Te}_{3}, \mathrm{SeTe}, \mathrm{Cu}_{3} \mathrm{P}, \mathrm{SnP}_{3}$, \\ $\mathrm{Co}_{3} \mathrm{O}_{4}, \mathrm{Fe}_{2} \mathrm{O}_{3}, \mathrm{Sb}_{2} \mathrm{O}_{4}$ \\ $\mathrm{Sb}_{2} \mathrm{Se}_{3}, \mathrm{In}_{2} \mathrm{~S}_{3}-\mathrm{Sb}_{2} \mathrm{~S}_{3}$ \\ $\mathrm{CuWO}_{4}, \mathrm{CuNCN}, \mathrm{ZnNCN}$
}

The heteroatom doping of a carbon structure with a large amount of nanocrystalline graphite can also improve both intercalation and the adsorption capacity. ${ }^{35}$ Furthermore, such carbonaceous nanocomposites also provide flexible architectures to buffer volume changes during cycling, improving the structural integrity and preventing the agglomeration of active material during continuous charging/discharging. ${ }^{36-38}$ These materials also exhibit facile film-forming properties and can be used as binderfree electrodes. ${ }^{39}$ In addition, the rational design of nanocomposites with two or more active materials without a carbon support can also result in improved electronic, mechanical, and electrochemical properties because of the heterogeneous structure/ interface and can synergistically improve the charge storage, rate performance, and cycling stability. For such nanocomposites, rational design is even more important, since the components are chosen with specific roles aimed towards charge storage and providing structural stabilization with room to accommodate pulverization during cycling.

Recent years have seen a large number of publications, including a few review articles, focusing on the design and development of electrode materials for SIBs. However, most of these have focused on a particular class of electrode material, e.g., polyanion-type electrodes, ${ }^{22,40,41}$ polymeric carbonyls, ${ }^{42-44}$ metal selenides, ${ }^{45}$ metal-organic frameworks, ${ }^{46-48}$ iron oxides and chalcogenides, ${ }^{49}$ phosphate frameworks, ${ }^{50}$ hard carbon-based electrodes, ${ }^{51,52}$ etc. However, inorganic/organic or MOF-type electrodes cannot provide the desired energy densities alone due to certain issues mostly arising from structural dissolution, poor conductivity, etc. Thus, the fabrication of high-performance electrodes often requires the coherent design of constituent materials in the form of nanocomposite hybrids with carbonaceous materials. Recently, a few review articles have discussed in detail the use of nanocomposite electrodes for SIBs. ${ }^{30,31,53}$ Liang et al. ${ }^{54}$ gave comprehensive details of carbonaceous (graphene, CNT, carbon fiber) and noncarbonaceous material-based nanocomposite anodes for use in
SIBs. Wasalathilake et al. ${ }^{55}$ mainly focused on the synthesis processes and a mechanistic overview of $\mathrm{Na}^{+}$storage in different forms of graphene and their nanocomposites via different intercalation paths. On the other hand, Wang et al. ${ }^{14}$ focused mainly on the $\mathrm{Na}^{+}$storage mechanisms relating to graphene and metal oxides, and their nanocomposite anodes.

Herein we present a comprehensive review of the recent developments relating to the rational design of carbonaceous (chemically synthesized carbon and biomass-derived carbon) and non-carbonaceous nanocomposites of different inorganic (metal-oxides/chalcogenides/phosphates/sulfates) and organic (carbonyl/carboxylate/hydroxyl/polymer) materials, MOF-derived nanocomposites, and organic-inorganic hybrid nanocomposite electrodes for SIB applications. A key consideration is synthesis strategies and favorable synergistic interactions for developing high-performance stable electrodes. Based on a comprehensive analysis of rationally designed composite materials, future key considerations for the design of high-performance SIB electrodes have been proposed. A schematic illustration of different synthesis approaches and types of composites/hybrids for next-generation SIBs is shown in Fig. 1.

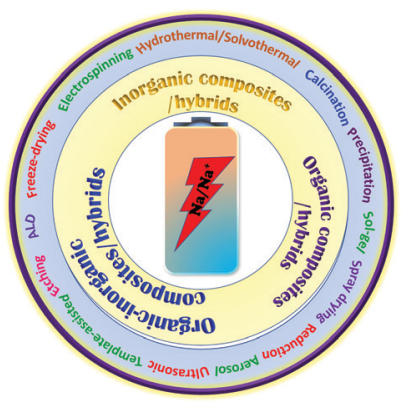

Fig. 1 A schematic illustration of the different types of composites/ hybrids and fabrication methods for next-generation SIBs. 


\section{Inorganic composite materials}

The commercialization of SIB electrodes so far involves quite a limited choice of electrodes. It is very important to maximize the active surface area of the electrode to allow large amounts of charge accumulation while maintaining a conducting network throughout the material for facile charge transport. Although nanosized materials reduce the ionic diffusion time, improving the rate performance, engineering nanostructures with a suitable conducting matrix can result in improved capacities, rate capabilities, and cycling stabilities through favorable synergetic cooperation. However, it is crucial to control the growth of nanostructures on the conducting phase or the confinement in a 3D conductive network with good dispersion and intimate interfacial contact, as these are decisive factors relating to electrochemical performance. Several datasets in this regard are available for evaluating reported improved structural features and electrochemical performance as a result of favorable synergetic effects. This section attempts to summarize the parameters associated with adopting hybrids of carbonaceous materials with different metal oxides/chalcogenides $\left(\mathrm{M}_{x} \mathrm{C}_{y}, \mathrm{C}=\mathrm{O}\right.$, $\mathrm{S}, \mathrm{Se}, \mathrm{Te}$ ), phosphides, and sulfates to overcome the drawbacks of $\mathrm{Na}^{+}$storage when using bare inorganic electrodes.

\subsection{Metal oxide/chalcogenide $\left(M_{x} C_{y}, C=O, S, S e, T e\right)$ based composite materials}

Metal oxides or chalcogenides $\left(\mathrm{M}_{x} \mathrm{C}_{y}, \mathrm{C}=\mathrm{O}, \mathrm{S}, \mathrm{Se}, \mathrm{Te}\right)$ in general are cost-effective and offer high theoretical capacities; however, their insulating nature and structural strain due to large volume changes during the continuous charge-discharge process can limit the rate capabilities and cycling stabilities of electrodes based on these materials. ${ }^{56-58}$ Real-world SIB design requires suitable synthetic approaches, aimed at improving the electrical conductivity and structural integrity, and enhancing the electrochemical performance through favorable synergetic effects. ${ }^{37,58}$

A yolk-shell architecture, constructed with an active material core and a protective conductive carbon hollow shell, provides unique morphological features and physicochemical properties, overcoming drawbacks relating to the volume expansion and structural degradation of SIB electrodes. Such nanostructures are often synthesized via conventional self-templating approaches, which include Ostwald ripening, the partial removal of the core from a core-shell structure, surface-protected etching, etc. Most yolk-shell nanoarchitectures investigated as SIB electrodes use the Ostwald ripening growth mechanism, which includes the dissolution of small crystals and the redeposition of dissolved species on the surfaces of larger crystals. ${ }^{59}$ For instance, Zhang et al. developed nitrogen-doped yolk-like $\mathrm{TiO}_{2}\left(\sim 0.8 \mathrm{~V} v s . \mathrm{Na} / \mathrm{Na}^{+}\right)$ wrapped with a carbon shell ${ }^{60}$ via a solvothermal process followed by calcination with much-improved storage capacity and cycling stability compared with $\mathrm{TiO}_{2}$ solid spheres. The growth of the $\mathrm{TiO}_{2}$ spherical core structure followed the Ostwald ripening mechanism, including the formation of nascent $\mathrm{TiO}_{2}$ nuclei via an alcoholysis reaction, followed by seed growth and aggregation. Finally, the well-defined yolk-shell (YS) structure is accomplished using diethylenetriamine, which facilitates the core dissolution, shell recrystallization, and re-deposition processes. The anode material (AM) core-conducting NC shell structure showed a significant improvement in performance, with a specific capacity of $242.7 \mathrm{~mA} \mathrm{~h} \mathrm{~g}^{-1}$ at $0.5 \mathrm{C}$, it maintained a considerable capacity of $115.9 \mathrm{~mA} \mathrm{~h} \mathrm{~g}^{-1}$ even at a high current of $20 \mathrm{C}$ ( $~ 7.5$ times higher than that of $\mathrm{TiO}_{2}$ solid spheres), and it exhibited good cycling stability, with capacity retention of $95.5 \%$ over 3000 cycles even at a high current of $24 \mathrm{C}$. Qiu et al. ${ }^{61}$ reported a similar YS structure consisting of a $\mathrm{TiO}_{2}$ core and furfural pyrolytic carbon shell synthesized via a self-catalyzing solvothermal process followed by calcination. Thanks to the conducting shell and voids for accommodating volume expansion, the YS architecture reported outstanding rate performance at a rate of $40 \mathrm{C}$ and excellent cycle life, with $85 \%$ capacity retention over 2000 cycles, which is far superior to bare $\mathrm{TiO}_{2}$. Jun Liu et al. reported an eggette-like Sn@C yolk-shell nanoarchitecture ${ }^{62}$ via facile self-assembly followed by carbonization/reduction strategies to achieve tin cores covered with a carbon membrane network. The large void space effectively buffers the volume variations of Sn, and the carbon membrane network provides abundant diffusion pathway, enhances the electrode kinetics, and prevents the aggregation of $\mathrm{Sn}$. Distinctive robust yolk-shell $\mathrm{NiS}_{2}$ nanoparticle (NP) embedded CFs $\left(\mathrm{NiS}_{2} \subset \mathrm{PCF}\right)^{63}$ were successfully fabricated and used as a high-performance flexible electrode in SIBs. The fabrication process and corresponding fibrous architecture of the $\mathrm{NiS}_{2} \subset$ PCF material are schematically demonstrated in Fig. 2a and b. Briefly, porous carbon fibers (PCFs) were subjected to hydrophilic treatment and immersed in concentrated $\mathrm{Ni}\left(\mathrm{NO}_{3}\right)_{2}$ solution (step 1). The PCFs loaded with $\mathrm{Ni}\left(\mathrm{NO}_{3}\right)_{2}$ were transformed into Ni $\subset$ PCF via annealing at $1000{ }^{\circ} \mathrm{C}$ for $1 \mathrm{~h}$ (step 2), and subsequent sulfuration of as-obtained $\mathrm{Ni} \subset \mathrm{PCF}$ was carried out at $160{ }^{\circ} \mathrm{C}$ for $10 \mathrm{~h}$ to form the $\mathrm{NiS}_{2} \subset \mathrm{PCF}$ material (step 3). The 3D $\mathrm{NiS}_{2} \subset \mathrm{PCF}$ anode $\left(\sim 1.4 \mathrm{~V} v\right.$ s. Na/Na $\left.{ }^{+}\right)$showed a capacity as high as $679 \mathrm{~mA} \mathrm{~h} \mathrm{~g}^{-1}$ at $0.1 \mathrm{C}$, excellent cycling performance, with $76 \%$ capacity retention over 5000 cycles, and excellent rate performance ( $245 \mathrm{~mA} \mathrm{~h} \mathrm{~g}^{-1}$ at $10 \mathrm{C}$ ) with a high reversible capacity, even in different bending states (Fig. 2c).

Wu et $a l^{64}$ demonstrated an interface-modulated two-step sintering strategy $\left(450{ }^{\circ} \mathrm{C}\right.$ for $2 \mathrm{~h}$ under an Ar atmosphere followed by annealing at $270{ }^{\circ} \mathrm{C}$ for $3 \mathrm{~h}$ in air) to fabricate a $\mathrm{CO}_{3} \mathrm{O}_{4} @ \mathrm{C}$ dodecahedron YS structure starting from a MOF (ZIF 67). The YS $\mathrm{Co}_{3} \mathrm{O}_{4} @ \mathrm{C}$ anode electrode demonstrated excellent rate capabilities with a high capacity of $307 \mathrm{~mA} \mathrm{~h} \mathrm{~g}^{-1}$ at $1 \mathrm{~A} \mathrm{~g}^{-1}$ and $269 \mathrm{~mA} \mathrm{~h} \mathrm{~g}^{-1}$ at $2 \mathrm{~A} \mathrm{~g}^{-1}$ thanks to the conducting carbon shell. Sb@C nanoconfined N/S co-doped 3D carbon microspheres (Sb@NS-3DPCMSs) ${ }^{65}$ that could undergo ultralong high-rate cycling were fabricated via a salt-templating directed spray-drying process combined with a continuous multi-step thermal treatment approach, and the formation of the yolk-shell structure was confirmed via first-principles simulations. The formation of the yolk-shell architecture provided enough space to buffer volume expansion, improving the structural integrity with a long cycle life (a capacity of $331 \mathrm{~mA} \mathrm{~h} \mathrm{~g}^{-1}$ was retained even after 10000 cycles at a high rate of $20 \mathrm{~A} \mathrm{~g}^{-1}$ ). The empty carbon box with abundant pores enhanced the conductivity and improved the electrode kinetics, and the co-dopants improved 

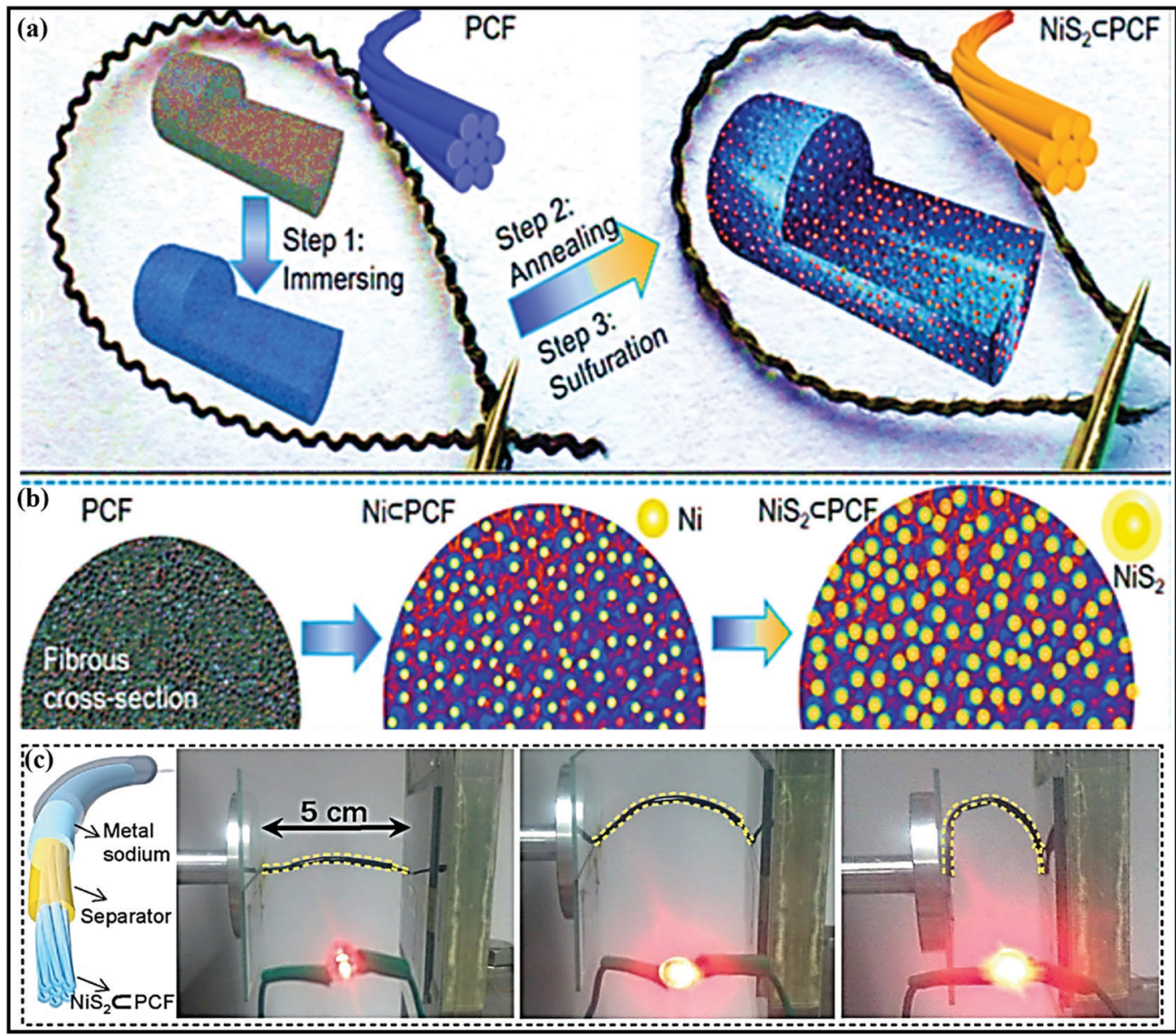

Fig. 2 (a) A schematic illustration of the fabrication procedure, (b) a cross-sectional view of the structural evolution of flexible $\mathrm{NiS}_{2} \subset \mathrm{PCF}$, and (c) a schematic illustration of the constructed structure of a flexible fiber-shaped SB and photos of LEDs lit using the as-assembled fiber-shaped SB in different bending states. Reproduced with permission. ${ }^{63}$ Copyright: 2018, Wiley-VCH Verlag GmbH \& Co. KGaA.

the intercalation kinetics and capacity (the 3D architecture showed a specific capacity of $\sim 540 \mathrm{~mA} \mathrm{~h} \mathrm{~g}^{-1}$ at $100 \mathrm{~mA} \mathrm{~g}^{-1}$ ).

Recently, yolk-shell structured $\mathrm{ZnCo}_{2} \mathrm{O}_{4}$ spheres fabricated with rGO via an electrostatic interaction process, ${ }^{66}$ also demonstrated superior electrochemical performance in both LIBs and SIBs. As an anode ( $0.75 \mathrm{~V} v s$. Na/Na $\left.{ }^{+}\right)$in SIBs, $\mathrm{ZnCo}_{2} \mathrm{O}_{4} @ \mathrm{OrGO}$ reported a dominant non-faradaic contribution $(89.2 \%$ at a scan rate of $1 \mathrm{mV} \mathrm{s}^{-1}$ ) with a discharge capacity of $280 \mathrm{~mA} \mathrm{~h} \mathrm{~g}{ }^{-1}$ after 1000 cycles at $1 \mathrm{~A} \mathrm{~g}^{-1}$. The enhanced performance of unique yolkshell $\mathrm{ZnCo}_{2} \mathrm{O}_{4} @ \mathrm{rGO}$ is mainly due to its unique morphology, which induces rapid electrode kinetics via enhancing electrode/electrolyte interactions and shortening the $\mathrm{Li}^{+} / \mathrm{Na}^{+}$diffusion distance. On the other hand, rGO effectively buffers the large volume variations and improves the cycle life via maintaining the structural integrity of the material. In another example, MOF-derived $\mathrm{Co}_{9} \mathrm{~S}_{8} @ \mathrm{C}$ yolk-shell nanocages ${ }^{67}$ were prepared and a direct conversion mechanism was demonstrated via first-principles calculations and various spectroscopic techniques. The unique composite, where the $\mathrm{Co}_{9} \mathrm{~S}_{8}$ NPs anode is dispersed in an amorphous carbon matrix, improved the overall electrochemical performance via accelerating the conversion reactions, improved the electrode kinetics via reducing the $\mathrm{Na}^{+}$-diffusion distance, and provided buffering against volume variations during cycling.

The other most widely followed approach to fabricate YS architectures is the template approach, which involves a series of steps, including the fabrication of the AM core, coating with a sacrificial template, a second coating of the outer layer, which can be carbonized to fabricate the outer thin carbon layer, and finally removing (via chemical etching, calcination, or solvent dissolution) the sacrificial template to create an inner void. ${ }^{59}$ For instance, Junjie Cai et al. fabricated yolk-double shell cube-like SnS@N-S co-doped carbon (YDSC-SnS@NSC) via a self-templating, selective etching, and self-assembly process. ${ }^{68}$ Details of yolk-double shell formation are given in Fig. 3a. The formation of a robust double-shell structure with void space provided strong buffering against SnS volume variations. The outer carbon shells prevent aggregation and maintain structural integrity during cycling, and highly conductive S and $\mathrm{N}$ doped into the carbon shell improve the electrical conductivity and speed up the charging kinetics. Benefiting from these merits, the YDSC-SnS@NSC anode $(\sim 0.9 \mathrm{~V} v \boldsymbol{s}$. $\mathrm{Na} / \mathrm{Na}^{+}$) in SIBs was reported to have a stable cycle life of over 1500 cycles with capacity retention of $83.5 \%$ and exceptional 

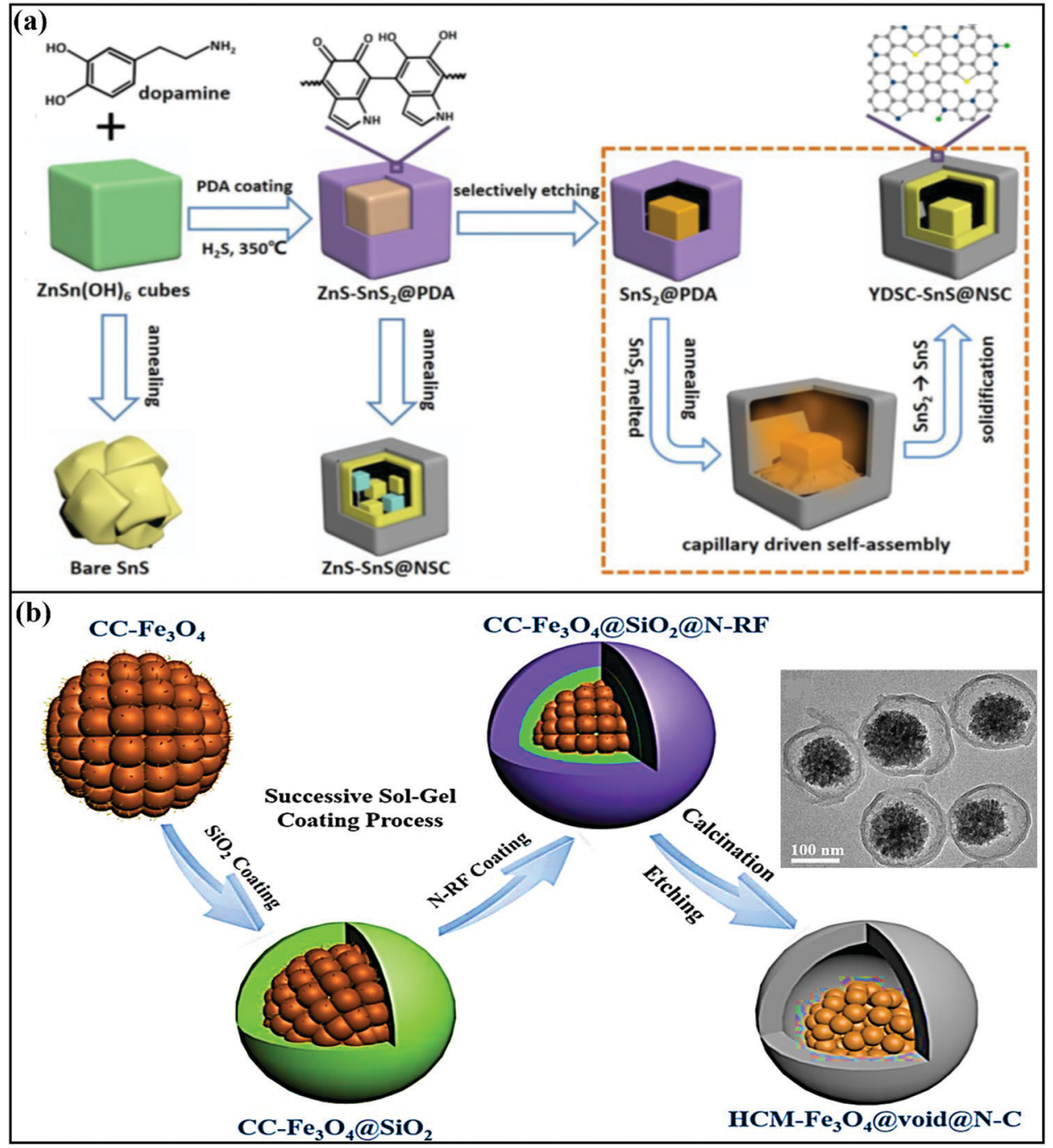

Fig. 3 (a) A schematic diagram of the synthesis of YDSC-SnS@NSC via a self-templating, selective etching, and heat and capillary induced self-assembly process. Reproduced with permission. ${ }^{68}$ Copyright: 2019. American Chemical Society. (b) A schematic illustration of the synthesis of yolk-shell structured $\mathrm{Fe}_{3} \mathrm{O}_{4} / \mathrm{N}$-doped carbon nanospheres with highly crystallized mesoporous $\mathrm{Fe}_{3} \mathrm{O}_{4}$ cores $\left(\mathrm{HCM}\right.$ - $\mathrm{Fe}_{3} \mathrm{O}_{4}$ (avoid@N-C) (inset: a TEM image of $\mathrm{HCM}-\mathrm{Fe}_{3} \mathrm{O}_{4}$ (avoid@N-C nanospheres). Reproduced with permission. ${ }^{57}$ Copyright: 2019, Elsevier.

rate performance, with a discharge capacity of $257 \mathrm{~mA} \mathrm{~h} \mathrm{~g}^{-1}$ even at $8 \mathrm{~A} \mathrm{~g}^{-1}$.

Zhao et al. demonstrated a highly crystalline mesoporous $\mathrm{Fe}_{3} \mathrm{O}_{4}$ yolk with a nitrogen-doped resorcinol formaldehyde pyrolytic N-doped carbon shell, with a silica interlayer as a sacrificial template. ${ }^{57}$ The typical yolk-shell structure prepared via a sol-gel approach followed by calcination (Fig. 3b) displayed an average particle size of around $200 \mathrm{~nm}$ with an $\mathrm{N}$-doped carbon shell thickness of $\sim 15 \mathrm{~nm}$, which was accompanied by the presence of large void space to accommodate volume changes. With an intercalation- and conversion-based mechanism, the composite anode $\left(\sim 0.8 \mathrm{~V} v s . \mathrm{Na} / \mathrm{Na}^{+}\right)$reported a capacity of $\sim 372 \mathrm{~mA} \mathrm{~h} \mathrm{~g}^{-1}$ for the first five cycles at $160 \mathrm{~mA} \mathrm{~g}^{-1}$ and exhibited a capacity of $196 \mathrm{~mA} \mathrm{~h} \mathrm{~g}^{-1}$ even at a high current density of $1200 \mathrm{~mA} \mathrm{~g}^{-1}$. In another instance, Zhiming Liu et al. ${ }^{69}$ reported novel $\mathrm{FeS}_{2}$ @C yolk-shell nanoboxes as a high-performance anode $\left(\sim 0.8 \mathrm{~V} v s . \mathrm{Na} / \mathrm{Na}^{+}\right)$for use in SIBs. The synthesis was carried out via a facile etching approach, followed by a sulfidationin-a-nanobox strategy. Electrochemically, the obtained yolk-shell nanobox anode registered excellent electrochemical performance via an intercalation and conversion mechanism. A stable specific capacity of $330 \mathrm{~mA} \mathrm{~h} \mathrm{~g}{ }^{-1}$ was retained with a large electrode/ electrolyte contact area and short diffusion path. With multistep strategies, Yun-Xiao Wang et al. designed nano-yolk-shell FeS@ $\mathrm{C}^{70}$ $(\sim 170 \mathrm{~nm})$ with void space of $\sim 20 \mathrm{~nm}$ and a porous carbon shell with a thickness of $\sim 30 \mathrm{~nm}$. Due to its multi-functionality, high structural stability, and synergetic co-operation, the rationally designed FeS@C anode with a conversion-based mechanism reported a capacity of $545 \mathrm{~mA} \mathrm{~h} \mathrm{~g}{ }^{-1}$ over 100 cycles, high rate capabilities ( $\sim 454 \mathrm{~mA} \mathrm{~h} \mathrm{~g}^{-1}$ at $\left.5 \mathrm{C}\right)$, and good cycling stability without sacrificing the capacity.

Chen and co-workers designed $\mathrm{Cu}$-doped $\mathrm{Co}_{3} \mathrm{O}_{4} @ \mathrm{~N}$-doped carbon with large void space $\left(\mathrm{Cu}-\mathrm{Co}_{3} \mathrm{O}_{4} @ \text { ovoid@NC }\right)^{71}$ through a successive coating-etching strategy. The material was designed 
in such a way that the highly conductive interior void space provides strong buffer action and stabilizes the structure, allowing a stable cycling life, and the introduction of copper is beneficial for improving the inherent electrical conductivity of $\mathrm{Co}_{3} \mathrm{O}_{4}$. In a distinctive approach, 3D $\mathrm{MoS}_{2} @ g r a p h e n e$ microspheres ${ }^{72}$ prepared via a one-pot spray pyrolysis process demonstrated highly reversible GCD capacities of 573/797 $\mathrm{mA} \mathrm{h} \mathrm{g}^{-1}$ at $0.2 \mathrm{~A} \mathrm{~g}^{-1}$. More significantly, the composite retained a specific capacity of $322 \mathrm{~mA} \mathrm{~h} \mathrm{~g}^{-1}$ at a current density of $1.5 \mathrm{~A} \mathrm{~g}^{-1}$ after 600 cycles, with Coulombic efficiency close to $100 \%$. However, the $\mathrm{MoS}_{2}$ layers buffer the strain and lower the barrier for $\mathrm{Na}^{+}$insertion, while the highly conductive graphene offers void space for volume changes and improves the electron/ion transport during repeated cycling. In another approach, $\mathrm{Sn}_{4} \mathrm{P}_{3}$ microspheres encapsulated in hollow carbon spheres $\left(\mathrm{Sn}_{4} \mathrm{P}_{3} @ \mathrm{C}\right)^{73}$ were prepared via a low-temperature phosphorization route, demonstrating superior electrochemical performance. A kinetics study revealed that the electrochemical performance is mainly dominated by a surface-controlled process involving the hollow nanostructure, which offers void space for large volume changes during long-term cycling. Zen Kong et al. ${ }^{74}$ designed $\mathrm{SnO}_{2}$-based novel $\mathrm{SnO}_{2} @$ @GO hollow spheres to resolve the issue of volume expansion and to improve the electronic conductivity and electrochemical performance. In this instance, $\mathrm{SnO}_{2}$ NPs are uniformly grown on a graphene sheet in the hydrolysis stage. Indeed, the authors achieved $\mathrm{SnO}_{2}$ @rGO with high conductivity and improved electrochemical performance, especially in terms of the cycling performance. As an anode ( $\sim 0.75 \mathrm{~V} v$ s. $\mathrm{Na} / \mathrm{Na}^{+}$), via a conversion- and alloy-based mechanism, a high initial discharge capacity of $821.6 \mathrm{~mA} \mathrm{~h} \mathrm{~g}^{-1}$ at $200 \mathrm{~mA} \mathrm{~g}^{-1}$ was reported, and the composite retained a capacity of $204 \mathrm{~mA} \mathrm{~h} \mathrm{~g}^{-1}$ even after 1500 cycles.

Ye Wang et al. ${ }^{75}$ reported flexible nitrogen-doped graphene quantum dot (NGQD) decorated $\mathrm{WS}_{2}$ nanosheets on porous 3D

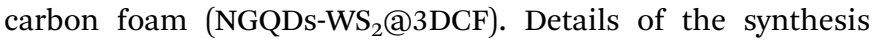

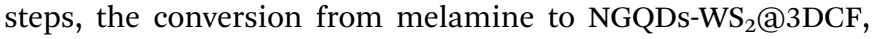
and the battery design are shown in Fig. $4 \mathrm{a}$ and b. The use of NGQDs for composite formation provides a greater surface contribution and they act as a stabilizer, improving the rate performance and supporting long-term cycling stability. In battery-based analysis, the free-standing anode $\left(\sim 1.0 \mathrm{~V} v s . \mathrm{Na} / \mathrm{Na}^{+}\right)$material reported high specific capacities of $460.9 \mathrm{~mA} \mathrm{~h} \mathrm{~g} \mathrm{~g}^{-1}$ and $268.4 \mathrm{~mA} \mathrm{~h} \mathrm{~g}^{-1}$ at 50 and $2000 \mathrm{~mA} \mathrm{~g}^{-1}$, respectively, and the architecture was stable even at various bending angles (Fig. 4c). Xiuqiang Xie and co-workers ${ }^{76}$ reported unique $\mathrm{MoS}_{2}$ @carbon paper as a free-standing electrode from hydrothermal synthesis followed by a calcination strategy. Electrochemically, the composite reported a GCD capacity of $442 / 556 \mathrm{~mA} \mathrm{~h} \mathrm{~g}^{-1}$ at a current density of $80 \mathrm{~mA} \mathrm{~g}^{-1}$, and promising high-rate performance was reported (205 $\mathrm{mA} \mathrm{h} \mathrm{g}{ }^{-1}$ was maintained even at a current density of $1000 \mathrm{~mA} \mathrm{~g}^{-1}$ ). In this study, carbon cloth was not only responsible for the fast electronic/ionic transport and good Na-ion storage properties, but it also improved the structural stability for long-term cycling performance. Meanwhile, the carboxymethyl cellulose sodium salt coating accommodated large volume changes during subsequent cycling processes. $\mathrm{MoS}_{2}$ nanosheets grown on CMK- $3^{77}$ also showed enhanced sodium storage properties and improved electrode kinetics,

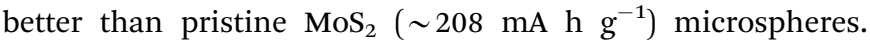

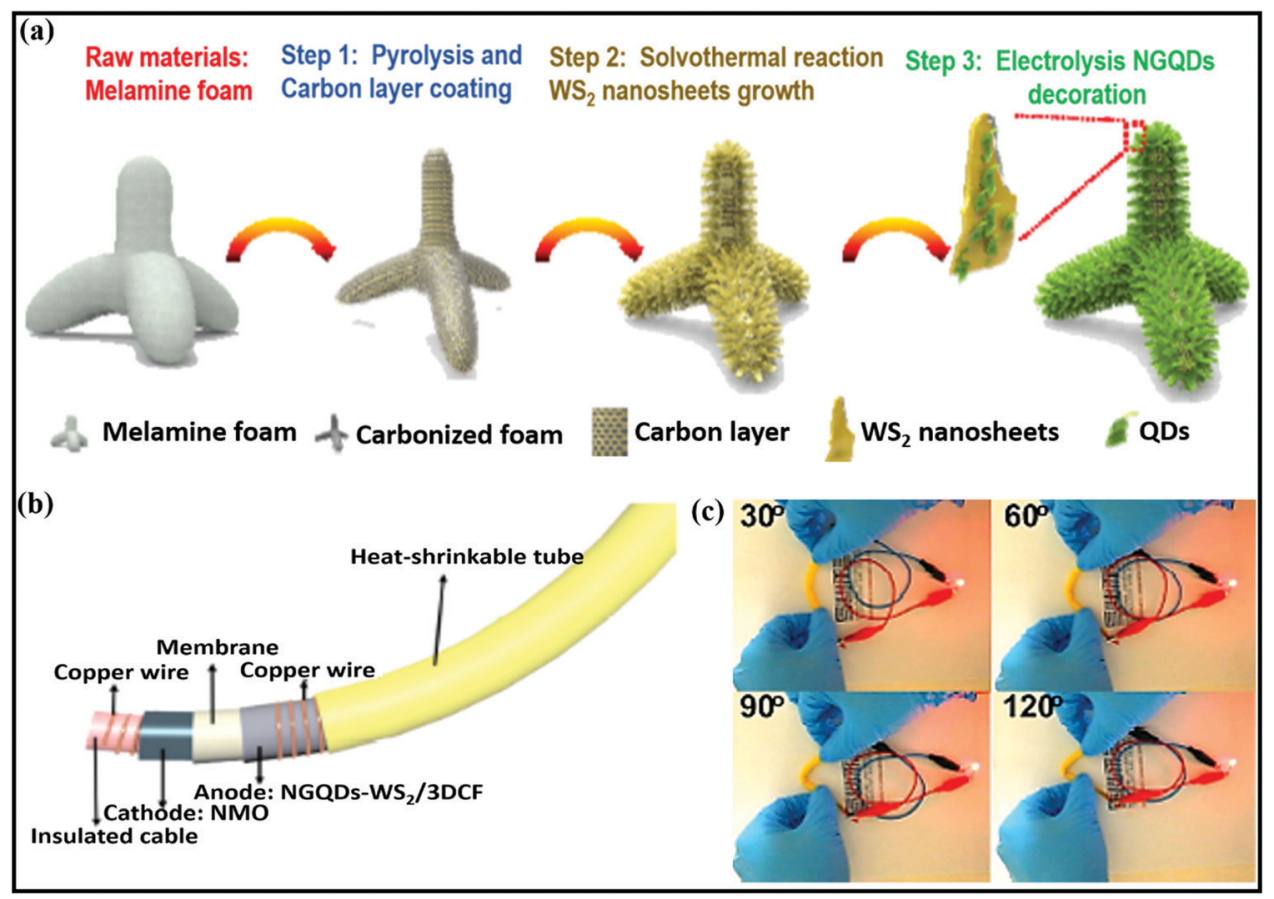

Fig. 4 (a) A schematic diagram of the NGQDs-WS 2 /3DCF nanoarchitecture synthesis process, (b) an image of a flexible cable-shaped SIB with NGQDs$\mathrm{WS}_{2} / 3 \mathrm{DCF}$ as the anode electrode, and (c) photographs of a red LED powered by the cable-shaped SIB at various bending angles. Reproduced with permission. ${ }^{75}$ Copyright: 2018 , Royal Society of Chemistry. 
In addition to showing a high GCD capacity and good cyclability, the composite also demonstrated high rate performance. Also, the expanded interlayer spacing between $\mathrm{MoS}_{2}$ nanosheets on highly conductive CMK-3 benefited the storage and transmission of sodium ions. Dan Sun and co-workers ${ }^{78}$ reported a new strategy for preparing mesoporous metal phosphide nanoarrays $\left(\mathrm{FeP}_{4} /\right.$ carbon felt, $\mathrm{CoP}_{4} /$ carbon felt, and $\mathrm{NiP}_{x} /$ carbon felt) on carbon felt as binder-free anodes with superior electrochemical performance. Details of the synthesis of metal phosphide nanoarrays are as shown in Fig. 5a. These integrated electrodes showed good performance, especially the $\mathrm{CoP}_{4} /$ carbon felt $\left(\sim 0.4 \mathrm{~V} v s . \mathrm{Na} / \mathrm{Na}^{+}\right)$ composite, which exhibited a high initial discharge capacity of $1691 \mathrm{~mA} \mathrm{~h} \mathrm{~g}^{-1}$ and retained a capacity of $851 \mathrm{~mA} \mathrm{~h} \mathrm{~g}^{-1}$ after 300 cycles at $0.3 \mathrm{~A} \mathrm{~g}^{-1}$. In addition, $\mathrm{CoP}_{4} /$ carbon felt exhibited considerable cycling stability for up to 1000 cycles, with more than $90 \%$ retention, through a conversion-based mechanism. This unique mesoporous structure with carbon felt, as a result of synergetic cooperation, buffers large volume changes, improves the electrode/electrolyte contact area, and reduces the ion-diffusion pathway lengths (Fig. 5b).

Distinctive $\mathrm{Co}_{9} \mathrm{~S}_{8}$ nanorods encapsulated in a $\mathrm{N}$-doped carbon shell $\left(\mathrm{r}-\mathrm{Co}_{9} \mathrm{~S}_{8} @ \mathrm{NC}\right)^{79}$ were mainly designed to prevent large volume changes during cycling, to enhance the storage performance and kinetics, and to prevent side reactions between the electrode and electrolyte. As a composite anode ( $\left.1.1 \mathrm{~V} v s . \mathrm{Na} / \mathrm{Na}^{+}\right)$, the rationally designed composite reported an initial discharge capacity of $675 \mathrm{~mA} \mathrm{~h} \mathrm{~g}^{-1}$ at $50 \mathrm{~mA} \mathrm{~g}^{-1}$, demonstrating high rate capabilities and good cycling stability via a conversion-based mechanism. In another study, $\mathrm{T}-\mathrm{Nb}_{2} \mathrm{O}_{5}$ NPs were encapsulated using $1 \mathrm{D}$ carbon nanofibers $\left(\mathrm{T}-\mathrm{Nb}_{2} \mathrm{O}_{5} @ \mathrm{CNFS}\right),{ }^{80}$ where the composite electrode not only provided continuous pathways for electrons to diffuse to electroactive interfaces for reactions with $\mathrm{Na}^{+}$ion during (de)sodiation but it also acted as a buffer layer to accommodate volume changes during prolonged cycling. Mingkai Liu et al. ${ }^{81}$ reported a $\mathrm{MoS}_{2}$ @carbon nanofiber interpenetrated graphene framework with superior electrochemical performance. In this case, the authors first prepared a carbon-nanofiber-interpenetrated graphene framework and then $\mathrm{MoS}_{2}$ nanoflakes were grown in situ alongside the entire framework. The obtained carbon nanoarchitecture prevents the restacking of graphene sheets and provides ample space between graphene sheets, creating an integrated structure with superior electric conductivity. The anode composite (with an approximate voltage of $\sim 1.2 \mathrm{~V}$ ) through an intercalation- and conversion-type mechanism showed a capacity of

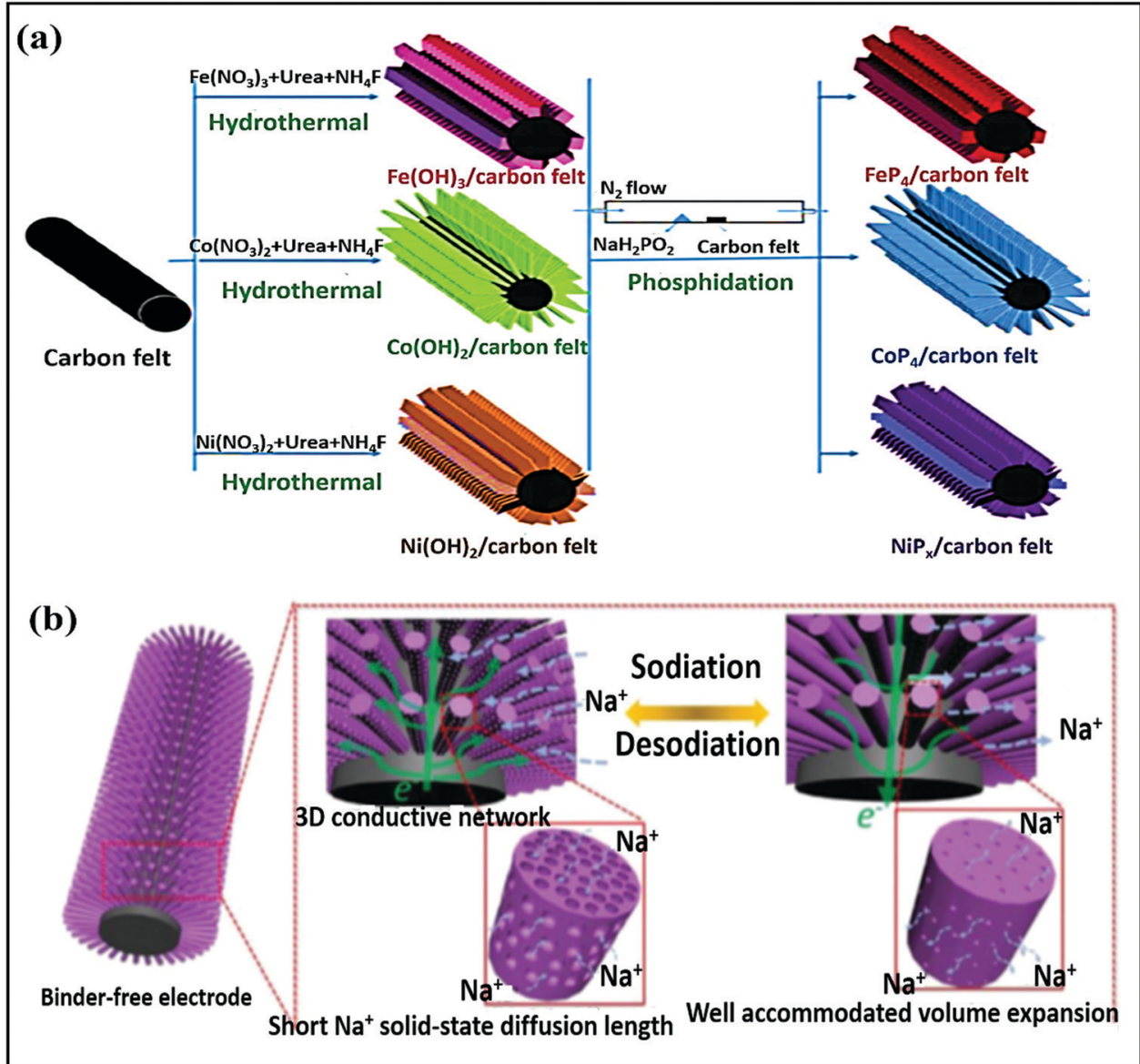

Fig. 5 (a) The preparation processes for different metal phosphide arrays on CF and (b) a schematic illustration of (de)sodiation with volume variations and the electron diffusion pathways of the mesoporous $\mathrm{CoP}_{4}$ array. Reproduced with permission. ${ }^{78}$ Copyright: $2018, \mathrm{Wiley}-\mathrm{VCH}$ Verlag $\mathrm{GmbH} \& \mathrm{Co}$. KGaA. 
$598 \mathrm{~mA} \mathrm{~h} \mathrm{~g}^{-1}$ at $0.1 \mathrm{~A} \mathrm{~g}^{-1}$, and $86.9 \%$ capacity retention was shown for up to 1000 cycles with high rate performance up to $10 \mathrm{~A} \mathrm{~g}^{-1}$.

Sheng Chen and co-workers reported red-blood-cell-like hollow carbon sphere supported $\mathrm{Na}_{2} \mathrm{Ti}_{3} \mathrm{O}_{7}\left(\mathrm{Na}_{2} \mathrm{Ti}_{3} \mathrm{O}_{7} @ \mathrm{RHCS}\right)^{82}$ with high rate performance. As shown in Fig. 6a, hydrothermal synthesis followed by a calcination strategy is adopted to prepare the $\mathrm{Na}_{2} \mathrm{Ti}_{3} \mathrm{O}_{7} @ \mathrm{RHCS}$ composite material. $\mathrm{Na}_{2} \mathrm{Ti}_{3} \mathrm{O}_{7}$ nanosheets are successfully grown on RHCS, offering tailored porosity with short electron-diffusion and ion-channel lengths. In a rate performance study, the composite retained capacities of 175.52 and $45.71 \mathrm{~mA} \mathrm{~h} \mathrm{~g}^{-1}$ at rates of 1 and $50 \mathrm{C}$, with a stable average voltage of $\sim 0.3 \mathrm{~V} v s . \mathrm{Na} / \mathrm{Na}^{+} .{ }^{84}$ In a distinctive approach, Ming Zhang et al. reported the highly conductive and good sodium-storage performance of graphene-encapsulated $\mathrm{FeS}_{2} \mathrm{NPs}$, which were further modified with $\mathrm{CNFs}\left(\mathrm{FeS}_{2} @ \mathrm{G} @ \mathrm{CNF}\right)$ through an electrospinning (Fig. 6b) process. ${ }^{83}$ The doubly protected anode $\left(\sim 1.3 \mathrm{~V} v s . \mathrm{Na} / \mathrm{Na}^{+}\right)$with a conversion-based mechanism reported a high reversible capacity, good rate performance, and excellent cycling stability $\left(305.5 \mathrm{~mA} \mathrm{~h} \mathrm{~g}{ }^{-1}\right.$ was reported after 2400 cycles at $3 \mathrm{~A} \mathrm{~g}^{-1}$ ) (Fig. 6c). In addition, the hybrid composite demonstrated excellent electrochemical performance even at low temperatures ( 0 and $-20{ }^{\circ} \mathrm{C}$ ). Chen et al. constructed a $\mathrm{FeS}_{2} / \mathrm{CNT}$ neural network composite ${ }^{85}$ with good cycling stability. The unique composite is endowed with high electronic conductivity and improved electrode kinetics, and volume changes are buffered during long-term cycling. As a result, the $\mathrm{FeS}_{2} / \mathrm{CNT}$ neural network showed a capacity of $394 \mathrm{~mA} \mathrm{~h} \mathrm{~g}^{-1}$ even after 400 cycles at $200 \mathrm{~mA} \mathrm{~g}^{-1}$ and it demonstrated excellent cycling stability for up to 8400 cycles. Recently, Shuangshuang Tan et al. ${ }^{86}$ fabricated $\mathrm{V}_{2} \mathrm{O}_{3}$ NPs embedded in amorphous CNTs which were then coassembled with rGO (Fig. 7a) to achieve improved electrochemical performance. Remarkably, the multidimensionally assembled composite anode $\left(\sim 1.1 \mathrm{~V} v s . \mathrm{Na} / \mathrm{Na}^{+}\right)$reported a high rate capacity of $165 \mathrm{~mA} \mathrm{~h} \mathrm{~g}^{-1}$ at $20 \mathrm{~A} \mathrm{~g}^{-1}$ (taking just $\sim 30 \mathrm{~s}$ per GCD cycle), and the composite demonstrated ultra-long cycling stability (retaining $72.3 \%$ at $5 \mathrm{~A} \mathrm{~g}^{-1}$ ) for over 15000 cycles (Fig. 7b) utilizing a reversible insertion and multiphase conversion mechanism.

Layered metal selenides as energy materials with crystal frameworks with tunable spacing have attracted great attention owing to their abundance and high electrical conductivities and theoretical capacities, ${ }^{87,88}$ but they suffer from large volume expansion, sluggish kinetics, and dissolution problems. ${ }^{87}$ Nevertheless, Xing Ou and co-workers reported a promising $\mathrm{Sb}_{2} \mathrm{Se}_{3} @$ rGO hybrid anode ${ }^{89}\left(\sim 0.7 \mathrm{~V} v s . \mathrm{Na} / \mathrm{Na}^{+}\right)$, which was

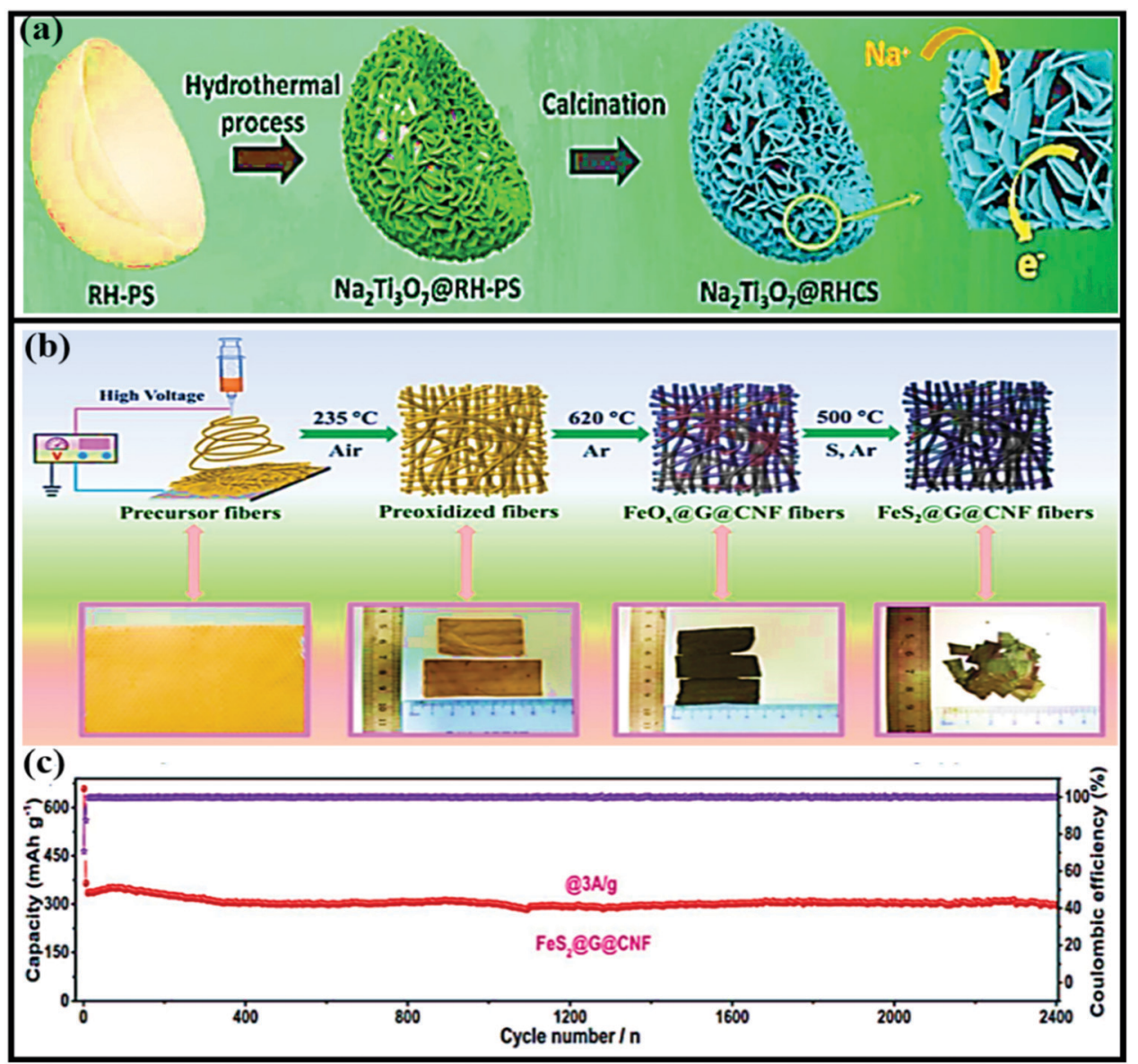

Fig. 6 (a) A schematic illustration of the formation of $\mathrm{Na}_{2} \mathrm{Ti}_{3} \mathrm{O}_{7} \mathrm{QRHCS}$. Reproduced with permission. ${ }^{82}$ Copyright: 2018, Royal Society of Chemistry. (b) Synthetic procedures for the preparation of $\mathrm{FeS}_{2} \mathrm{QGQCNF}$ and corresponding digital photos. (c) The long-term cycling stability of FeS $\mathrm{QG}_{2} \mathrm{aCNF}$ at $3 \mathrm{~A} \mathrm{~g}^{-1}$. Reproduced with permission. ${ }^{83}$ Copyright: 2019, Wiley-VCH Verlag GmbH \& Co. KGaA. 


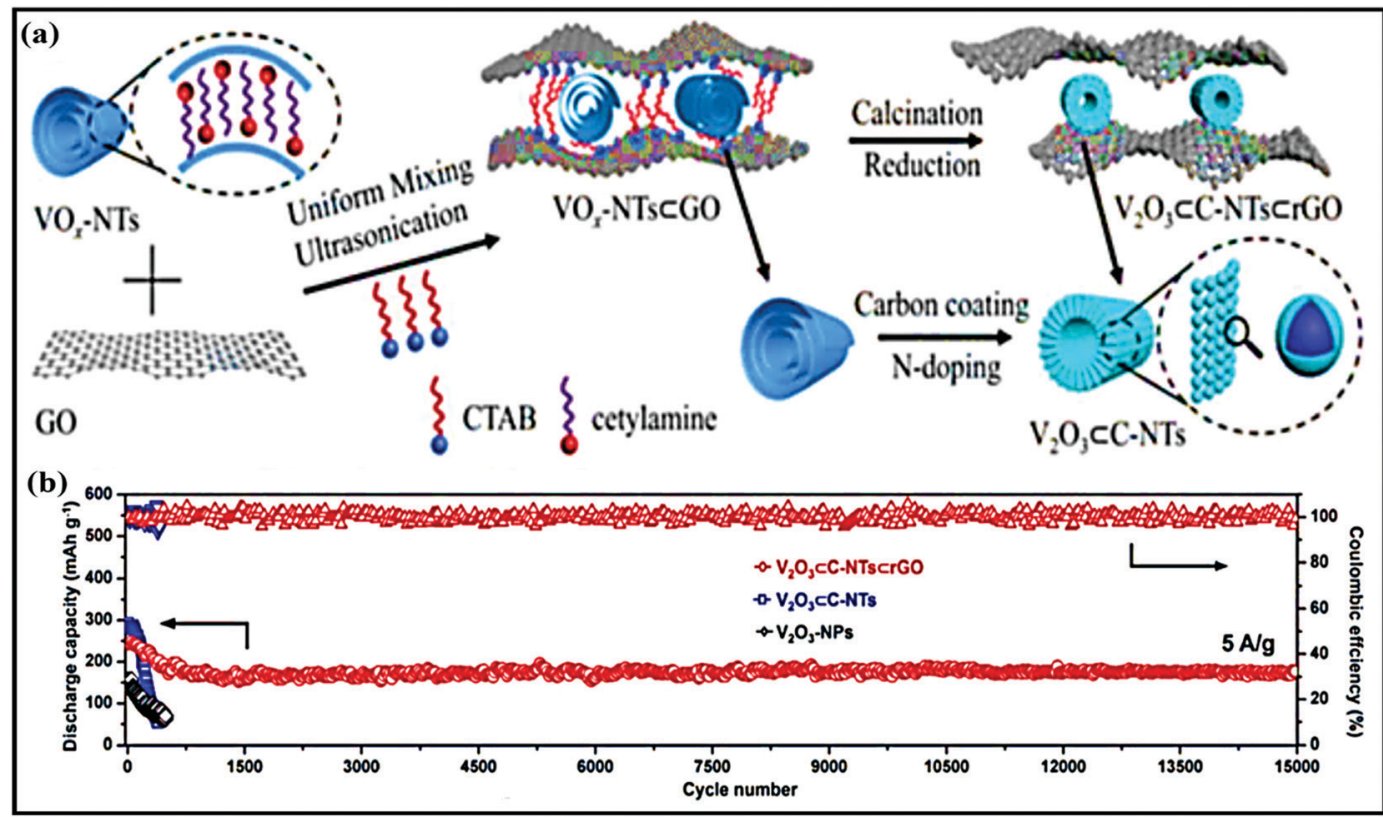

Fig. 7 (a) A schematic diagram of the synthesis of $\mathrm{V}_{2} \mathrm{O}_{3} \subset \mathrm{C}-\mathrm{NTs} \subset \mathrm{rGO}$ and (b) the cycling performances of $\mathrm{V}_{2} \mathrm{O}_{3} \subset \mathrm{C}-\mathrm{NTs} \subset \mathrm{rGO}, \mathrm{V}_{2} \mathrm{O}_{3} \subset \mathrm{C}-\mathrm{NTs}$, and $\mathrm{V}_{2} \mathrm{O}_{3}$-NPs at $5.0 \mathrm{~A} \mathrm{~g}^{-1}$ (after being initially activated at $0.1 \mathrm{~A} \mathrm{~g}^{-1}$ for 3 cycles). Reproduced with permission. ${ }^{86} \mathrm{Copyright:} 2018$, Wiley-VCH Verlag GmbH \& Co. KGaA.

prepared via a facile one-step solvothermal method. This newly designed composite yields a high reversible capacity even after 500 cycles at $1.0 \mathrm{~A} \mathrm{~g}^{-1}$ (equal to capacity retention of $90.2 \%$ ). This recorded reversible (de)sodiation process and marked cycling stability can be attributed to a combination of intercalation and conversion between $\mathrm{Na}^{+}$and Se and an alloying reaction between $\mathrm{Na}^{+}$and $\mathrm{Sb}$, respectively.

$\mathrm{Co}_{0.8} \mathrm{Se} @ \mathrm{rGO}$ hierarchical nanosheets prepared by Yongxin Huang et al. ${ }^{90}$ through a simple hydrothermal route registered impressive electrochemical performance with a high reversible capacity of $460 \mathrm{~mA} \mathrm{~h} \mathrm{~g}^{-1}$ at $0.5 \mathrm{~A} \mathrm{~g}^{-1}$ and high rate performance of 448 and $327 \mathrm{~mA} \mathrm{~h} \mathrm{~g}^{-1}$ at 0.5 and $4 \mathrm{~A} \mathrm{~g}^{-1}$, respectively $(\sim 1.2 \mathrm{~V}$ vs. $\left.\mathrm{Na} / \mathrm{Na}^{+}\right)$. Even at a high current density of $6 \mathrm{~A} \mathrm{~g}^{-1}$, a

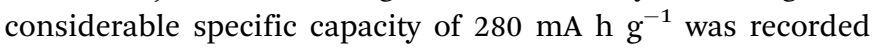
(achieved with $81 \%$ capacity retention). This is mainly attributed to: (i) synergetic effects and the hierarchical porous structure improving the electronic/ionic transport and buffering volume expansion during long-term cycling; (ii) the high conductivity of the rGO layers participating in improvements in the electrochemical performance; and (iii) the novel structural design providing a strong pseudo-capacitive effect with an intercalation- and conversion-based mechanism. Xianfen Wang et al. ${ }^{91}$ also reported that improved electrochemical performance was shown by a $\mathrm{Co}_{9} \mathrm{Se}_{8} @$ @GO anode $(\sim 1.2 \mathrm{~V} v s$. $\mathrm{Na} / \mathrm{Na}^{+}$) in SIBs. The high performance of this composite is due to the charging process, where Co first reacts with $\mathrm{Na}_{2} \mathrm{Se}$ to form $\mathrm{Na}_{x} \mathrm{CoSe}_{2}$ and then returns to $\mathrm{CoSe}_{2}$ (a conversion reaction) with the help of high conductivity rGO. rGO also played a significant role in controlling the growth and prevents the stacking of $\mathrm{Co}_{9} \mathrm{Se}_{8}$ particles, effectively buffering volume changes during charging/discharging and improving the conductance.
A NiSe ${ }_{2} @$ carbon composite $\left(\sim 1.4 \mathrm{~V} v s . \mathrm{Na} / \mathrm{Na}^{+}\right)$anode,${ }^{87}$ prepared via self-assembly, in situ polymerization, selenization, and carbonization strategies (Fig. 8a), recorded an excellent capacity of $374 \mathrm{~mA} \mathrm{~h} \mathrm{~g}{ }^{-1}$ even after 3000 cycles (Fig. 8b) at a current density of $10 \mathrm{~A} \mathrm{~g}^{-1}$, and it demonstrated ultra-rare performance at various current densities due to strong buffer action (Fig. 8c). Electrochemical kinetics studies demonstrated that the redox reactions were mainly dominated by pseudocapacitive behaviour. A $\mathrm{MOSe}_{2}$ @rGO composite anode, ${ }^{92}$ which is known to be one of the best intercalation hosts, was prepared via a facile hydrothermal method, and it showed improved electrochemical performance, such as high GCD capacities of $556 / 820 \mathrm{~mA} \mathrm{~h} \mathrm{~g}{ }^{-1}$ (while pristine $\mathrm{MOSe}_{2}$ delivers charge/discharge capacities of $353 / 469 \mathrm{~mA} \mathrm{~h} \mathrm{~g}^{-1}$ ) at $0.5 \mathrm{~A} \mathrm{~g}^{-1}$. Bare $\mathrm{MOSe}_{2}$ retained a capacity of $220-250 \mathrm{~mA} \mathrm{~h} \mathrm{~g}{ }^{-1}$ for 70 cycles and then rapidly decayed. Meanwhile, the $\mathrm{MOSe}_{2} @ \mathrm{rGO}$ composite shows good cycling stability for up to 200 cycles with capacities of 430 and $380 \mathrm{~mA} \mathrm{~h} \mathrm{~g}^{-1}$ at 0.5 and $0.1 \mathrm{~A} \mathrm{~g}^{-1}$, respectively.

Phosphides, analogous to metal selenides, have shown great potential for energy applications owing to their low cost and appealing electrochemical characteristics, ${ }^{93-97}$ such as high theoretical and volumetric specific capacities. However, poor charge transfer kinetics and alloying reactions accompanied by large volume expansion make them less useful as individual materials. ${ }^{87,94}$ However, utilizing a suitable host and adopting unique structural design can improve the electrochemical performance via favorable synergetic effects. In one such study, a $\mathrm{Sn}_{4} \mathrm{P}_{3} @$ @rGO composite reported by Qun Li et al. ${ }^{98}$ demonstrated enhanced electrochemical performance and electronic/ionic conductivity. The alloy-type $\left(\sim 0.5 \mathrm{~V} v s . \mathrm{Na} / \mathrm{Na}^{+}\right)$composite material anode showed a high reversible capacity and, more significantly, 


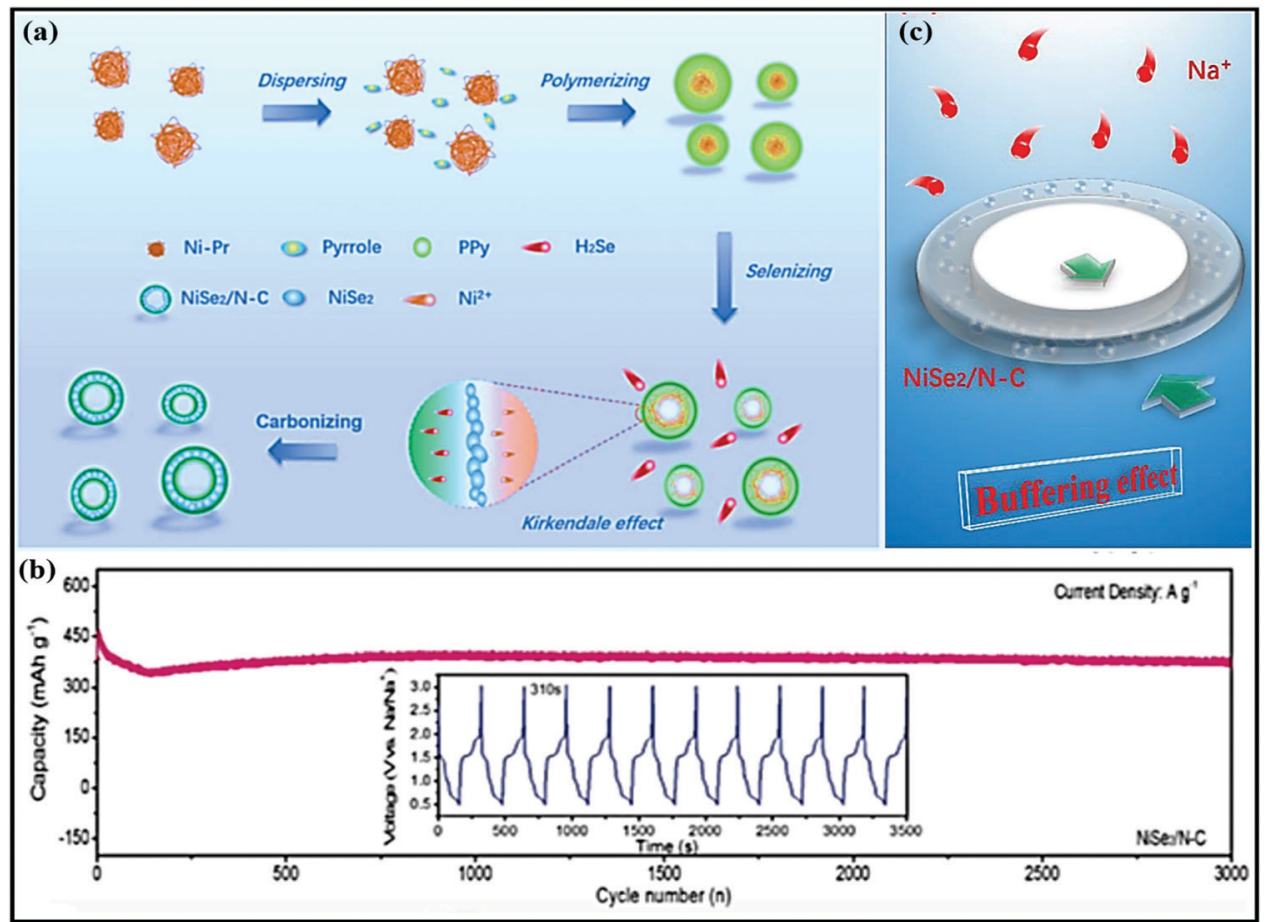

Fig. 8 (a) The formation of a hollow-like NiSe $/ 2 \mathrm{~N}-\mathrm{C}$ composite. (b) The long-term cycling stability of the NiSe $/ \mathrm{N}-\mathrm{C}$ composite and charge/discharge profiles from the 1000th to the 1010th cycle. (c) The mechanism of buffer effect. Reproduced with permission. ${ }^{87}$ Copyright: 2019 , Wiley-VCH Verlag GmbH \& Co. KGaA.

the composite demonstrated a capacity of $362 \mathrm{~mA} \mathrm{~h} \mathrm{~g}^{-1}$ even after 1500 repeated cycles; this performance was attributed to the abundantly porous nanoarchitecture. Similarly, a phosphorousand tin-based anode material $\left(\mathrm{Sn}_{4} \mathrm{P}_{3}-\mathrm{P} ; \mathrm{Sn}: \mathrm{P}\right)$ with graphene (Sn:P@graphene) ${ }^{99}$ demonstrated excellent cycling stability (capacities of more than 550 and $371 \mathrm{~mA} \mathrm{~h} \mathrm{~g}^{-1}$ at 1 and $2 \mathrm{~A} \mathrm{~g}^{-1}$, respectively) for over 1000 cycles and high rate performance (capacities of $\sim 815,585$, and $315 \mathrm{~mA} \mathrm{~h} \mathrm{~g}{ }^{-1}$ at $0.1,2$, and $10 \mathrm{~A} \mathrm{~g}^{-1}$, respectively). This improved cycling stability and rate performance could be ascribed to the novel structural design and stable architecture involving $\mathrm{Sn}_{4} \mathrm{P}_{3}-\mathrm{P}$ and the graphene scaffold. Porous $\mathrm{Li}_{4} \mathrm{Ti}_{5} \mathrm{O}_{12}$ (PLTO) nanofibers confined in a 3D-interconnected graphene framework (G-PLTO) composite aerogel ${ }^{100}$ were designed via a hydrothermal process followed by a freeze-drying strategy. The composite was formed due to electrostatic attraction between the positively charged PLTO nanofibers and negatively charged GO. Synergetic effects between PLTO and graphene enabled the composite to demonstrate a high capacity of $195 \mathrm{~mA} \mathrm{~h} \mathrm{~g}^{-1}$ at a rate of $0.2 \mathrm{C}$, good rate performance with discharge capacities of 200 and $58 \mathrm{~mA} \mathrm{~h} \mathrm{~g}^{-1}$ at rates of $0.2 \mathrm{C}$ and $12 \mathrm{C}$, respectively, and remarkable cycling stability (a high capacity of $120 \mathrm{~mA} \mathrm{~h} \mathrm{~g}^{-1}$ was retained even after 12000 cycles). In addition, an excellent and highly durable anode $\left(\sim 1.0 \mathrm{~V}\right.$ vs. $\left.\mathrm{Na} / \mathrm{Na}^{+}\right)$is obtained showing intercalation and interfacial $\mathrm{Na}^{+}$storage between the composite and electrolyte. Liu Wang et al. ${ }^{101}$ demonstrated a novel scalable approach for preparing a $\mathrm{Nb}_{2} \mathrm{O}_{5}$ @graphene composite. Electrochemically, $\mathrm{Nb}_{2} \mathrm{O}_{5} @ g r a p h e n e$ nanosheets, via an insertion-type mechanism $\left(\sim 0.75 \mathrm{~V}\right.$ vs. $\mathrm{Na} / \mathrm{Na}^{+}$storage $)$, reported high rate performance in a range of 0.25 to $20 \mathrm{C}$ (a reversible capacity of nearly $100 \mathrm{~mA} \mathrm{~h} \mathrm{~g}{ }^{-1}$ was obtained in just $3 \mathrm{~min}$ at a rate of $20 \mathrm{C}$, which signifies the excellent rate performance). Bin Luo et al. ${ }^{102}$ demonstrated controllable conversion from $\mathrm{SnO}_{2}$ to $\mathrm{SnS}_{2}$ on the surface of nanocarbon, depending on the initial $\mathrm{SnO}_{2}$ content. A nanocarbon substrate (rGO or CNTs) with a discontinuous distribution or densely packed distribution of metal oxide nanoparticles $\left(\mathrm{SnO}_{2}\right)$ could lead to, when sulfurized, the parallel growth of large-area $\mathrm{SnS}_{2}$ film and vertically aligned thicker $\mathrm{SnS}_{2}$ sheets with a smaller contact area with the carbon support. The best interfacial contact can be achieved with ultrathin sheet-like nanostructures, which have parallel alignment with the rGO or CNT phase. However, in either case, the cycling stability is limited due to the large area of insulating $\mathrm{SnS}_{2}$ that is exposed. However, the generation of an amorphous conducting carbon coating before the sulfurization process via the hydrothermal carbonization of glucose was found to stabilize the cell performance, allowing both high rate capabilities and good cycle stability. A layered $\mathrm{SnS}_{2} @ \mathrm{rGO}$ composite $^{103}$ was fabricated via a facile hydrothermal route, and the main intention was to prevent large volume changes during subsequent cycling and to ultimately boost the electrochemical performance. As expected, the authors achieved enhanced storage performance due to the use of a layered structure with increased interlayer spacing. In addition, rGO improves the electron conductivity and helps to maintain the structural integrity through a synergetic effect. Exfoliated $\mathrm{SnS}_{2}$ (with sizes ranging from 20-50 nm) restacked on graphene ${ }^{104}$ also showed high performance. The composite was designed through the exfoliation of $\mathrm{SnS}_{2}$ via hydrolysis and it was restacked on graphene via a cetyltrimethylammonium bromideassisted hydrothermal process. The composite showed a capacity 
as high as $650 \mathrm{~mA} \mathrm{~h} \mathrm{~g}{ }^{-1}$ at a current density of $200 \mathrm{~mA} \mathrm{~g}^{-1}$ with more than $98 \%$ Coulombic efficiency. A synergetic effect between the highly conductive graphene scaffold and nanosized $\mathrm{SnS}_{2}$ improved the Na-ion diffusion coefficient and electronic/ionic conductivity. Meanwhile, the graphene network provided more reaction sites and reduced aggregation and volume fluctuations during long-term cycling.

\subsection{Phosphate-based composite materials}

Phosphate framework materials have undergone a dramatic increase in interest in recent years for use in both LIBs and SIBs owing to some of their intrinsic benefits, ${ }^{2,50,105-108}$ such as (i) high structural stability due to the very stable P-O crystal framework, which enables long-term cycling stability; (ii) low volumetric expansion and fewer phase transitions; and (iii) high redox potential values and low thermal expansion. However, the intrinsically isolating nature of the phosphate group results in poor electron conductivity and moderate capacities. ${ }^{50}$ Composite/hybrid formation through rational design is one of the most promising platforms for improving electronic conductivity and electrochemical performance. ${ }^{50,109}$ For instance, Yang et al. designed 3D $\mathrm{NaTi}_{2}\left(\mathrm{PO}_{4}\right)_{3} @ \mathrm{rGO}$ microspheres ${ }^{110}$ as a composite with high-rate and ultra-long cycling abilities. Due to the high surface area, high structural integrity, and conductivity, the $\mathrm{NaTi}_{2}\left(\mathrm{PO}_{4}\right)_{3} @ \mathrm{gGO}$ anode showed a high discharge/charge capacity and superior cycling performance $(77 \%$ retention after 1000 cycles at a rate of 20C) with high rate performance (capacities of 130 and $75 \mathrm{~mA} \mathrm{~h} \mathrm{~g}{ }^{-1}$ were recorded at 0.1 and 100C, respectively). $\mathrm{NaTi}_{2}\left(\mathrm{PO}_{4}\right)_{3} @ \mathrm{C}^{111}$ was prepared via an innovative and facile impregnation method followed by a calcination strategy; it adopted the form of 3D porous architecture and demonstrated favorable electrochemical performance in aqueous electrolyte. In a half-cell $\left(\mathrm{NaTi}_{2}\left(\mathrm{PO}_{4}\right)_{3} @ \mathrm{C}\right.$ vs. SCE), the composite recorded capacities of $\sim 130 \mathrm{~mA} \mathrm{~h} \mathrm{~g} \mathrm{~g}^{-1}$ and $\sim 67 \mathrm{~mA} \mathrm{~h} \mathrm{~g}^{-1}$ at $0.5 \mathrm{C}$ and 90C, respectively, and the composite reported $89 \%$ capacity retention after cycling for up to 2000 cycles with nearly $100 \%$ Coulombic efficiency. Recently, Ping Lei et al. fabricated a $\mathrm{Na}_{2} \mathrm{Ti}_{3 / 2} \mathrm{Mn}_{1 / 2}\left(\mathrm{PO}_{4}\right)_{3}$ @carbon ${ }^{112}$ nanocomposite anode in the form of nanodots, which were uniformly planted in a carbon matrix with an average size of less than $10 \mathrm{~nm}(\sim 4 \mathrm{~nm})$. A Na-storage capacity of around $88.6 \mathrm{~mA} \mathrm{~h} \mathrm{~g}^{-1}$ was reported at $0.5 \mathrm{C}$, with capacity retention of $90 \%$ even after 1000 repeat cycles at a rate of $10 \mathrm{C}$ in aqueous electrolyte.

A layer-by-layer fabricated $\mathrm{NaV}_{3}\left(\mathrm{PO}_{4}\right)_{3} @ \mathrm{rGO}^{115}$ cathode $\left(\sim 3.3 \mathrm{~V}\right.$ vs. $\left.\mathrm{Na} / \mathrm{Na}^{+}\right)$prepared via a self-assembly approach exhibited remarkable electrochemical performance (especially in terms of rate capabilities and cycling stability) due to its high electrochemical stability and electronic and ionic conductivity, leading to excellent cycling stability $(70 \%$ capacity retention even after 15000 cycles at 50C) and rate performance, even in low- and high-temperature ranges. Xianhong Rui et al. ${ }^{116}$ designed a 3D hierarchically porous $\mathrm{NaV}_{3}\left(\mathrm{PO}_{4}\right)_{3} @ \mathrm{C} @ \mathrm{rGO}$ composite through a convenient freeze-drying assisted strategy. This improved the $\mathrm{Na}^{+} /$electron transport pathways and enhanced the electrode-electrolyte contact area. More significantly, a discharge capacity of $55 \mathrm{~mA} \mathrm{~h} \mathrm{~g}{ }^{-1}$ is retained, even after 10000 repeat cycles, which corresponds to $64 \%$ capacity retention at an ultrahigh rate of $100 \mathrm{C}$. The highly porous and hierarchical 1D $\mathrm{NaV}_{3}\left(\mathrm{PO}_{4}\right)_{3} @ \mathrm{C}^{117}$ nanofiber nanoarchitecture demonstrated fast ion/electron transport capabilities, high structural stability, and high electrochemical performance. Electrospinning followed by a fast-rotating receiver strategy has been applied to fabricate novel $\mathrm{NaV}_{3}\left(\mathrm{PO}_{4}\right)_{3} @ \mathrm{C}$ nanofiber films. In aqueous electrochemical analysis, especially in a full-cell configuration $\left(\mathrm{Na}_{0.44} \mathrm{MnO}_{2}\right.$ vs. NVP@C), the well-designed 1D nanoarchitecture reported a discharge capacity of $\sim 126 \mathrm{~mA} \mathrm{~h} \mathrm{~g}^{-1}$ and demonstrated high-rate and long-term cycling abilities (it retains $84 \%$ of the initial capacity after 500 cycles at alternate rates of 5C and 20C with nearly $100 \%$ Coulombic efficiency).

Amorphous $\mathrm{FePO}_{4}$ cathodes suffer from low electronic conductivity and low diffusion coefficients. ${ }^{118}$ The development of $\mathrm{FePO}_{4}$ using graphene not only improved the overall performance of the material but also stabilized the active material through a strong co-operative effect. ${ }^{118}$ Indeed, the composite registered enhanced rate performance (with capacities of $\sim 139$ and $41 \mathrm{~mA} \mathrm{~h} \mathrm{~g}^{-1}$ at rates of 0.1 and 20C, respectively). As claimed by the authors, the improved performance (especially the rate performance) could be attributed to the unique structural architecture, which not only allows the greater penetration of electrolyte and accommodates the strain induced by volume changes during cycling but also provides shorter electron/ion diffusion pathways. In the case of $\mathrm{FePO}_{4} @ \mathrm{rGO},{ }^{119}$ the composite provides high-speed pathways for electrons/ions and improves electronic conductivity, and the stable $\mathrm{FePO}_{4} /$ electrolyte interface makes sodium ions jump up and down easily, leading to high rate performance and high GCD capacity as a result. Using an $\mathrm{FePO}_{4} @ \mathrm{CNTs}$ composite, capacity retention of about 70, 60, and $55 \mathrm{~mA} \mathrm{~h} \mathrm{~g}^{-1}$ was achieved at high current densities of 20,40, and $60 \mathrm{~mA} \mathrm{~g}{ }^{-1}$, respectively. Fan et al. $^{113}$ applied electrospinning followed by heat treatment to obtain $\mathrm{NaFePO}_{4}$ nanodots embedded in porous interlinked $\mathrm{N}$-doped carbon nanofibers ( $\mathrm{NaFePO}_{4} @ \mathrm{C}$ ) (Fig. 9a). The rationally designed $\mathrm{NaFePO}_{4} @ \mathrm{C}$ composite cathode $\left(\sim 2.7 \mathrm{~V}\right.$ vs. $\left.\mathrm{Na} / \mathrm{Na}^{+}\right)$showed superior cycling stability (89\% capacity retention after 6300 cycles) (Fig. 9b) with superior rate performance (a capacity of $61 \mathrm{~mA} \mathrm{~h} \mathrm{~g}^{-1}$ at a rate of $5 \mathrm{C}$ ). Recently, binder-free $\mathrm{Na}_{4} \mathrm{Fe}_{3}\left(\mathrm{PO}_{4}\right)_{2}\left(\mathrm{P}_{2} \mathrm{O}_{7}\right) @ \mathrm{NaFePO}_{4} @$ core doubleshell architectures grown on flexible carbon cloth were designed via a facile sol-gel method followed by a heat treatment strategy ${ }^{114}$ (Fig. 9c). The carbonaceous parts, such as the carbon cloth and outermost carbon shell, were employed to create a fast 3D electronic conducting network. The porous core-shell electrode could provide ample space to accommodate the strain of volume changes. In battery studies, the composite hybrid cathode $\left(\sim 3.05 \mathrm{~V} v s . \mathrm{Na} / \mathrm{Na}^{+}\right)$ reported a discharge capacity of $136 \mathrm{~mA} \mathrm{~h} \mathrm{~g}^{-1}$ at a rate of $0.1 \mathrm{C}$, good cycling stability over 3000 cycles at a rate of 10C (Fig. 9d) and good rate performance, even at a rate of $100 \mathrm{C}$, delivering a capacity of $68 \mathrm{~mA} \mathrm{~h} \mathrm{~g}^{-1}$ through strong synergetic cooperation.

\subsection{Sulfate-based composite materials}

Similar to phosphate-based electrode materials, lately sulfatebased electrodes have gained prominence for use in LIBs and SIBs due to their stronger electronegativity, which is useful for 

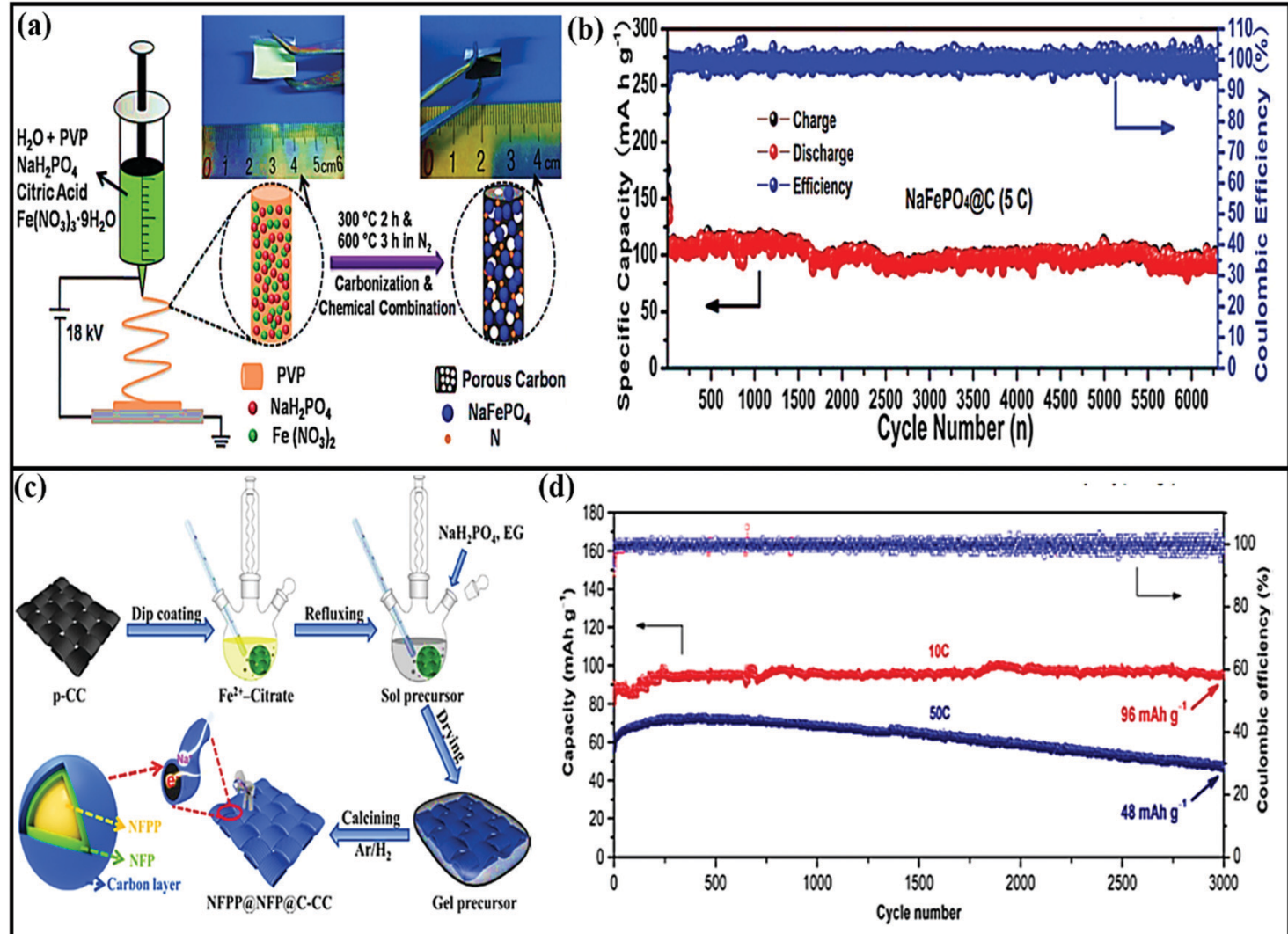

Fig. 9 (a) A schematic illustration of the preparation process and (b) the long-term cycling performance at a rate of $5 \mathrm{C}$ of $\mathrm{NaFePO}_{4}(\mathrm{aC}$ nanofibers. Reproduced with permission. ${ }^{113}$ Copyright: 2018, Wiley-VCH Verlag GmbH \& Co. KGaA. (c) A schematic illustration of the preparation process of a NFPP@NFP@C-CC flexible electrode and (d) the long-term cycling performance of NFPPaNFPaC-CC at current rates of $10 \mathrm{C}$ and $50 \mathrm{C}$ for 3000 cycles. Reproduced with permission. ${ }^{114}$ Copyright: 2019, Elsevier.

achieving high working potentials. ${ }^{22,120}$ Although sulfates have shown great potential, they suffer from major drawbacks, like low electronic conductivity, high solubility, and sensitivity to moisture, making them unsuitable materials for SIBs. ${ }^{121,122}$ However, the rational combination of sulfates with carbonbased networks could be a feasible and promising way to improve the electrochemical performance. Aiming in this direction, Mingzhe Chen and co-workers fabricated a graphene-wrapped $\mathrm{Na}_{2} \mathrm{Fe}_{2}\left(\mathrm{SO}_{4}\right)_{3}$ (NFS@C@GO) composite via adopting a freezedrying approach. ${ }^{123}$ The intercalation-type composite cathode recorded a voltage of $\sim 3.8 \mathrm{~V}$ with a discharge capacity of $107.9 \mathrm{~mA} \mathrm{~h} \mathrm{~g}^{-1}$ at a rate of $0.1 \mathrm{C}$, and favorable capacity retention of $80.1 \%$ even after 800 cycles at $0.6 \mathrm{~A} \mathrm{~g}^{-1}$. The Non-faradic process contribution (surface contribution) is calculated to be $27.90 \%$ at a scan rate of $0.3 \mathrm{mV} \mathrm{s}^{-1}$ with diffusion coefficient values to be of around $10^{-10.8}-10^{-12} \mathrm{~cm}^{2} \mathrm{~s}^{-1}$. A high-performance $\mathrm{Na}_{6} \mathrm{Fe}_{5}\left(\mathrm{SO}_{4}\right)_{8}$ cathode $(3.6 \mathrm{~V}$ vs. Na/Na $)$ integrated with 5 wt $\%$ CNTs (NFS@CNTs) was designed using a hard carbon (HC) material. ${ }^{124}$ The composite reported high rate capabilities at different $\mathrm{C}$ rates (with specific capacities of 110.2 and $86.4 \mathrm{~mA} \mathrm{~h} \mathrm{~g}^{-1}$ at rates of 0.1 and $2 \mathrm{C}$, respectively), with a diffusion coefficient of up to $6.1 \times 10^{-13} \mathrm{~cm}^{2} \mathrm{~s}^{-1}$. Recently, a stretchable $\mathrm{Na}_{2+2 x} \mathrm{Fe}_{2-x}\left(\mathrm{SO}_{4}\right)_{3} @$ graphene (NFS@graphene) composite ${ }^{121}$ was reported with high conductivity, hydrophobicity, and high electrochemical performance. As a cathode material $(\sim 3.7 \mathrm{~V} v s$. $\mathrm{Na} / \mathrm{Na}^{+}$) with an intercalation-type mechanism, NFS@graphene reported an initial discharge capacity of $\sim 106 \mathrm{~mA} \mathrm{~h} \mathrm{~g}^{-1}$ at $25^{\circ} \mathrm{C}$ with capacity retention of more than $98 \%$ after 700 cycles at $0{ }^{\circ} \mathrm{C}$. Tiantian $\mathrm{Yu}$ et al. reported the use of a unique $\mathrm{Na}_{2+2 x} \mathrm{Fe}_{2-x}\left(\mathrm{SO}_{4}\right)_{3}$ @porous carbon-nanofiber hybrid film ${ }^{125}$ that was obtained using a combination of electrospinning and electrospraying strategies to produce a flexible and selfsupported high-performance cathode $\left(\sim 3.8 \mathrm{~V} v s . \mathrm{Na} / \mathrm{Na}^{+}\right)$for SIBs. The composite maintained flexible and rigid architecture after cycling and bending tests.

Representative physical properties, capacity values, rate capabilities, and capacity retention data for inorganic materials are summarized in Table 2 .

\section{Biomass-derived carbonaceous composite materials}

In view of environmental concerns, biomass-based energy materials stand out as greener and more sustainable owing to their abundance; other advantages include the manifestation of inherent heteroatoms (N, P, S, Ca, etc.), ease of recycling, tunable surface functionality with high electronic conductivity, 


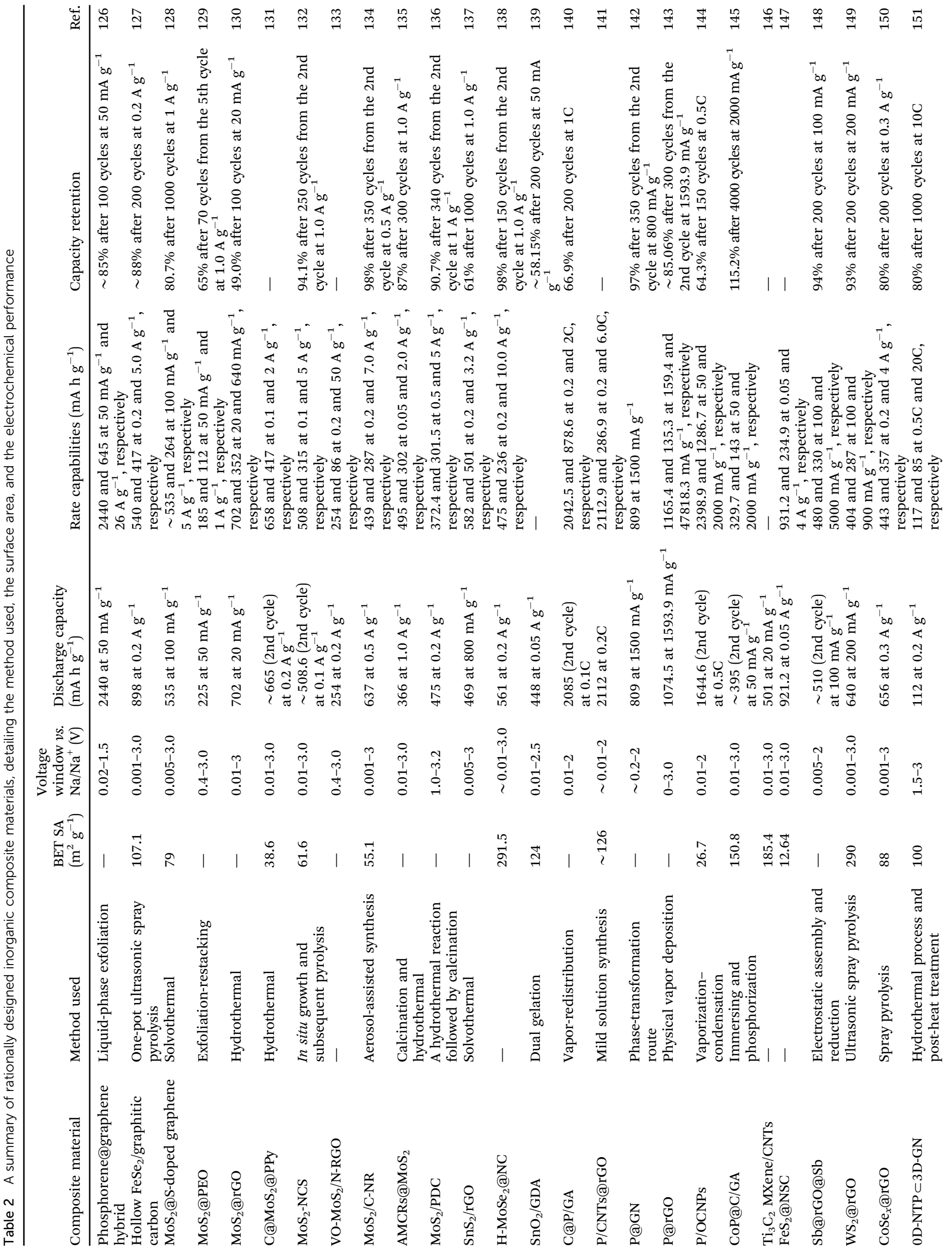


the existence of interconnected hierarchical frameworks and open large pore channels (which accelerate the mass transport of ions and electrolytes), etc. ${ }^{160,161}$ From examining the literature, various biomass-derived carbon sources and strategies adapted to improve the electrochemical performances of SIBs are discussed in this section.

$\mathrm{A} \mathrm{MoSe}_{2} / \mathrm{NP}-\mathrm{C}-2$ composite anode ${ }^{162}$ derived from N,P co-doped bio-carbon obtained using chlorella and $\mathrm{MoSe}_{2}$ was fabricated via a single-step selenization process. The composite electrode in SIBs demonstrated a high reversible capacity of $523 \mathrm{~mA} \mathrm{~h} \mathrm{~g}^{-1}$ even after 100 cycles at $100 \mathrm{~mA} \mathrm{~g}^{-1}$ as a result of a prominent capacitive contribution, and it retained a capacity of $348 \mathrm{~mA} \mathrm{~h} \mathrm{~g}^{-1}$ at $2 \mathrm{~A} \mathrm{~g}^{-1}$ with good cycling stability. Recently Junzhi Li and co-workers reported a novel composite from fungus-derived N-doped CFs with various metal sulfides $\left(\mathrm{MS} / \mathrm{NCF} ; \mathrm{MS}=\mathrm{ZnS}, \mathrm{Co}_{9} \mathrm{~S}_{8}, \mathrm{FeS}\right.$, $\mathrm{Cu}_{1.81} \mathrm{~S}$ ), and this was subjected to LIB/SIB applications. ${ }^{163}$ The composites were prepared via a metal-Aspergillus niger bioleaching approach, followed by freeze-drying and a pyrolysis process, to achieve 1D architecture (Fig. 10a). 1D MS/NCF formed with a high surface area, high porosity, and good permeability for $\mathrm{Na}^{+}$diffusion and transport (Fig. 10b). In particular, the $\mathrm{ZnS} / \mathrm{NCF}$ composite anode, when used in SIBs, showed a stable capacity of $455 \mathrm{~mA} \mathrm{~h} \mathrm{~g}^{-1}$ at $0.1 \mathrm{~A} \mathrm{~g}^{-1}$, and it retained reversible capacities of $540.2 \mathrm{~mA} \mathrm{~h} \mathrm{~g}^{-1}$ at $0.1 \mathrm{~A} \mathrm{~g}^{-1}$ and $291.5 \mathrm{~mA} \mathrm{~h} \mathrm{~g}^{-1}$ at $5 \mathrm{~A} \mathrm{~g}^{-1}$ (Fig. 10c).

In a more noteworthy fashion, Daohao Li et al. ${ }^{165}$ used a double-helix carrageenan-metal hydrogel structure for the synthesis of series of hierarchical porous 3D nano-metal-sulfide $\left(\mathrm{M}_{x} \mathrm{~S}_{y}\right) /$ carbon aerogel (CA) materials, and these were used in high-performance SIBs. The unique structure improved the Na-ion storage performance through feasible ion/electron transport kinetics and through stabilizing the structure of $\mathbf{M}_{x} \mathrm{~S}_{y}$. For example, a rationally designed FeS/CA anode $\left(\sim 1.2 \mathrm{~V}\right.$ vs. $\left.\mathrm{Na} / \mathrm{Na}^{+}\right)$composite showed a high reversible capacity with excellent cycling stability $\left(280 \mathrm{~mA} \mathrm{~h} \mathrm{~g}{ }^{-1}\right.$ at $0.5 \mathrm{~A} \mathrm{~g}^{-1}$ for up to 200 cycles). Subsequently, a porous $\mathrm{Ni}_{3} \mathrm{~S}_{4} /$ carbon aerogel (CA) ${ }^{164}$ composite anode was fabricated with carrageenan and Ni hydrogel as the precursor via a pyrolysis route (Fig. 10d). The electrode, when used in SIBs, showed a stable reversible capacity of $297 \mathrm{~mA} \mathrm{~h} \mathrm{~g}^{-1}$ at $1 \mathrm{~A} \mathrm{~g}^{-1}$ after 100 cycles and good rate performance, with discharge capacities of 424 and $179 \mathrm{~mA} \mathrm{~h} \mathrm{~g}^{-1}$ at current densities of 0.2 and $5 \mathrm{~A} \mathrm{~g}^{-1}$, respectively.

Jiang-ping Tu et al. constructed a new composite from loofah sponge and metal sulfide ( $\left.\mathrm{LSDCM} / \mathrm{MoS}_{2} / \mathrm{N}-\mathrm{C}\right)^{166}$ in the form of ternary sandwich architecture. Due to the novel abundantly porous ternary architecture, the $\mathrm{LSDCM} / \mathrm{MoS}_{2} / \mathrm{N}-\mathrm{C}$ composite anode showed improved electrochemical performance, such as a high reversible capacity $\left(\sim 534 \mathrm{~mA} \mathrm{~h} \mathrm{~g}^{-1}\right.$ after 100 cycles at $\left.0.2 \mathrm{~A} \mathrm{~g}^{-1}\right)$ and good cycling stability $\left(214 \mathrm{~mA} \mathrm{~h} \mathrm{~g}^{-1}\right.$ after 300 cycles at $\left.4.0 \mathrm{~A} \mathrm{~g}^{-1}\right)$. This improved electrochemical performance could be attributed to the 3D sandwich core/shell structure, which prevents aggregation and limits the diffusion of polysulfides into the electrolyte, while the omni-directional conductive network facilitates faster reaction kinetics. Recently, Yuhui Zhang and co-workers ${ }^{167}$ designed a transition-metal-sulfide hollow NPs@CFs (TMS-HNP@CFs-T, where M = Co, Ni) material from abundant, renewable, and eco-friendly seaweed-derived alginate 


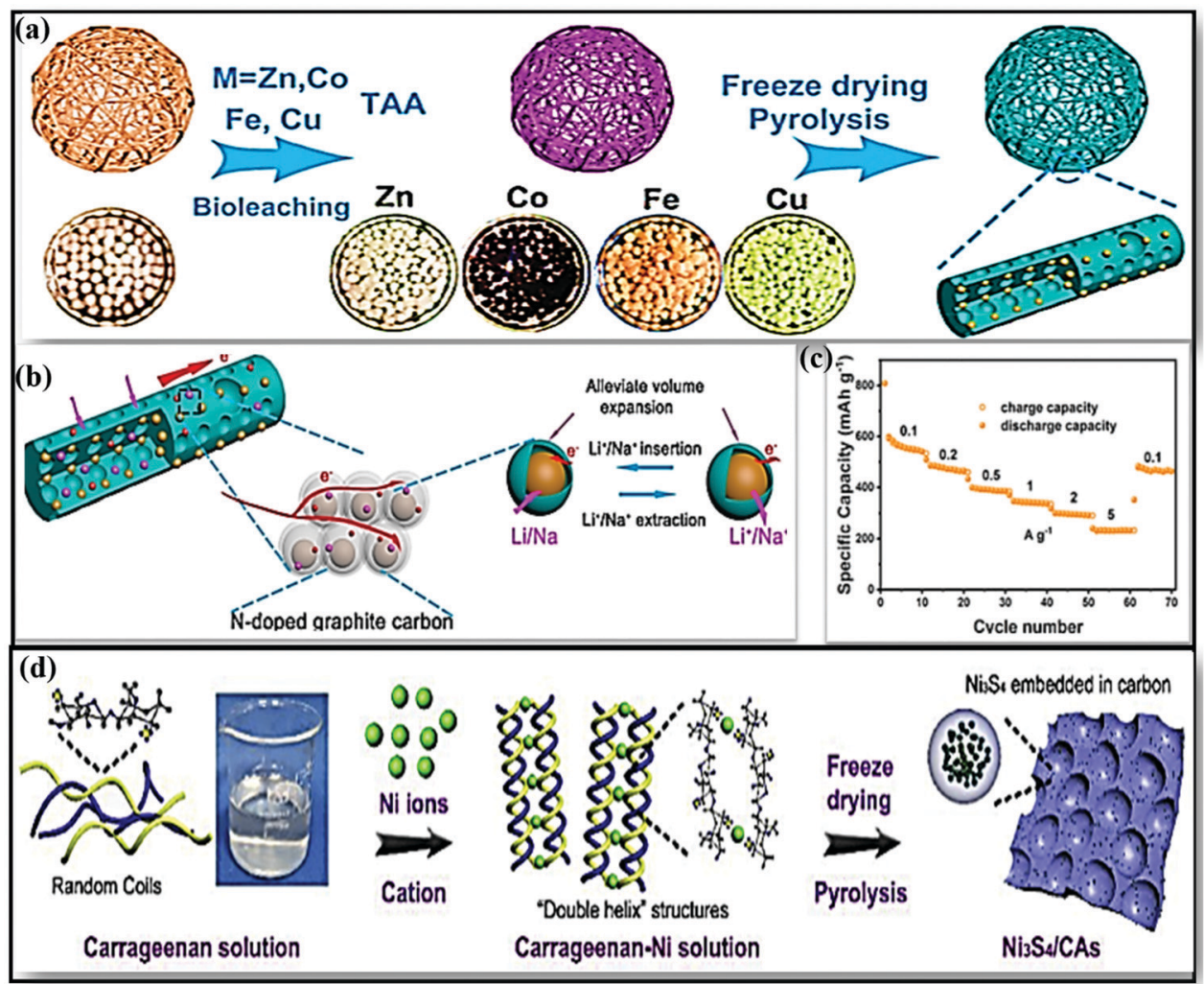

Fig. 10 (a) A schematic illustration of the formation of MS/NCF (MS = ZnS, Cog $S_{8}, F e S, \mathrm{Cu}_{1.81} \mathrm{~S}$ ). (b) A schematic illustration of the good storage performance of MS/NCF. (c) The rate performance of ZnS/NCF at various current densities. Reproduced with permission. ${ }^{163}$ Copyright: 2019 , American Chemical Society. (d) The synthesis of $\mathrm{Ni}_{3} \mathrm{~S}_{4} / \mathrm{CAs}$. Reproduced with permission. ${ }^{164}$ Copyright: 2019, Elsevier.

in the form of CFs. The 1D composite anode material was designed via annealing followed by a sulfuration strategy, as shown in Fig. 11a and b. In this scenario, the CFs effectively improved the electrode/electrolyte surface, resulting in improved electrode kinetics, and the S-doped CFs offer alternative electron transfer paths between the 1D CFs and TMS-HNP.

In another instance, a 1D porous Fe-carrageenan-based material $(\mathrm{FeS} / \mathrm{CFs})^{169}$ was prepared via pyrolysis. FeS NPs are formed in situ via interacting with the sulfur-containing groups of $\mathbf{t}$-carrageenan, and they are uniformly embedded in the unique 1D porous carbon fibrous matrix. As an anode, the FeS/CFs aerogel showed a high capacity of $\sim 310 \mathrm{~mA} \mathrm{~h} \mathrm{~g}^{-1}$, excellent cycling stability (retaining a capacity of $283 \mathrm{~mA} \mathrm{~h} \mathrm{~g}{ }^{-1}$ after 400 cycles at $1 \mathrm{~A} \mathrm{~g}^{-1}$ ), and high rate performance (a reported capacity of $247 \mathrm{~mA} \mathrm{~h} \mathrm{~g}{ }^{-1}$ even at $5 \mathrm{~A} \mathrm{~g}^{-1}$ ). Subsequently, $\mathrm{FeS}_{2}$ NPs anchored on biomass-derived carbon tubes $^{170}$ also showed a high reversible capacity of $542.2 \mathrm{~mA} \mathrm{~h} \mathrm{~g}^{-1}$ at $0.5 \mathrm{~A} \mathrm{~g}^{-1}$ with reasonable rate performance (it delivers a capacity of $426.2 \mathrm{~mA} \mathrm{~h} \mathrm{~g}^{-1}$ even at $2 \mathrm{~A} \mathrm{~g}^{-1}$ ) and excellent cycling stability (95.4\% retention after 1000 cycles). The outstanding electrochemical performances of all these FeS composite materials are due to the 1D network architectures, which provide paths for ion and electron transport, offer sufficient void space to alleviate volume expansion, improve the electronic conductivity, and enhance the transport kinetics of FeS particles. 3D carbon nanofiber aerogel with welldistributed FeS NPs (CNA) ${ }^{168}$ was fabricated via a carbonization and sulfuration strategy (Fig. 11c). Electrochemically, the aerogel not only showed a high reversible capacity and good cycling stability (97.4\% capacity retention after 400 cycles) but it also showed exceptional high-rate capabilities (with capacities of 473 and $291 \mathrm{~mA} \mathrm{~h} \mathrm{~g}^{-1}$ at 0.1 and $5 \mathrm{~A} \mathrm{~g}^{-1}$, respectively) (Fig. 11d and e).

In a distinctive multi-step approach, $\mathrm{Na}_{7} \mathrm{~V}_{3}\left(\mathrm{P}_{2} \mathrm{O}_{7}\right)_{4}$ @fungusderived porous carbon ${ }^{171}$ was designed to form a $3 \mathrm{D}$ porous graphene-like carbon framework. Taking advantage of the porous framework, highly conductive skeleton, and good stability, the 3D hybrid achieved higher electrochemical performance via improved electron/ion transport. With a voltage of $\sim 4.0 \mathrm{~V} v s . \mathrm{Na} / \mathrm{Na}^{+}$, the composite reported a capacity of $\sim 90 \mathrm{~mA} \mathrm{~h} \mathrm{~g}^{-1}$, and it retains $91 \%$ of the initial capacity after 800 cycles.

\section{Bimetallic hybrid composite materials}

The use of hybrid materials, combining the advantages of individual components, has been considered as an ideal approach for forming unique nanostructures with improved storage performance. Furthermore, the formation of hybrid composites using carbonaceous materials has led to advantages for facile Na-ion storage performance. For instance, a bimetallic SbS@Fes hollow nanorod hybrid embedded into a N-doped carbon matrix ${ }^{172}$ was fabricated via a facile two-step solvothermal method (first $\mathrm{Sb}_{2} \mathrm{~S}_{3}$ was obtained via a solvothermal method, then $\mathrm{Sb}_{2} \mathrm{~S}_{3} @ \mathrm{Fe}_{2} \mathrm{O}_{3}$ was 


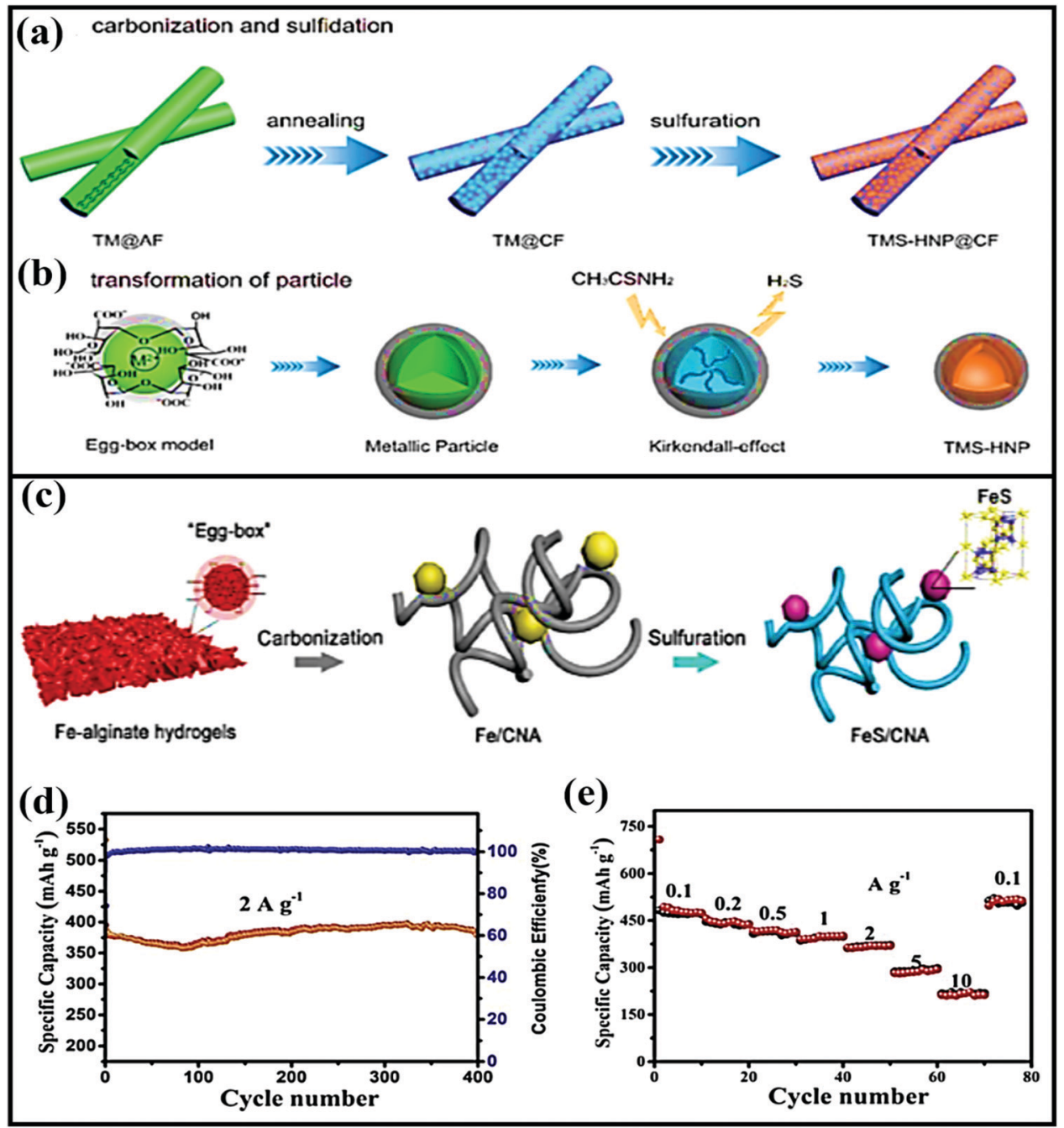

Fig. 11 Schematic illustrations of the synthesis of (a) TMS-HNP@CFs and (b) the transformation of TMS-HNP. Reproduced with permission. ${ }^{167}$ Copyright: 2018, American Chemical Society. (c) A schematic illustration of the synthesis process of FeS/CNA. (d) The cycling performance of FeS/ CNA at $2 \mathrm{~A} \mathrm{~g}^{-1}$ and (e) the rate performance of the FeS/CNA electrode. Reproduced with permission. ${ }^{168}$ Copyright: 2019 , Elsevier.

prepared via a hydrothermal process, and this was combined with nitrogen-doped graphene) (Fig. 12a) and used as a highperformance anode $\left(\sim 1.0 \mathrm{~V}\right.$ vs. $\left.\mathrm{Na} / \mathrm{Na}^{+}\right)$. The novel designed hybrid structure not only accelerated the electrode kinetics, providing enormous numbers of electrochemically active sites, but it also effectively alleviated volume expansion during cycling via maintaining high structural stability (Fig. 12b). Therefore, the composite reported a capacity as high as $882.2 \mathrm{~mA} \mathrm{~h} \mathrm{~g}^{-1}$ at $0.1 \mathrm{Ag}^{-1}$, and high rate performance of $537.9 \mathrm{~mA} \mathrm{~h} \mathrm{~g}{ }^{-1}$ even at $10 \mathrm{~A} \mathrm{~g}^{-1}$, with $85.7 \%$ capacity retention even after 1000 cycles at $5 \mathrm{~A} \mathrm{~g}^{-1}$.

A heterostructure composed of $\mathrm{In}_{2} \mathrm{~S}_{3}-\mathrm{Sb}_{2} \mathrm{~S}_{3}$ (I-S) was prepared via a solvothermal process ${ }^{173}$ and further modified with MCNTs (I-S@MCNTs) to improve the electronic conductivity and sodium storage performance. The resulting anode $(\sim 0.7 \mathrm{~V}$ vs. $\mathrm{Na} / \mathrm{Na}^{+}$), utilizing an intercalation-, conversion-, and alloybased mechanism, reported excellent storage performance, with a high reversible capacity of $400 \mathrm{~mA} \mathrm{~h} \mathrm{~g}{ }^{-1}$ at $200 \mathrm{~mA} \mathrm{~g}^{-1}$, high rate performance, and good cycling stability (a capacity of $\sim 400 \mathrm{~mA} \mathrm{~h} \mathrm{~g}^{-1}$ was retained even after 1000 cycles, with capacity retention of $84.2 \%$ ). Therefore, the promising high electrochemical performance could be due to the formed microspheres, which provide abundant channels for facile diffusion, the dominant pseudocapacitive contribution due to the large surface area, and I-S modification, which lowers the migration barrier via improving the electronic structure of the heterostructure. In addition, MWCNTs maintained the structural integrity, providing effective buffer action and improving the electrode kinetics. Distinctly, 3D SnS-ZnS@C hollow nanoboxes embedded in graphene ${ }^{174}$ were prepared via incorporating a ZnS-SnS heterostructure. The heterostructured anode showed a capacity as high as $756 \mathrm{~mA} \mathrm{~h} \mathrm{~g}^{-1}$ at $0.1 \mathrm{~A} \mathrm{~g}^{-1}$ and it reported good rate capabilities of $347 \mathrm{~mA} \mathrm{~h} \mathrm{~g}^{-1}$, even at a high current density of $1 \mathrm{~A} \mathrm{~g}^{-1}$. In addition, the anode registered a capacity of $247 \mathrm{~mA} \mathrm{~h} \mathrm{~g}^{-1}$ after 1000 cycles at a current density of $2.0 \mathrm{~A} \mathrm{~g}^{-1}$ via a conversion- and alloy-based mechanism.

In a similar fashion, Yongjin Fang et al. ${ }^{175}$ designed threelayered $\mathrm{Cu}_{2} \mathrm{~S} @$ carbon@MOS nanoboxes through a multistep template-engaged strategy (the synthesis process and corresponding 


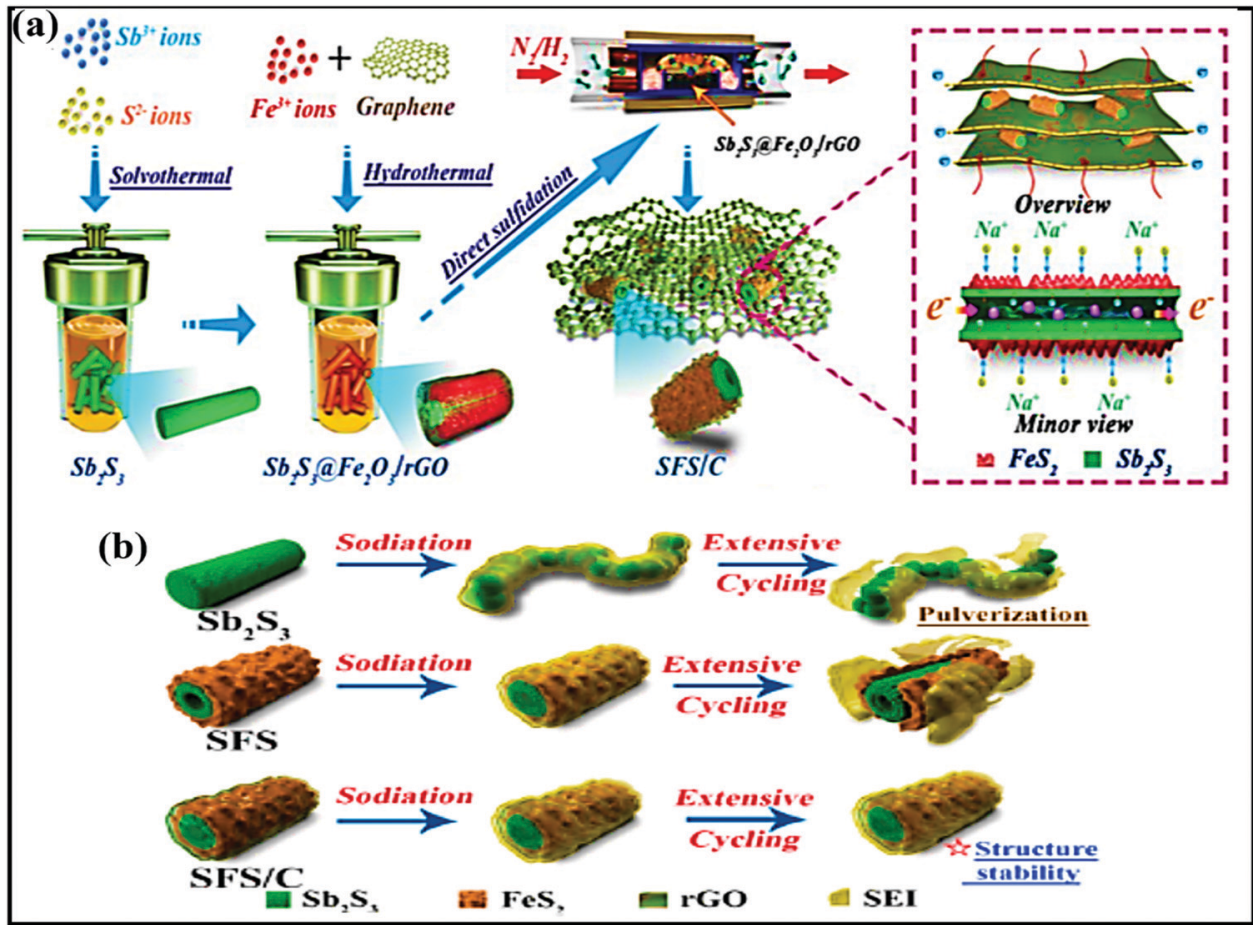

Fig. 12 (a) A schematic illustration of the fabrication process of the SFS/C composite and (b) schematic diagrams of the evolution of $\mathrm{Sb}_{2} \mathrm{~S}_{3}$, $\mathrm{SFS}$, and SFS/C composites upon long-term cycling. Reproduced with permission. ${ }^{172}$ Copyright: 2020, American Chemical Society.

FESEM and TEM images are shown in Fig. 13a-c) and used this material as an anode $\left(\sim 1.25 \mathrm{~V} v s\right.$. Na/Na $\left.{ }^{+}\right)$. The resultant composite is endowed with improved electrode kinetics and conductivity, and it strongly buffers volume variations during cycling and offers abundant active sites. Electrochemically, the hybrid@composite material, through an intercalation- and conversion-based mechanism, showed a charge capacity of $442 \mathrm{~mA} \mathrm{~h} \mathrm{~g}^{-1}$ at $0.05 \mathrm{~A} \mathrm{~g}^{-1}$ and reported decent rate capabilities of 316 and $297 \mathrm{~mA} \mathrm{~h} \mathrm{~g}^{-1}$ even at 2.0 and $3.0 \mathrm{~A} \mathrm{~g}^{-1}$, respectively (Fig. 13d). $\mathrm{NiS}_{2} @ \mathrm{CoS}_{2}$ nanocrystals encapsulated in $\mathrm{N}$-doped carbon nanocubes ${ }^{176}$ were prepared via the polymerization of polydopamine on the surface of NiCoCP and thermally induced sulfurization processes. When used as an anode $(\sim 1.25 \mathrm{~V} v s$. $\left.\mathrm{Na} / \mathrm{Na}^{+}\right)$, capacities of 660 and $560 \mathrm{~mA} \mathrm{~h} \mathrm{~g}{ }^{-1}$ were reported at 0.1 and $5 \mathrm{~A} \mathrm{~g}^{-1}$, respectively. This enhanced storage performance could be due to the mesoporous structure and interconnected network. Guozhao Fang et al. ${ }^{177}$ reported a bimetallic $\mathrm{Co}_{9} \mathrm{~S}_{8} / \mathrm{ZnS}$ heterostructure embedded in hollow N-doped carbon nanosheets with excellent reversibility, a high diffusion coefficient, and pseudocapacitive effects. Indeed, when used as an anode ( $\sim 0.9 \mathrm{~V} v$ s. $\mathrm{Na} / \mathrm{Na}^{+}$with a conversion- and alloy-type mechanism) material, a dominant pseudocapacitive contribution (a surface
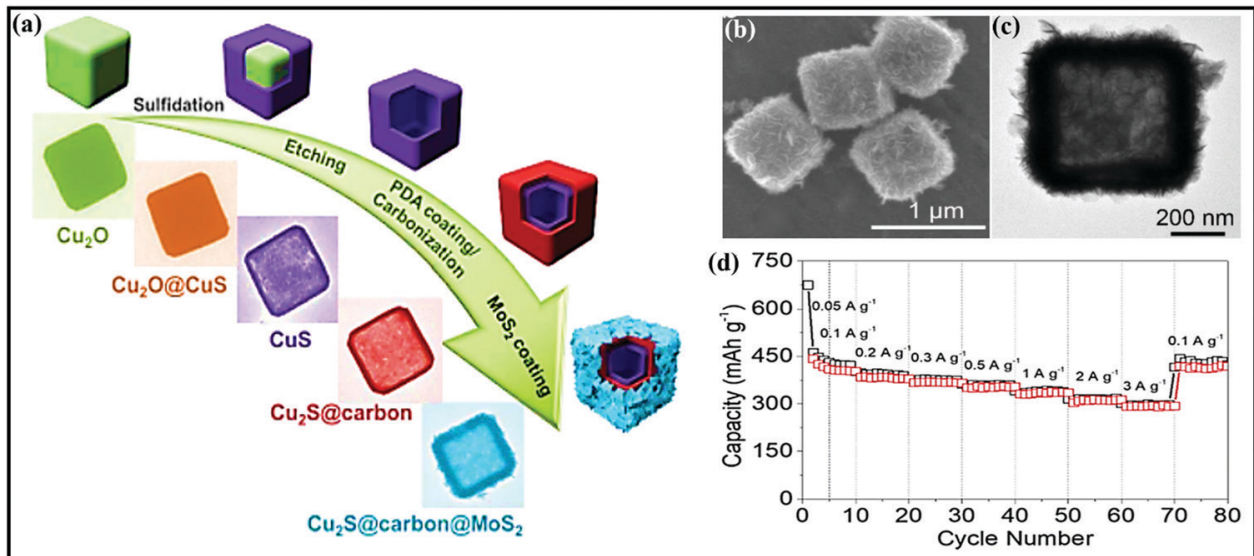

Fig. 13 (a) A schematic diagram of the synthetic process of three-layered $\mathrm{Cu}_{2} \mathrm{~S}$ (acarbonaMoS $\mathrm{S}_{2}$ nanoboxes and corresponding (b) FESEM and (c) TEM

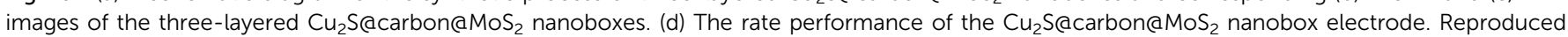
with permission. ${ }^{175}$ Copyright: 2020, Wiley-VCH Verlag GmbH \& Co. KGaA. 
contribution of $79.9 \%$ at $0.2 \mathrm{mV} \mathrm{s}^{-1}$ ) was reported with a high discharge capacity of $542 \mathrm{~mA} \mathrm{~h} \mathrm{~g}^{-1}$ at $0.1 \mathrm{~A} \mathrm{~g}^{-1}$, and good rate capabilities were demonstrated even at $10 \mathrm{~A} \mathrm{~g}^{-1}$, with a capacity of $258.6 \mathrm{~mA} \mathrm{~h} \mathrm{~g}^{-1}$, and a high diffusion coefficient value.

Heterostructured $\mathrm{Ni}_{2} \mathrm{P} / \mathrm{ZnP}_{4}$ embedded in P-doped carbon microspheres ${ }^{178}$ was reported to show robust structural integrity, abundant active sites, and fast charge-transfer kinetics. Electrochemically, the rationally designed composite $\left(\sim 0.7 \mathrm{~V} v s . \mathrm{Na} / \mathrm{Na}^{+}\right)$, through a conversion- and alloy-based mechanism, showed a capacity of $701 \mathrm{~mA} \mathrm{~h} \mathrm{~g}^{-1}$ at $100 \mathrm{~mA} \mathrm{~g}^{-1}$, and it managed decent capacities of 441 and $133 \mathrm{~mA} \mathrm{~h} \mathrm{~g}{ }^{-1}$ at 0.1 and $2.0 \mathrm{~A} \mathrm{~g}^{-1}$ with capacity retention of $66.8 \%$ after 500 cycles at $500 \mathrm{~mA} \mathrm{~g}^{-1}$. Kunjie Zhu et al. ${ }^{179}$ prepared a $\mathrm{MoS}_{2} / \mathrm{MoO}_{3} / \mathrm{N}$-doped carbon hybrid anode $\left(\sim 1.3 \mathrm{~V} v s . \mathrm{Na} / \mathrm{Na}^{+}\right)$for the first time. The addition of heteroatoms, such as via $\mathrm{N}$ doping, and the unique porous structure increased the electroactive surface area, provided facile diffusion channels due to the 1D architecture, and reduced the transfer distance of ions from/to the electrodes with improved conductivity. In a SIB study, the hybrid retained a capacity of $538.7 \mathrm{~mA} \mathrm{~h} \mathrm{~g}^{-1}$ after 200 cycles at $300 \mathrm{~mA} \mathrm{~g}^{-1}$ and it maintained a capacity of $339.9 \mathrm{~mA} \mathrm{~h} \mathrm{~g}^{-1}$ after 220 cycles even at $1000 \mathrm{~mA} \mathrm{~g}^{-1}$ with nearly $100 \%$ capacity retention.

\section{Organic composite materials}

Electroactive organic materials and their derivatives represent promising alternatives to inorganic moieties and have attracted major research interest in recent years ${ }^{180}$ owing to their many fundamental merits, some of which are as follows: (i) organic electrode materials derived from renewable and abundant resources $^{181,182}$ do not suffer from issues relating to scarcity or geopolitical conflict issues for resourcing; (ii) they are lightweight and flexible; ${ }^{183}$ (iii) they are eco-friendly and easily processable; ${ }^{184}$ (iv) they are cost-effective (being inexpensive, and heavy metals are not involved) and sustainable; ${ }^{4,185,186}$ (v) there are easy synthesis approaches (typically preparation involves low-cost solution-phase or wet chemistry routes); (vi) they have structural and chemical diversity and tunable properties; ${ }^{187,188}$ and (vii) there is a minimal environmental footprint. ${ }^{189,190}$
However, on the contrary, electroactive organic materials and their derivatives often exhibit poor rate performance, high self-discharge, rapid capacity loss, and low practical capacities due to low electronic conductivity ${ }^{21,191}$ and solubility issues in common battery electrolytes. ${ }^{21,192-196}$ Therefore, several studies and modifications (Fig. 14) have been carried out following different strategies, such as the optimization ${ }^{197}$ and polymerization of native molecular structures, ${ }^{198-200}$ rational design/ modification with highly conducting materials, ${ }^{180,201-204}$ and the use of solid-state or gel-state electrolytes. ${ }^{198}$ Among these strategies, molecular design and/or structural engineering with highly conducting but insoluble carbonaceous materials, such as graphene, GO, rGO, CNTs, CFs, CMK-3, etc., is the most preferred and elegant way to enhance the structural and electrochemical performances in common battery electrolytes. In this section, we will summarize various organic composite/ hybrid materials, and methods adopted to enhance the electrochemical performance are highlighted.

\subsection{Carbonyl-based composite materials}

Organic carbonyl moieties are potential high-energy electrode materials due to their high capacities, strong mechanical properties, and fast electrode kinetics. ${ }^{205,206}$ Moreover, conjugated carbonyl moieties offer numerous chemical options for adjusting the redox properties. However, practical issues, such as low electrical conductivity and high solubility have resulted in low utilization and unsatisfactory electrochemical performance. ${ }^{187,196,205}$ In an effort to reduce the solubility and stabilize the electrochemical performance, carbonyls containing organic moieties were combined with insoluble carbonaceous materials. ${ }^{207,208}$ For instance, an effective novel strategy was applied to allow a carbonyl $(3,4,9,10$ perylene-tetracarboxylic acid-dianhydride; PTCDA) material to be confined on $3 \mathrm{D}$ graphene ${ }^{208}$ through strong $\pi-\pi$ interactions (PTCDA particles are dispersed with GO and subjected to a hydrothermal process and, finally, graphene-aerogel-wrapped PTCDA particles (PGC) are obtained after freeze-drying) (Fig. 15a-d). The use of a 3D graphene framework significantly improves the electrical conductivity and $\mathrm{Li}^{+} / \mathrm{Na}^{+}$ion accessibility, shortens the diffusion path length, and, mainly, prevents the dissolution of

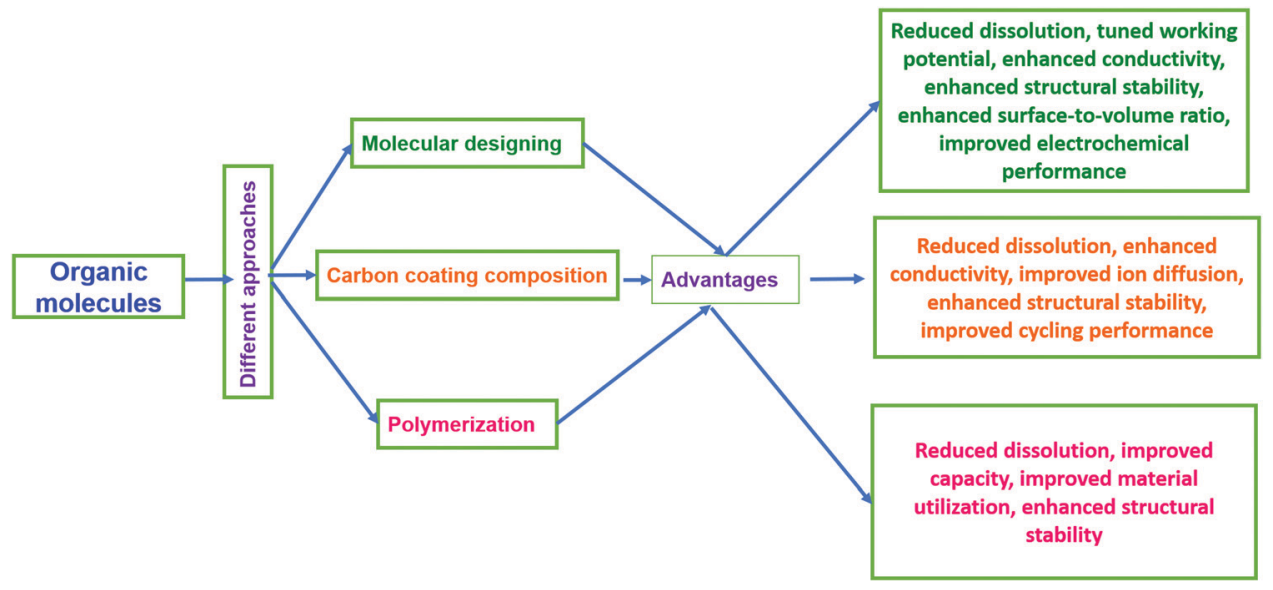

Fig. 14 Different approaches for enhancing the properties of organic electrodes. 


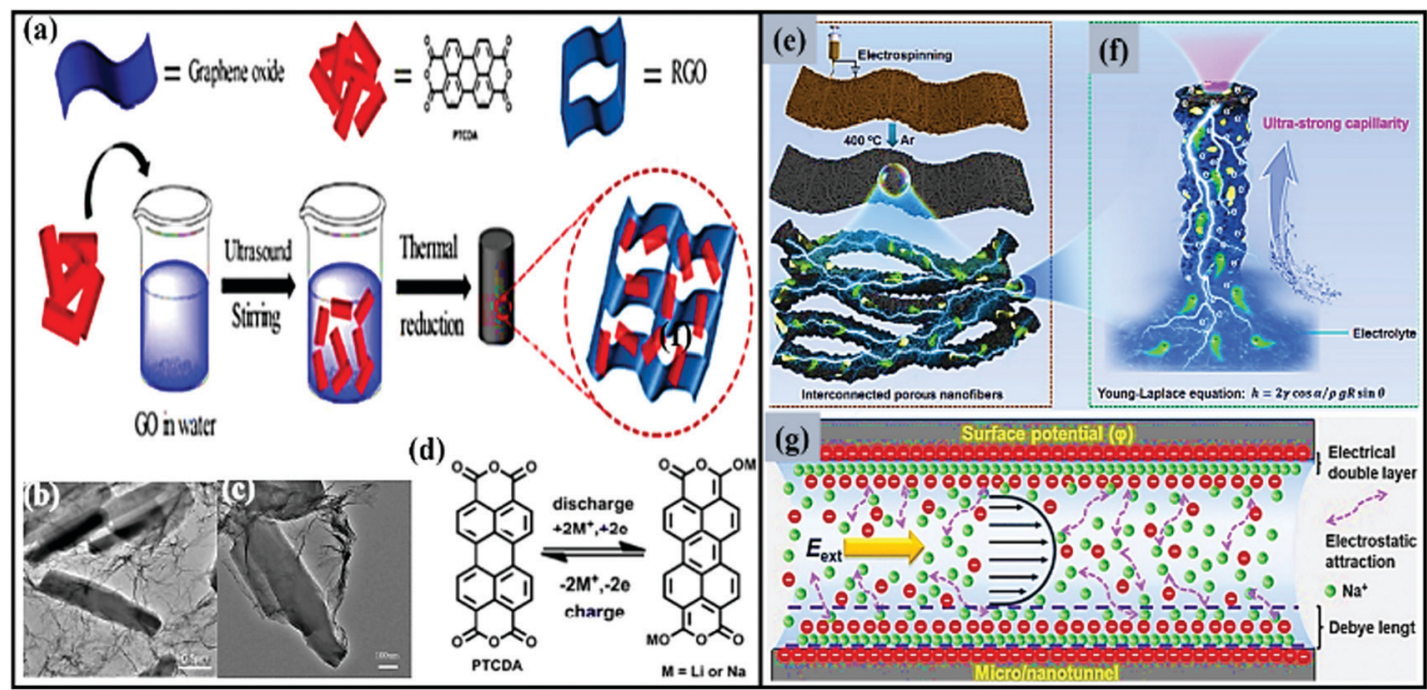

Fig. 15 (a) A schematic representation of the fabrication process of PGC. (b and c) TEM images at different magnifications and (d) the redox process of $\mathrm{PGC}_{40}$ during the charge/discharge process. Reproduced with permission. ${ }^{208}$ Copyright: 2018 , American Chemical Society. (e) The preparation of a PTCDA/NC/CNT electrode. (f) A schematic illustration of ultra-fast $\mathrm{Na}^{+}$transport in a single porous PTCDA/NC/CNT nanofiber assisted by the ultrastrong capillary phenomenon, and $(\mathrm{g})$ a schematic illustration of the ion transport behavior in a negatively charged micro/nanochannel. $E_{\text {ext }}$ denotes an external electric field. Reproduced with permission. ${ }^{209}$ Copyright: 2020, Elsevier.

active material. Benefiting from the above advantages, the composite cathode $\left(\sim 2.3 \mathrm{~V} v s . \mathrm{Na} / \mathrm{Na}^{+}\right)$showed moderate storage capacities (discharge/charge capacities of $81 / 97 \mathrm{~mA} \mathrm{~h} \mathrm{~g}^{-1}$ at a current density of $25 \mathrm{~mA} \mathrm{~g}^{-1}$ ) and long-term cycling stability ( $\sim 66.9$ and $66.4 \%$ capacity retention even after 1000 cycles at 50 and $100 \mathrm{~mA} \mathrm{~g}^{-1}$, respectively), with Coulombic efficiency close to $100 \%$.

Considerable progress was achieved via introducing electroactive carbonyl compounds into CNTs. For example, 3,4,9,10perylenetetracarboxylic dianhydride (PTCDA) was used as an organic carbonyl cathode ${ }^{210}\left(\sim 2.25 \mathrm{~V} v s . \mathrm{Na} / \mathrm{Na}^{+}\right)$modified with CNTs to overcome solubility issues and improve the storage performance. As expected, the rationally designed flexible and binder-free composite not only provided considerable reversible capacities $\left(150 \mathrm{~mA} \mathrm{~h} \mathrm{~g}^{-1}\right.$ at $50 \mathrm{~mA} \mathrm{~g}^{-1}$ in LIBs and $57.8 \mathrm{~mA} \mathrm{~h} \mathrm{~g}^{-1}$ at $25 \mathrm{~mA} \mathrm{~g}^{-1}$ in SIBs) but it also exhibited good cycling stability (over 500 cycles for LIBs and 300 cycles for SIBs) and good rate capabilities ( $48 \mathrm{~mA} \mathrm{~h} \mathrm{~g}^{-1}$ even at $2000 \mathrm{~mA} \mathrm{~g}^{-1}$ for LIBs and $48 \mathrm{~mA} \mathrm{~h} \mathrm{~g}^{-1}$ at $1000 \mathrm{~mA} \mathrm{~g}^{-1}$ for SIBs). Herein, CNTs used for composite formation not only act as a current collector but they also improved the electronic conductivity, reduced the solubility, and prevented drastic structural changes during subsequent cycling. Very recently, a PTCDA/N-doped carbon/carbon nanotube (PTCDA/NC/CNT) composite ${ }^{209}$ nanofiber cathode material, inspired by the microchannels of wood, was designed via electrospinning followed by heat-treatment at $400{ }^{\circ} \mathrm{C}$ under an $\mathrm{Ar}$ atmosphere (Fig. 15e). The material was designed in such a way that the composite showed fast ionic/electronic transport channels and facilitated fast reaction kinetics (Fig. 15f and g) due to synergetic co-operation between the interconnected conductive framework and ultra-strong capillaries derived from hierarchical micro/nanotunnels. More significantly, the rationally designed composite demonstrated superior structural stability and high in-plane conductivity. The resultant hybrid composite showed good cycling stability for over 500 cycles, with 95\% capacity retention at $1 \mathrm{~A} \mathrm{~g}^{-1}$, and high energy (85 $\mathrm{W} \mathrm{h} \mathrm{kg}^{-1}$ ) and power (665 $\mathrm{W} \mathrm{kg}^{-1}$ ) densities; the performance obtained using this hybrid is far superior to other reported SIB systems.

Recently, Aihua Li et al. ${ }^{211}$ prepared a composite of the sodium salt of poly(2,5-dihydroxy- $p$-benzoquinonyl sulfide) and rGO ( $\mathrm{Na}_{2}$ PDHBQS@rGO) to enhance the conductivity and electrochemical performance of $\mathrm{Na}_{2} \mathrm{PDHBQS}$. As per their expectations, the $\mathrm{Na}_{2} \mathrm{PDHBQS}$ cathode performed well in terms of capacity (179 $\mathrm{mA} \mathrm{h} \mathrm{g}^{-1}$ for the first cycle and $183 \mathrm{~mA} \mathrm{~h} \mathrm{~g}^{-1}$ after 150 cycles), cycling performance, and rate performance (showing capacities of 228 and $147 \mathrm{~mA} \mathrm{~h} \mathrm{~g}^{-1}$ at 0.1 and $0.4 \mathrm{C}$, respectively, compared to the pure $\mathrm{Na}_{2} \mathrm{PDHBQS}$ polymer, which showed capacities of 172 and $83 \mathrm{~mA} \mathrm{~h} \mathrm{~g}^{-1}$ at 0.1 and $0.4 \mathrm{C}$, respectively) in composite form. The improved electrochemical performance of $\mathrm{Na}_{2} \mathrm{PDHBQS}$ could be attributed to (i) the insoluble conductive rGO scaffold, which not only enhances the conductivity, but also provides a suitable framework for pore formation; (ii) the formation of a porous structure, which facilitated rapid Na-ion transport and expanded the contact area between the electrode and the electrolyte; and (iii) the effectiveness of polymerization, which improved the electrochemical performance via reducing the solubility. A 4,8-dihydrobenzodithiophene-4,8-dione (BDT) organic cathode also exhibits poor cycling and rate performance due to its high solubility, poor mechanical strength, and low electrical conductivity. ${ }^{212,213}$ In an effort to reduce the solubility and to improve the cycling stability, Xiaoju and co-workers ${ }^{214}$ fabricated BDT with a graphene network (BDT-G). Indeed, the novel BDP@graphene composite cathode $\left(\sim 2.2 \mathrm{~V} v s . \mathrm{Na} / \mathrm{Na}^{+}\right)$ displayed a high reversible capacity of $217 \mathrm{~mA} \mathrm{~h} \mathrm{~g}{ }^{-1}$ and showed better rate capabilities compared to the basic BDT electrode material. Therefore, composite formation with graphene 
significantly prevented the dissolution of BDT into the electrolyte and intensified the electrode reactions.

In addition to GO, rGO, and CNTs, other insoluble carbonbased materials, such as CMK-3, have also been reported for the fabrication/modification of organic moieties to overcome solubility issue and improve the conductivity. For example, Chunyang Guo and co-workers ${ }^{215}$ prepared a 9,10-anthraquinone@ CMK-3 hybrid cathode composite to improve the electrochemical performance in ether-based electrolyte. At an optimized ratio of $1: 1$, encapsulated 9,10-anthraquinone demonstrated the highest discharge capacity of $214 \mathrm{~mA} \mathrm{~h} \mathrm{~g}{ }^{-1}$ with $88 \%$ capacity retention over 50 cycles compared to a capacity of about $178 \mathrm{~mA} \mathrm{~h} \mathrm{~g}^{-1}$ with $71 \%$ capacity retention after the 50th cycle for an electrode without CMK. The author assumed that dissolution and/or decomposition are the main reasons for the low electrochemical performance of pure 9,10-anthraquinone. Subsequently, Shibing Zheng et al. ${ }^{216}$ designed a series of calix[4]quinone@ordered mesoporous carbon (CMK-3) composite cathodes $\left(\sim 2.8 \mathrm{~V} v s . \mathrm{Na} / \mathrm{Na}^{+}\right)$to analyze the sodium storage properties. After systematic physical characterization studies, they found that calix[4]quinone was encapsulated inside the pores of CMK-3, and it demonstrated enhanced electrochemical properties due to the stable architecture and synergetic co-operation. This novel calix[4]quinone@CMK-3 composite (especially at a 1:2 ratio) reported an initial discharge capacity as high as $438 \mathrm{~mA} \mathrm{~h} \mathrm{~g}^{-1}$ and retained a capacity of $219.2 \mathrm{~mA} \mathrm{~h} \mathrm{~g}^{-1}$ after 50 cycles. Further, EIS studies reveal that higher conductivity (reduced cell impedance) and faster ionic mobility (high diffusion coefficient) were achieved in composite form than when using pure calix[4]quinone molecules. However, the authors believed that the CMK-3 nanoporous structure is mainly responsible for the dramatic improvements in the electrochemical performance because it provides high conductivity and fast ionic/electronic mobility and hinders dissolution via strongly encapsulating calix[4]quinone.

A disodium terephthalate@rGO ( $\left.\mathrm{N}_{2} \mathrm{TP} @ \mathrm{rGO}\right)$ composite $^{217}$ hybrid anode $\left(\sim 0.3 \mathrm{~V}\right.$ vs. $\left.\mathrm{Na} / \mathrm{Na}^{+}\right)$was designed to overcome solubility issues and to enhance the Na-ion storage properties. Both hybrid (95\% $\mathrm{N}_{2} \mathrm{TP}$ and $5 \% \mathrm{GO}$ ) and pristine compounds reported capacities in the range of $355-365 \mathrm{~mA} \mathrm{~h} \mathrm{~g}^{-1}$ at $0.1 \mathrm{C}$, but improved cycling stability and rate performance were observed for the $\mathrm{N}_{2}$ TP@rGOcomposite. Similar to many works in the literature, the GO used here for making the composite not only stabilized the structure of $\mathrm{N}_{2} \mathrm{TP}$ but it also improved the electrical conductivity after being electrochemically reduced. A 2,5-disodium1,4-benzoquinone $\left(\mathrm{Na}_{2} \mathrm{DBQ}\right)$ organic anode $\left(\sim 1.2 \mathrm{~V} v s . \mathrm{Na} / \mathrm{Na}^{+}\right)$was immobilized on ordered mesoporous carbon (OMC) through strong $\pi-\pi$ supporting interactions. The intimate contact between $\mathrm{Na}_{2} \mathrm{DBQ}$ and the conductive carbon improved the specific surface area and electrochemical performance ${ }^{218}$ in an ionic-liquid-assisted electrolyte media. Liqiao Zhong et al. fabricated high-performance aqueous rechargeable SIBs using alloxazine@CMK-3 ${ }^{219}$ as an anode and polyacrylamide hydrogel as an electrolyte. Alloxazine encapsulated in CMK-3 demonstrated a two-electron transfer reaction, with an initial discharge capacity of $160 \mathrm{~mA} \mathrm{~h} \mathrm{~g}^{-1}$, and the composite in full-cell configuration exhibited an energy density of $50 \mathrm{~W} \mathrm{~h} \mathrm{~kg} \mathrm{~kg}^{-1}$ (corresponding to $146 \mathrm{~mA} \mathrm{~h} \mathrm{~g}{ }^{-1}$ ). Hua Wang et al. ${ }^{220}$ presented a novel biomolecule "juglone" derived from waste walnut epicarp and immobilized onto rGO nanosheets through $\pi-\pi$ interactions. This ordered fabricated juglone recrystallized and assembled into microrods on the rGO layer, and it was directly used as an anode material $\left(\sim 0.8 \mathrm{~V} v\right.$ s. $\left.\mathrm{Na} / \mathrm{Na}^{+}\right)$without using a binder. In electrochemical studies, the pristine juglone molecules immobilized onto rGO nanosheets are less soluble in the electrolyte and they exhibited impressive electrochemical performance, such as high electronic/ionic conductivity and good reversibility, with a high discharge capacity of $305 \mathrm{~mA} \mathrm{~h} \mathrm{~g}^{-1}$, which is higher than the capacity of pure juglone molecules $\left(40 \mathrm{~mA} \mathrm{~h} \mathrm{~g}{ }^{-1}\right)$ and the rGO network charge/discharge capacities $\left(110 / 123 \mathrm{~mA} \mathrm{~h} \mathrm{~g}^{-1}\right)$. Stable capacity retention (a capacity of $\sim 212 \mathrm{~mA} \mathrm{~h} \mathrm{~g}{ }^{-1}$ is maintained after cycling up to 300 times) and high rate performance (capacities of $\sim 398$ and $210 \mathrm{~mA} \mathrm{~h} \mathrm{~g}^{-1}$ are achieved at current densities of 0.05 and $0.4 \mathrm{~A} \mathrm{~g}^{-1}$, respectively) are also seen. It is believed that the great mechanical strength and high conductivity of rGO are the main reasons for the excellent electrochemical performance of the juglone molecules.

\subsection{Carboxylate-based composite materials}

Conjugated carboxylate moieties are considered as candidate materials with high capacities ${ }^{221}$ and high thermal stabilities ${ }^{222}$ for RLIB and SIB applications. However, the use of polymerizable molecular structures and easy-to-fabricate conductive materials is highly desirable to reduce solubility issues, stabilize structures, and improve electrochemical performances. For instance, a graphenewrapped sodium naphthalene dicarboxylate $\left(\mathrm{Na}_{4} \mathrm{C}_{8} \mathrm{H}_{2} \mathrm{O}_{6}\right)^{223}$ composited anode $\left(\sim 0.4 \mathrm{~V} v\right.$ s. $\left.\mathrm{Na} / \mathrm{Na}^{+}\right)$demonstrated a high reversible capacity of $226 \mathrm{~mA} \mathrm{~h} \mathrm{~g}^{-1}$, exceptional cycling stability (92\% capacity retention over 100 cycles), and high rate capabilities. Meanwhile, the specific capacity of $\mathrm{Na}_{4} \mathrm{C}_{8} \mathrm{H}_{2} \mathrm{O}_{6}$ nanoflowers is limited to $179.5 \mathrm{~mA} \mathrm{~h} \mathrm{~g}^{-1}$ at $164.7 \mathrm{~mA} \mathrm{~g}^{-1}$ with $89 \%$ capacity retention over 100 cycles. Chao Luo et al. ${ }^{224}$ introduced a new croconic acid disodium salt (CADS) as an anode for SIB applications. CADS exhibited a high reversible capacity, but it suffers from fast capacity decay during subsequent GCD cycles. After a detailed investigation, the authors reveal that the loss of electrode performance is mainly attributed to large volume changes (phase transformation) rather than the dissolution of CADS into the electrolyte. Therefore, to overcome severe capacity loss, CADS particles were wrapped in GO to enhance the reversible specific capacity and stability. The resultant composite, benefiting from a synergetic effect between the GO scaffold and CADS NPs, shows a higher discharge capacity of $293 \mathrm{~mA} \mathrm{~h} \mathrm{~g}^{-1}$ (after subtracting the GO capacity contribution) at $20 \mathrm{~mA} \mathrm{~g}^{-1}$, with better cycling life compared to the performance of a basic CADS electrode. Subsequently, sodium humate $\left(\mathrm{Na}_{2} \mathrm{HA}\right)$, with non-conjugated carboxylate groups, coupled with $\mathrm{rGO}^{225}\left(\mathrm{Na}_{2} \mathrm{HA}\right.$ was mixed with a GO suspension via ultrasonic irradiation, and then the mixture was dried and thermally treated at $200{ }^{\circ} \mathrm{C}$ for $2 \mathrm{~h}$ under an $\mathrm{Ar} / \mathrm{H}_{2}$ atmosphere) (Fig. 16a) was reported as an anode ( $0.6 \mathrm{~V} v s$. $\mathrm{Na} / \mathrm{Na}^{+}$) material with a reversible capacity of $\sim 133 \mathrm{~mA} \mathrm{~h} \mathrm{~g}^{-1}$ at a current density of $500 \mathrm{~mA} \mathrm{~g}^{-1}$. More significantly, the composite, especially with $6 \%$ rGO, was exceptionally stable, with a capacity retention of $91.6 \%$ even after 2000 repeated GCD cycles (Fig. 16b-d). 

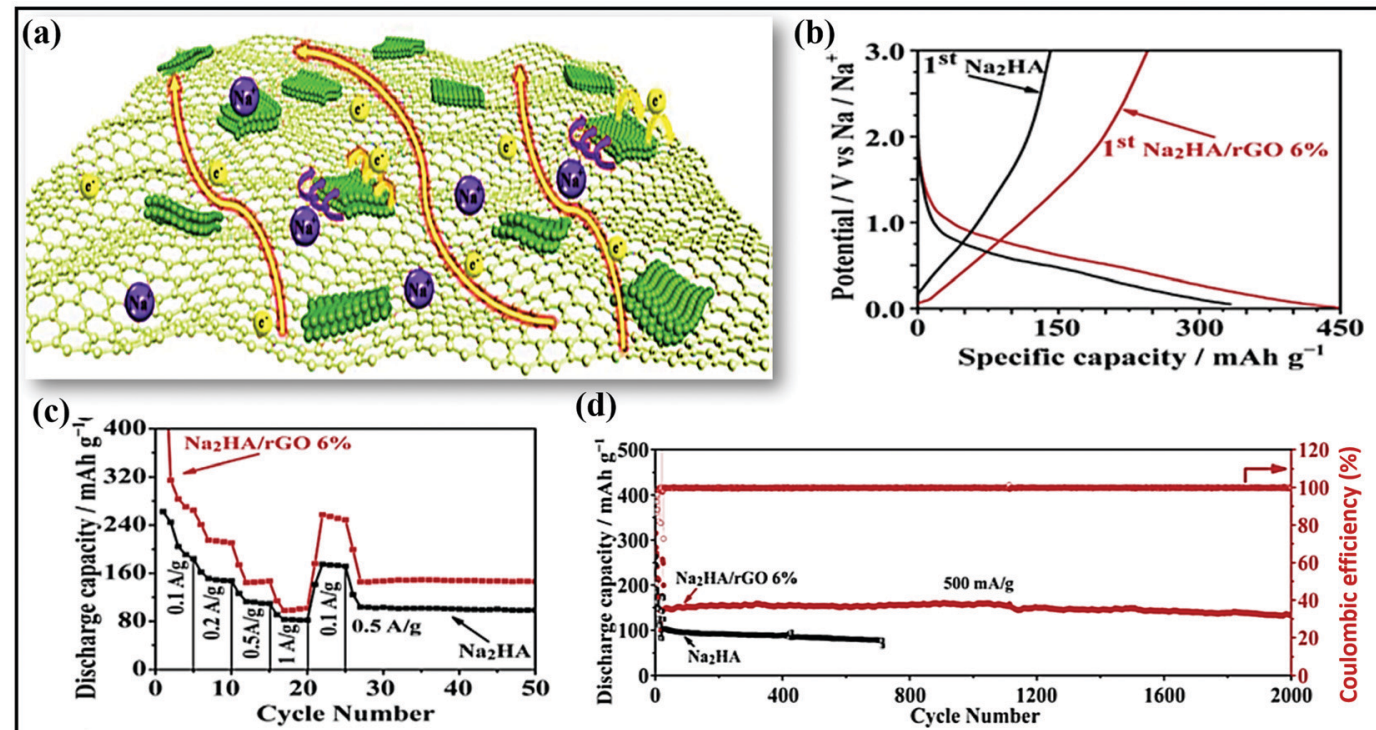

(d)

Fig. 16 (a) A schematic illustration of charge transfer in a hybrid $\mathrm{Na}_{2} \mathrm{HA} @ \mathrm{rGO}$ electrode. (b) The initial charge-discharge curves from 0.01 to $3.0 \mathrm{~V}$ at a current density of $100 \mathrm{~mA} \mathrm{~g}^{-1}$, (c) the rate capabilities, and (d) the cycling stabilities of bare $\mathrm{Na}_{2} \mathrm{HA}_{\text {and }}$ the $\mathrm{Na}_{2} \mathrm{HA}(\mathrm{arGO}(6 \%)$ composite material at $500 \mathrm{~mA} \mathrm{~g}^{-1}$. Reproduced with permission. ${ }^{225}$ Copyright: 2018, Elsevier.

\subsection{Hydroxyl-based composite materials}

Tianyuan Liu et al. ${ }^{226}$ reported a dopamine@rGO framework cathode, which was obtained via coating dopamine onto a 3D graphene framework. In this case, GO plays an important role as an oxidant and acts as a strong protective barrier and high surface area template to enhance polydopamine surface redox reactions. The resulting hybrid cathode $\left(\sim 2.8 \mathrm{~V} v s . \mathrm{Na} / \mathrm{Na}^{+}\right)$ showed high reversible capacities of 230 and $211 \mathrm{~mA} \mathrm{~h} \mathrm{~g}^{-1}$ in LIBs and SIBs, respectively, at $0.05 \mathrm{~A} \mathrm{~g}^{-1}$, and 1000 cycles could be carried out with more than $95 \%$ Coulombic efficiency. The impact of composite formation is further exemplified by polydopamine@few-walled CNT (FWCNT) ${ }^{227}$ composite cathode $\left(\sim 3.2 \mathrm{~V} v\right.$ s. $\left.\mathrm{Na} / \mathrm{Na}^{+}\right)$formation. Similar to the polydopamine@rGO framework, ${ }^{226}$ the polydopamine@FWCNTs composite demonstrated an improved gravimetric capacity of $133 \mathrm{~mA} \mathrm{~h} \mathrm{~g}{ }^{-1}$ in a Li-ion cell and $109 \mathrm{~mA} \mathrm{~h} \mathrm{~g}^{-1}$ in a Na-ion cell. In subsequent cycles, the specific charge/discharge capacities (polydopamine@FWCNTs vs. $\mathrm{Li} / \mathrm{Li}^{+}$) remained constant in a reversible manner with high cycling stability for over 10000 cycles. Moreover, the high-rate performance was also maintained via utilizing double-layer capacitance from the FWCNTs and multiple redox reactions involving polydopamine.

\subsection{Polymer-based composite materials}

A novel graphene@polyimide (GF-PI) hybrid composite ${ }^{228}$ was prepared via a one-step solvothermal process and used as a binder-free cathode $\left(\sim 2.2 \mathrm{~V} v\right.$ s. $\left.\mathrm{Na} / \mathrm{Na}^{+}\right)$material for LIB and SIB applications. Compared with polyimide, the graphene@polyimide composite showed an enhanced specific capacity and good cycling life. Here, the polyamide (PI) polymer is mainly responsible for the high stability and fast Li- and Na-ion diffusion properties. Similar beneficial effects were observed for a rationally designed
PI@MWCNTs nanocomposite (Fig. 17a) material. ${ }^{229}$ The nanocomposite was prepared via two-step polycondensation. In the first step, the polycondensation of PTCDA and diaminopropane in NMP in the presence of MWCNTs leads to the formation of PAA/MWCNT and in the second step, the PI/MWCNTs nanocomposite is formed via the imidization of polyamic acid during stepwise thermal treatment up to $400{ }^{\circ} \mathrm{C}$. The combination of MWCNTs with a gel-polymer electrolyte was used to stabilize the native PI and to improve the electrochemical performance. The resultant composite cathode $\left(\sim 2.1 \mathrm{~V} v s . \mathrm{Na} / \mathrm{Na}^{+}\right)$material in gel-polymer electrolyte reported good cycling life for up to 3000 cycles and good rate performance (Fig. $17 \mathrm{~b}$ and c) at rates up to $10 \mathrm{C}$, despite a low specific capacity (the initial discharge capacity is $98 \mathrm{~mA} \mathrm{~h} \mathrm{~g}^{-1}$ and this will reach $100 \mathrm{~mA} \mathrm{~h} \mathrm{~g}^{-1}$ after a few cycles), compared to a novel graphene@polyimide (G@PI) hybrid composite material. ${ }^{228}$ However, the interconnected 3D network of the MWCNTs enhanced the electrode conductivity and improved the utilization of active material. A gel-polymerelectrolyte-based polyacrylonitrile nanofibrous membrane was also used to enhance the electrode kinetics.

Abundant, low-cost, and eco-friendly nitroxide radical polymers (NRPs) have been reported as high-voltage $\left(\sim 3.47 \mathrm{~V} v s . \mathrm{Na} / \mathrm{Na}^{+}\right)$ cathode materials, ${ }^{230}$ but they suffer from low electrochemical performance; nevertheless, they demonstrated high electrochemical performance in composite/hybrid form. For example, pyrene-functionalized NRPs were anchored on highly conductive CNTs through $\pi-\pi$ interactions. ${ }^{230}$ Such pyrene-functionalized NRPs homogenously and non-covalently attached (like molecular glue) to CNTs forming a stable architecture. Detailed electrochemical studies revealed that the rationally designed composite not only demonstrated a high reversible capacity $\left(107 \mathrm{~mA} \mathrm{~h}^{-1}\right.$ at a rate of $1 \mathrm{C}$ ) but it also showed superior cycling stability (92\% capacity was retained even after up to 6000 cycles at a 

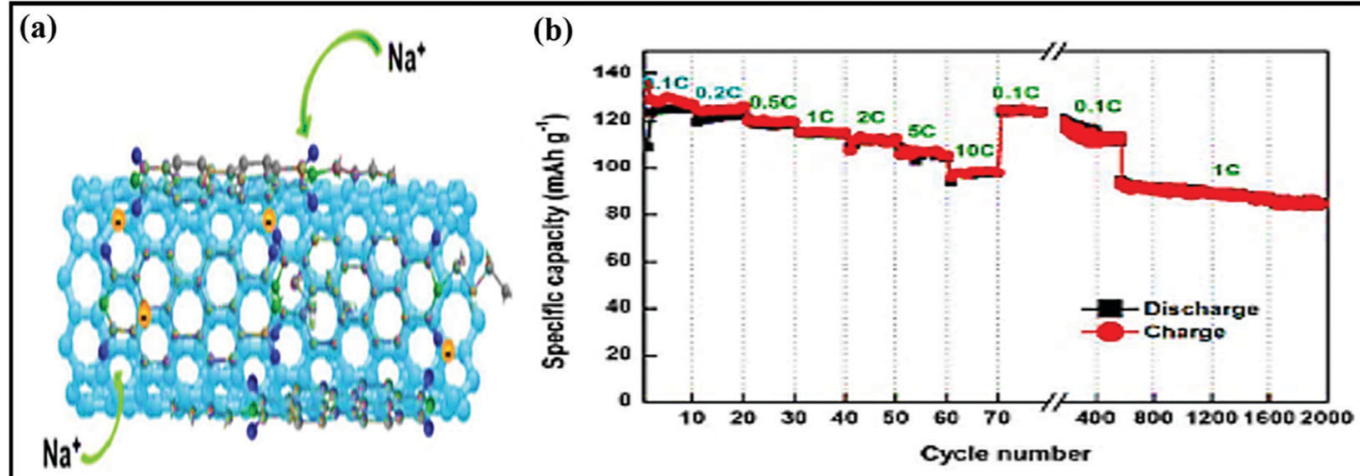

(c)

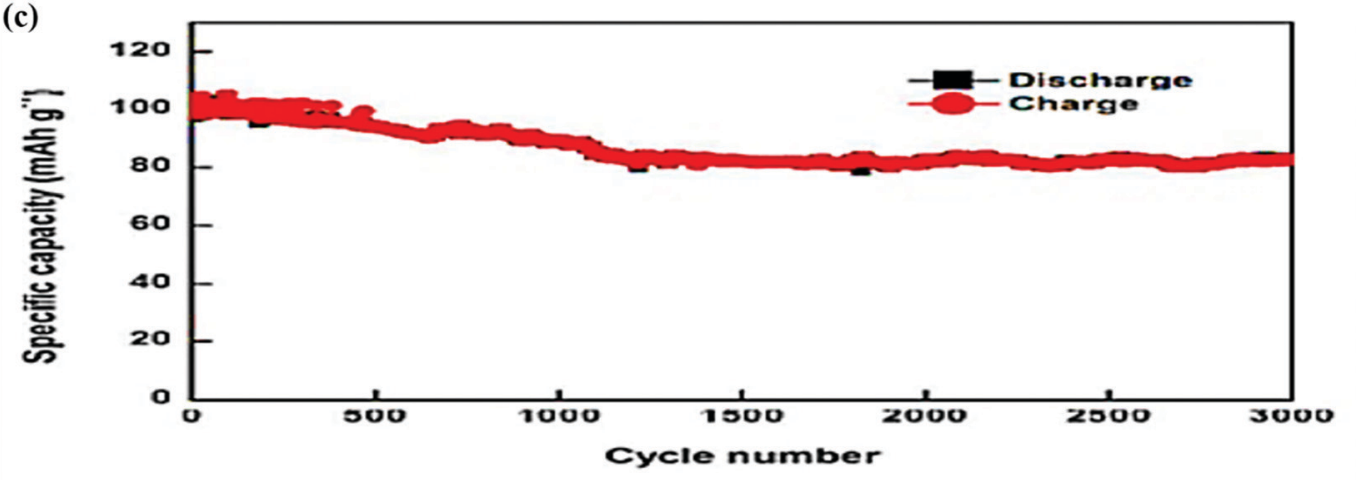

Fig. 17 (a) The PI/MWCNT nanocomposite cathode. (b) The cycling performance at different C-rates and (c) the cycling performance at a rate of $5 \mathrm{C}$ of the PI/MWCNT nanocomposite cathode. Reproduced with permission. ${ }^{229}$ Copyright: 2018, American Chemical Society.

current density of $2.2 \mathrm{~A} \mathrm{~g}^{-1}$ ) with good rate capabilities (78 $\mathrm{mA} \mathrm{h} \mathrm{g}^{-1}$ at $\left.5.5 \mathrm{~A} \mathrm{~g}^{-1}\right)$.

Similarly, the poly(2,2,6,6-tetramethyl piperidinyloxy-4-vinylmethacrylate) (PTMA) polymer was reported to be a promising cathode material for SIB applications, but its high self-discharging tendencies due to solubility issues raise questions relating to future rechargeable battery applications. ${ }^{192,231}$ However, to address the solubility issues and enhance the storage performance, JaeKwang Kim and co-workers synthesized a PTMA@CNTs hybrid composite material. ${ }^{193}$ The novel PTMA-impregnated CNT composite cathode $\left(\sim 3.4 \mathrm{~V} v\right.$ s. $\left.\mathrm{Na} / \mathrm{Na}^{+}\right)$exhibited high thermal stability, a large surface area $\left(122.1 \mathrm{~m}^{2} \mathrm{~g}^{-1}\right)$, high conductivity, fast electron transport properties, and enhanced electrochemical performance, with a high reversible capacity, better capacity retention, and higher rate capabilities. The used highly conductive CNTs not only alleviated the dissolution and self-discharge issues relating to PTMA but they also provided effective conducting paths and enabled rapid electron transport throughout the PTMA polymer.

A poly(2,5-dimercapto-1,3,4-thiadiazole) (PDMcT)@nitrogen and sulfur co-doped graphene nanosheets ${ }^{232}$ material was prepared via the polymerization of PDMcT on the surface of GO and subsequent calcination (Fig. 18a-c). The proposed PDMcT@rGO anode $\left(\sim 1.2 \mathrm{~V} v s\right.$. Na/Na ${ }^{+}$(Fig. $\left.18 \mathrm{~d}-\mathrm{h}\right)$ showed a high discharge capacity of $240 \mathrm{~mA} \mathrm{~h} \mathrm{~g}{ }^{-1}$ at $500 \mathrm{~mA} \mathrm{~g}^{-1}$ and exhibited superior cycling stability, with a capacity of $153 \mathrm{~mA} \mathrm{~h} \mathrm{~g}^{-1}$ even after 5000 cycles at $5000 \mathrm{~mA} \mathrm{~g}^{-1}$, and high rate performance (144 $\mathrm{mA} \mathrm{h} \mathrm{g}{ }^{-1}$ even at $\left.10 \mathrm{Ag}^{-1}\right)$. Kinetics studies suggest that the surface contribution (a capacitive contribution of
$85 \%$ was obtained at $2.0 \mathrm{mV} \mathrm{s}^{-1}$ ) is more dominant in this electrochemical process.

Representative physical properties, capacity values, rate capabilities, and cycling performance data for organic composite materials are summarized in Table 3.

\section{Organic-inorganic hybrid/ composite materials}

Inorganic-organic hybrid electrode materials used in SIBs mostly include metal-organic framework and polymeric nanocomposites.

\subsection{MOF-derived composites}

The new fascinating class of periodic framework porous materials known as metal-organic frameworks (MOFs), prepared via the combination of various inorganic metals and organic ligands $s^{47,245,246}$ through coordination bonds, has shown great potential for energy (LIB) applications. Similarly, the application of MOFs in SIBs ${ }^{46,47,247}$ has been intensively investigating owing to their structural diversity, high surface areas, hierarchical nanostructures, high porosity, controllable functionality, good redox properties, and simple synthesis strategies. ${ }^{248,249}$

Although MOFs have many attractive properties that are suitable for SIBs, most MOF parent/precursor materials are limited by inherent limitations, such as poor electrical conductivity and stability issues (limited cycle lives), ${ }^{47,245,249,250}$ which are detrimental to obtaining high reversible capacities, good rate capabilities, 


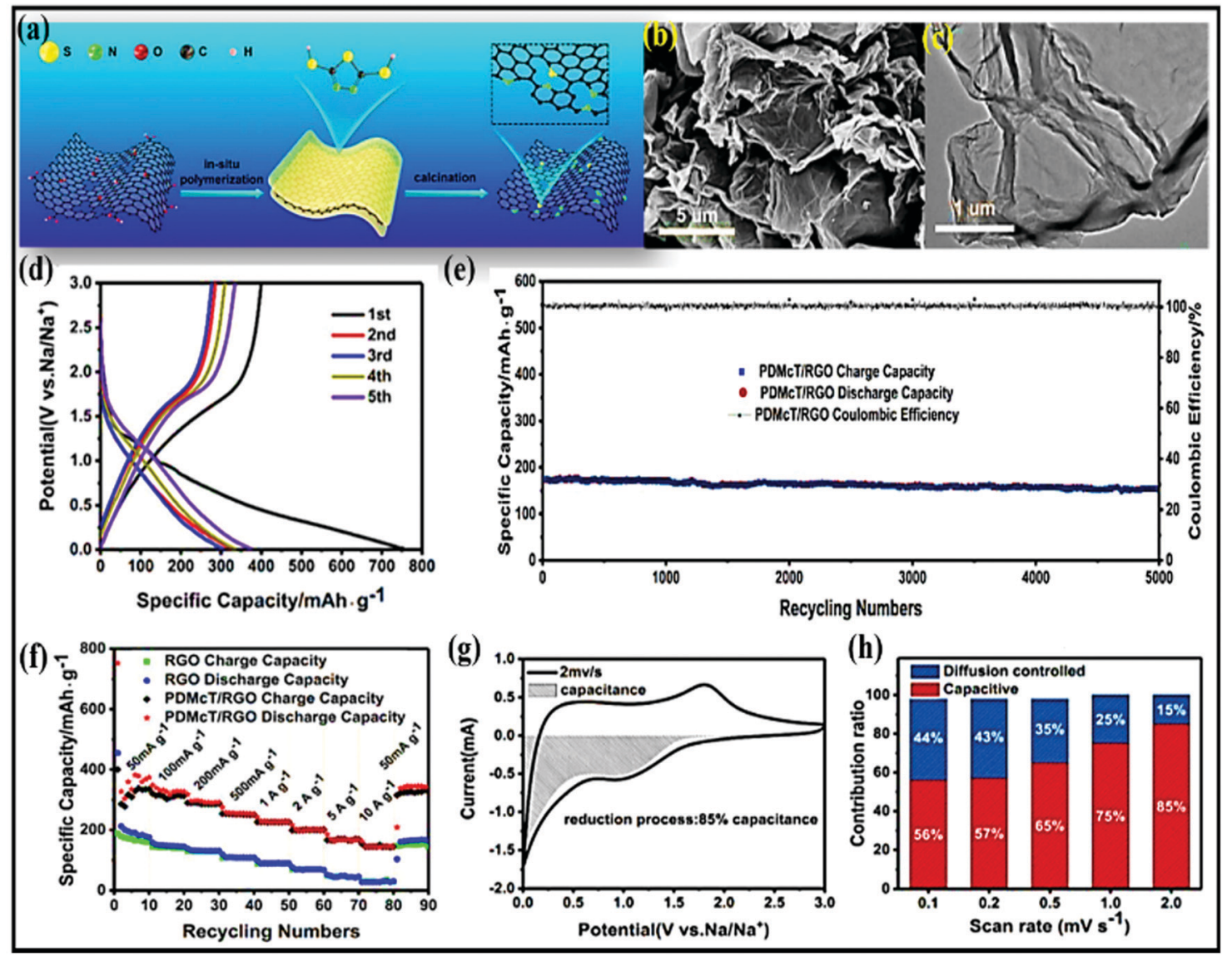

Fig. 18 (a) The preparation process and (b and c) SEM and TEM images of PDMcT@rGO. (d) Charge/discharge profiles of PDMcT arGO at 50 mA $g^{-1}$, (e) the cycling stability of PDMcT@arGO at $5000 \mathrm{~mA} \mathrm{~g}^{-1}$, and (f) rate capability profiles of PDMcT@rGO and rGO at various current densities. (g) The separation of the capacitive and diffusion currents during the reduction process at a scan rate of $2.0 \mathrm{mV} \mathrm{s}^{-1}$ and (h) the capacitive contribution ratios of the PDMcT@rGO composite at different scan rates. Reproduced with permission. ${ }^{232}$ Copyright: 2018, American Chemical Society.

and long-term cyclability. However, MOF-derived materials, especially rationally designed MOF-derived materials such as composites and/or hybrids, encapsulated materials, substratesupported materials, etc., are expected to exhibit remarkable electrochemical performances via improvements in electronic/ ionic conductivity, electrochemical stability, insolubility, and flexibility through favorable synergetic effects. ${ }^{245,250}$

Furthermore, the desired composition and structural architecture (Fig. 19) can be obtained through tuning either the internal or external structure or a combination of both via a suitable synthetic pathway. ${ }^{251}$ For instance, Xijun et al. ${ }^{252}$ prepared advanced carbon-encapsulated metal selenides through calcination followed by a selenidation strategy (Fig. 20a). Rationally designed selenides, such as $\mathrm{Cu}_{2} \mathrm{Se} @ \mathrm{C}, \mathrm{Fe}_{7} \mathrm{Se}_{8} @ \mathrm{C}$, and NiSe@C, can be used to generate anodes with particular nanostructured and microstructured architectures, demonstrating long-term cycling stability and superior rate performance (Fig. 20b and c). In particular, a MOF-derived $\mathrm{Fe}_{7} \mathrm{Se}_{8} @ \mathrm{C}$ nanorod anode $\left(\sim 1.25 \mathrm{~V} v s . \mathrm{Na} / \mathrm{Na}^{+}\right)$retained a specific capacity of $218 \mathrm{~mA} \mathrm{~h} \mathrm{~g}^{-1}$ after 500 cycles, while NiSe@C spheres with an intercalation-based mechanism reported a capacity of $160 \mathrm{~mA} \mathrm{~h} \mathrm{~g}^{-1}$, even after cycling for up to 2000 cycles at $3 \mathrm{~A} \mathrm{~g}^{-1}$, with high rate performance. $\mathrm{A} \mathrm{Co}_{3} \mathrm{O}_{4} @ \mathrm{~N}$-doped carbon composite anode $\left(\sim 0.8 \mathrm{~V} v \text { s. } \mathrm{Na} / \mathrm{Na}^{+}\right)^{253}$ derived from the MOF ZIF67 was fabricated to achieve a high storage capacity and to improve the cycling stability. As expected, the rationally designed $\mathrm{Co}_{3} \mathrm{O}_{4}$ @ $\mathrm{N}$-doped carbon composite, through a conversion-based mechanism, reported GCD capacities $\left(516 / 813 \mathrm{~mA} \mathrm{~h} \mathrm{~g}^{-1}\right.$ at $\left.0.1 \mathrm{~A} \mathrm{~g}^{-1}\right)$ that are much higher than those of pure $\mathrm{Co}_{3} \mathrm{O}_{4}\left(326 / 495 \mathrm{~mA} \mathrm{~h} \mathrm{~g}{ }^{-1}\right.$ at $\left.0.1 \mathrm{~A} \mathrm{~g}^{-1}\right)$, and the rate performance results in capacities of 506 and $263 \mathrm{~mA} \mathrm{~h} \mathrm{~g}{ }^{-1}$ at current densities of 100 and $1000 \mathrm{~mA} \mathrm{~g}^{-1}$, respectively. More importantly, capacity degradation of a mere $0.03 \%$ per cycle over 1100 cycles was seen, depicting the robust integrated composite framework. In this scenario, the nitrogen-doped carbon coating improved the electrode kinetics, reduced volume changes, and facilitated capacitive reaction. John B. Goodenough et al. $^{254}$ designed robust integrated $\mathrm{N}$-doped carbon hollow tubes from a bimetallic MOF-based nanocomposite precursor with abundant Na-ion sites. With a voltage of $\sim 1.0 \mathrm{~V}$ vs. $\mathrm{Na} / \mathrm{Na}^{+}$, the rationally integrated $\mathrm{N}$-doped carbon hollow tubes gave a high GCD capacity of around $346 \mathrm{~mA} \mathrm{~h} \mathrm{~g}{ }^{-1}$. More significantly, unprecedented cycling stability for up to 10000 cycles with superior rate performance was demonstrated at $4.5 \mathrm{~A} \mathrm{~g}^{-1}$. 
Table 3 A summary of rationally designed organic composite materials, the method used, the surface area, and the electrochemical performance

\begin{tabular}{|c|c|c|c|c|c|c|c|}
\hline Composite material & Method used & $\begin{array}{l}\text { BET SA } \\
\left(\mathrm{m}^{2} \mathrm{~g}^{-1}\right)\end{array}$ & $\begin{array}{l}\text { Voltage } \\
\text { window } \\
\text { (V) }\end{array}$ & $\begin{array}{l}\text { Discharge } \\
\text { capacity } \\
\left(\mathrm{mA} \mathrm{h} \mathrm{g}{ }^{-1}\right)\end{array}$ & Rate capabilities ( $\mathrm{mA} \mathrm{h} \mathrm{g}^{-1}$ ) & Cycling stability & Ref. \\
\hline $\begin{array}{l}\text { Potassium } \\
\text { terephthalate@graphene }\end{array}$ & Wet chemistry & & $0.01-2$ & 210 at $0.1 \mathrm{C}$ & $\begin{array}{l}192 \text { and } 95 \text { at } 0.1 \text { and } 2 C \text {, } \\
\text { respectively }\end{array}$ & $\sim 91 \%$ after 200 cycles at $1 \mathrm{C}$ & 233 \\
\hline $\begin{array}{l}\text { Pillar[5]quinone@ } \\
\text { CMK-3@SWCNTs }\end{array}$ & - & 1330 & $1.5-4.2$ & 418 at $0.1 \mathrm{C}$ & $\begin{array}{l}\approx 425 \text { and } 201 \text { at } 0.1 \text { and } 1 \mathrm{C}, \\
\text { respectively }\end{array}$ & $\sim 69 \%$ after 300 cycles at $0.1 \mathrm{C}$ & 234 \\
\hline $\begin{array}{l}\text { Pyromellitic } \\
\text { dianhydride- } \\
4,4^{\prime} \text {-diaminodiphenyl } \\
\text { etherpolyimide@CNTs }\end{array}$ & $\begin{array}{l}\text { Electrospinning and } \\
\text { step-by-step heat } \\
\text { treatment }\end{array}$ & - & $1.2-3.5$ & 123 at $0.1 \mathrm{C}$ & $\begin{array}{l}\sim 123 \text { and } 56 \text { at } 0.1 \text { and } 1 \mathrm{C}, \\
\text { respectively }\end{array}$ & $\sim 93 \%$ after 200 cycles at $0.5 \mathrm{C}$ & 235 \\
\hline PYT-TABQ@rGO & $\begin{array}{l}\text { Direct } \\
\text { polycondensation }\end{array}$ & 97.7 & $1.0-3.5$ & $\begin{array}{l}\sim 245 \text { at } \\
0.2 \mathrm{~A} \mathrm{~g}^{-1}\end{array}$ & $\begin{array}{l}\sim 254 \text { and } 210 \text { at } 0.2 \text { and } \\
1.0 \mathrm{~A} \mathrm{~g}^{-1}, \text { respectively }\end{array}$ & $98 \%$ after 1400 cycles at $0.5 \mathrm{C}$ & 236 \\
\hline PDBM@graphene & - & - & $2.0-4.0$ & $\begin{array}{l}210 \mathrm{at}^{-1} \\
30 \mathrm{~mA} \mathrm{~g}^{-1}\end{array}$ & $\begin{array}{l}\sim 200 \text { and } 125 \text { at } 60 \text { and } \\
480 \mathrm{~A} \mathrm{~g}^{-1}, \text { respectively }\end{array}$ & $\begin{array}{l}\sim 57 \% \text { after } 100 \text { cycles at } \\
30 \mathrm{~mA} \mathrm{~g}^{-1}\end{array}$ & 237 \\
\hline C4Q/CMK-3/SWCNTs & - & - & $1.2-4.2$ & $\begin{array}{l}\sim 440 \text { at } \\
0.1 \mathrm{C}\end{array}$ & $\begin{array}{l}439 \text { and } 346 \text { at } 0.1 \text { and } \\
1 \mathrm{C} \text {, respectively }\end{array}$ & $\sim 65 \%$ after 100 cycles at $0.1 \mathrm{C}$ & 238 \\
\hline DHTPA@CB & - & - & $0.01-2.0$ & $\begin{array}{l}\sim 100 \mathrm{at}^{-1} \\
25 \mathrm{~mA} \mathrm{~g}^{-1}\end{array}$ & $\begin{array}{l}\sim 95 \text { and } 73 \text { at } 25 \text { and } \\
1500 \mathrm{~mA} \mathrm{~g}^{-1} \text {, respectively }\end{array}$ & $\begin{array}{l}\sim 90 \% \text { after } 100 \text { cycles at } \\
25 \mathrm{~mA} \mathrm{~g}^{-1}\end{array}$ & 239 \\
\hline $\begin{array}{l}\text { Polyacrylonitrile/ } \\
\text { humic acid }\end{array}$ & $\begin{array}{l}\text { Electrospinning and } \\
\text { carbonization }\end{array}$ & 27.57 & $0.01-2.7$ & $\begin{array}{l}261.3 \mathrm{at}^{-1} \\
0.02 \mathrm{~A} \mathrm{~g}^{-1}\end{array}$ & $\begin{array}{l}208.6 \text { and } 81.7 \text { at } 0.2 \\
\text { and } 1 \mathrm{~A} \mathrm{~g}^{-1} \text {, respectively }\end{array}$ & $\begin{array}{l}92.8 \% \text { after } 100 \text { cycles at } \\
0.1 \mathrm{~A} \mathrm{~g}^{-1}\end{array}$ & 240 \\
\hline $\mathrm{Na}_{2} \mathrm{TP} @ \mathrm{GE}$ & $\begin{array}{l}\text { Freeze-drying and } \\
\text { sintering }\end{array}$ & - & $0.01-2$ & $\begin{array}{l}268.9 \mathrm{at}^{\circ} \\
0.1 \mathrm{~A} \mathrm{~g}^{-1}\end{array}$ & 141 at $0.6 \mathrm{~A} \mathrm{~g}^{-1}$ & $\begin{array}{l}207.9 \mathrm{~mA} \mathrm{~h} \mathrm{~g}{ }^{-1} \text { after } 500 \text { cycles } \\
\text { at } 0.1 \mathrm{~A} \mathrm{~g}^{-1}(77.3 \% \text { capacity } \\
\text { retention })\end{array}$ & 241 \\
\hline PDIDA/CBs & $\begin{array}{l}\text { In situ } \\
\text { condensation }\end{array}$ & - & $1.50-3.50$ & $\begin{array}{l}90 \mathrm{at}^{-1} \\
2 \mathrm{~A} \mathrm{~g}^{-1}\end{array}$ & - & $\begin{array}{l}\text { No capacity loss after } \\
1000 \text { cycles at } 1.0 \mathrm{~A} \mathrm{~g}^{-1}\end{array}$ & 242 \\
\hline $\mathrm{Na}_{2} \mathrm{C}_{6} \mathrm{O}_{6}-\mathrm{PANI}$ & $\begin{array}{l}\text { Antisolvent } \\
\text { precipitation }\end{array}$ & - & $0.5-3.2$ & - & 220 at $500 \mathrm{~mA} \mathrm{~g}^{-1}$ & $\begin{array}{l}174 \mathrm{~mA} \mathrm{~h} \mathrm{~g}{ }^{-1} \text { after } 50 \text { cycles } \\
(63 \% \text { capacity retention })\end{array}$ & 243 \\
\hline PDI/RGO & $\begin{array}{l}\text { Solvothermal and } \\
\text { thermal treatment }\end{array}$ & 211.4 & $1.5-4.3$ & - & $\begin{array}{l}122 \text { and } 73 \text { at } 100 \text { and } \\
800 \mathrm{~mA} \mathrm{~g}^{-1}\end{array}$ & $\begin{array}{l}\sim 175 \mathrm{~mA} \mathrm{~h} \mathrm{~g}^{-1} \text { after } 500 \text { cycles } \\
\text { at } 50 \mathrm{~mA} \mathrm{~g}^{-1}\end{array}$ & 244 \\
\hline
\end{tabular}

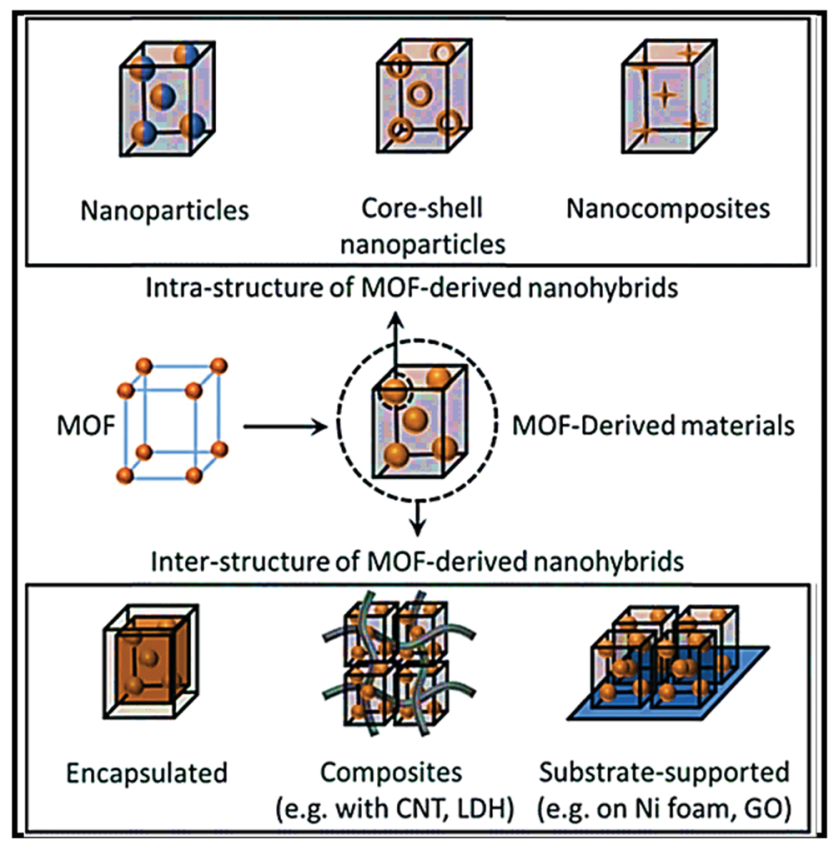

Fig. 19 Variants of MOF-derived nanohybrids for energy-storage applications obtained via tuning either the internal or external structures, or a combination of both. Reproduced with permission. ${ }^{251}$ Copyright: 2018 , Royal Society of Chemistry.

Wei Shuang et al. ${ }^{255}$ carried out the novel sulfuration of Ni-based MOFs and polypyrrole (PPy) coating strategies to achieve a $\mathrm{N}$-doped carbon shell-confined $\mathrm{Ni}_{3} \mathrm{~S}_{2}$ composite anode (the synthesis involves the solvothermal synthesis of Ni-MOF, the sulfuration of Ni-MOF to obtain the NiSx precursor, the coating of PPY onto NiSx, and annealing at $600{ }^{\circ} \mathrm{C}$ to achieve NiSx@C-600) $\left(\sim 1.2 \mathrm{~V} v s . \mathrm{Na} / \mathrm{Na}^{+}\right)$(Fig. 21a) with a high specific capacity of $432.8 \mathrm{~mA} \mathrm{~h} \mathrm{~g}^{-1}$ for up to 100 cycles and high rate capabilities of $317.6 \mathrm{~mA} \mathrm{~h} \mathrm{~g}^{-1}$ at a rate of $6.4 \mathrm{~A} \mathrm{~g}^{-1}$ with a high capacitive contribution $\left(90.78 \%\right.$ at $\left.0.6 \mathrm{mV} \mathrm{s}^{-1}\right)$ (Fig. $\left.21 \mathrm{~b}\right)$. In this work, the authors believed that PPy in the N-doped carbon shell during the annealing process protects the nanosized particles from aggregation. Meanwhile, the nanosized architecture improved the reaction kinetics and shielded against volume changes. N-Doped carbon improves the electronic conductivity via connecting short electronic pathways and buffering volume changes during the conversion-based mechanism. In another instance, a 2D derived $\mathrm{NiSe}_{2} / \mathrm{N}$-rich carbon composite anode $\left(\sim 1.5 \mathrm{~V} v s . \mathrm{Na} / \mathrm{Na}^{+}\right)^{256}$ prepared from a Ni-hexamine MOF through pyrolysis and a subsequent selenization process showed a reversible capacity of $410 \mathrm{~mA} \mathrm{~h} \mathrm{~g}^{-1}$ at $1 \mathrm{~A} \mathrm{~g}^{-1}$, with a capacity of $240 \mathrm{~mA} \mathrm{~h} \mathrm{~g}^{-1}$ even after 1000 cycles at $5 \mathrm{~A} \mathrm{~g}^{-1}$.

Meng Shao et al. ${ }^{257}$ designed a MOF-derived $\mathrm{FeS}_{2} @ \mathrm{C}$ composite that has a dominant capacitive contribution (the surface contribution ratio is around $70.0 \%$ at $0.1 \mathrm{mV} \mathrm{s}^{-1}$ ). In batterybased analysis, the $\mathrm{FeS}_{2} @ \mathrm{NSC} / \mathrm{G}$ composite demonstrated improved rate capabilities of $200 \mathrm{~mA} \mathrm{~h} \mathrm{~g}^{-1}$ even at $10 \mathrm{~A} \mathrm{~g}^{-1}$. Sodium storage takes place via diffusion as a result of the redox properties at low current densities and the surface contribution at higher current densities (Fig. 21c and d). A $\mathrm{CuO} / \mathrm{Cu}_{2} \mathrm{O}-\mathrm{GPC}$ hybrid material ${ }^{258}$ derived from a Cu-based MOF via a one-step thermal transformation process demonstrated favorable electrochemical performance in both LIBs and SIBs. In SIB applications, the $\mathrm{CuO} / \mathrm{Cu}_{2} \mathrm{O}-\mathrm{GPC}$ composite anode $\left(\sim 0.75 \mathrm{~V} v s . \mathrm{Na} / \mathrm{Na}^{+}\right)$ 

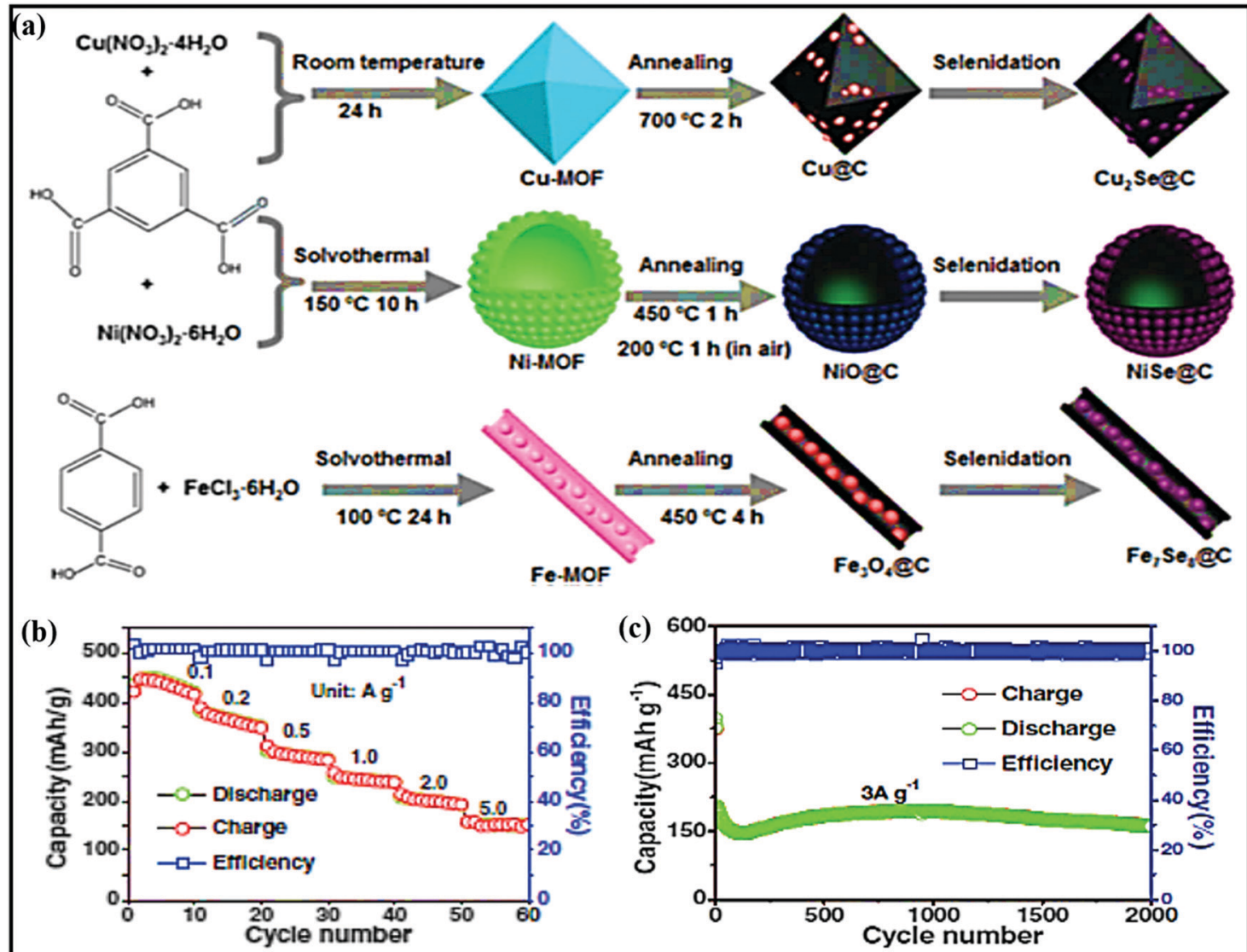

Fig. 20 (a) A schematic illustration of the fabrication of MOF-derived $\mathrm{Cu}_{2} \mathrm{Se}$ aC porous octahedra, NiSeaC hollow microspheres, and peapod-like $\mathrm{Fe}_{7} \mathrm{Se}_{8} \mathrm{QC}$ nanorods. (b) The rate performance from 0.1 to $5 \mathrm{~A} \mathrm{~g}^{-1}$ and (c) the cycling performance of NiSeaC hollow spheres at $3 \mathrm{~A} \mathrm{~g}^{-1}$. Reproduced with permission. ${ }^{252}$ Copyright: 2018, Wiley-VCH Verlag GmbH \& Co. KGaA.

recorded a stable discharge capacity of around $330 \mathrm{~mA} \mathrm{~h} \mathrm{~g}^{-1}$ at $50 \mathrm{~mA} \mathrm{~g}^{-1}$, and this was maintained at $303 \mathrm{~mA} \mathrm{~h} \mathrm{~g}^{-1}$ after cycling for up to 200 cycles with a conversion-type mechanism. In another instance, MOF-derived $\mathrm{NiS}_{2}$ anode hollow spheres encased in a graphene layer ${ }^{259}$ (during the process, the in situ formed graphene layer is thinly coated on the surface of nanosized $\mathrm{NiS}_{2}$ ) also showed a high reversible capacity of $1027 \mathrm{~mA} \mathrm{~h} \mathrm{~g}^{-1}$ and after 100 cycles a discharge capacity of $848 \mathrm{~mA} \mathrm{~h} \mathrm{~g}{ }^{-1}$ was maintained at $0.1 \mathrm{~A} \mathrm{~g}^{-1}$ with excellent rate performance (a capacity of $527.8 \mathrm{~mA} \mathrm{~h} \mathrm{~g}^{-1}$ was obtained at $2 \mathrm{~A} \mathrm{~g}^{-1}$ ). This enhanced electrochemical performance could be due to an optimized unique structure and the highly graphitized carbon coating layers.

Xinye Liu et al. ${ }^{260}$ prepared a unique binary-MOF-derived hierarchical hollow $\mathrm{Ni}_{3} \mathrm{~S}_{2} / \mathrm{Co}_{9} \mathrm{~S}_{8} / \mathrm{N}$-doped carbon hybrid composite anode $\left(\sim 1.2 \mathrm{~V}\right.$ vs. $\left.\mathrm{Na} / \mathrm{Na}^{+}\right)$via a carbonization and sulfurization strategy with different reaction times. A specific capacity of $419.9 \mathrm{~mA} \mathrm{~h} \mathrm{~g}^{-1}$ was reported at a current density of $0.1 \mathrm{~A} \mathrm{~g}^{-1}$ after 100 cycles (the initial discharge capacity was around $554 \mathrm{~mA} \mathrm{~h} \mathrm{~g}^{-1}$ ) through a conversion- and intercalationbased mechanism. In addition, good rate performance was seen (specific capacities of 416.7 and $347.8 \mathrm{~mA} \mathrm{~h} \mathrm{~g}^{-1}$ at current densities of 0.05 and $1 \mathrm{~A} \mathrm{~g}^{-1}$, respectively, were recorded, and even at $2 \mathrm{~A} \mathrm{~g}^{-1}$, it takes only $15 \mathrm{~min}$ to achieve a capacity of $323.2 \mathrm{~mA} \mathrm{~h} \mathrm{~g}^{-1}$ ), and $92 \%$ capacity retention was seen after 300 cycles. An $\mathrm{Fe}_{2} \mathrm{O}_{3} @ M I L-101(\mathrm{Fe}) / \mathrm{C}$ hierarchical hollow hybrid $^{261}$ anode was also reported with improved electrochemical performance. A stable reversible capacity of $710 \mathrm{~mA} \mathrm{~h} \mathrm{~g}{ }^{-1}$ was achieved with $93.2 \%$ capacity retention (a capacity of $662 \mathrm{~mA} \mathrm{~h} \mathrm{~g}^{-1}$ is retained) after 200 cycles with high rate performance through a conversion-based mechanism. The intrinsic hollow nanostructure architecture accommodates volume changes during (de)sodiation cycling.

The representative physical properties, capacity values, rate capabilities, and cycling performance data of MOF-derived composite materials are summarized in Table 4 .

\subsection{Polymeric nanocomposites of inorganic materials}

In this section, we discuss mainly conducting-polymer-based binary or ternary composites with different inorganic materials and their synergistic interactions that improve the sodium-ion storage performance. Conducting polymers such as polyaniline (PANI), polypyrrole (Ppy), and poly(3,4-ethylenedioxythiophene) (PEDOT) are well known for electrochemical energy storage applications, both in supercapacitors and rechargeable batteries. ${ }^{307}$ They offer high conductivity for facile charge transport, high porosity for electrolyte infiltration, and network structures with flexibility to buffer volume changes of active material during (de)sodiation, remaining interconnected, thereby improving the capacity, rate 

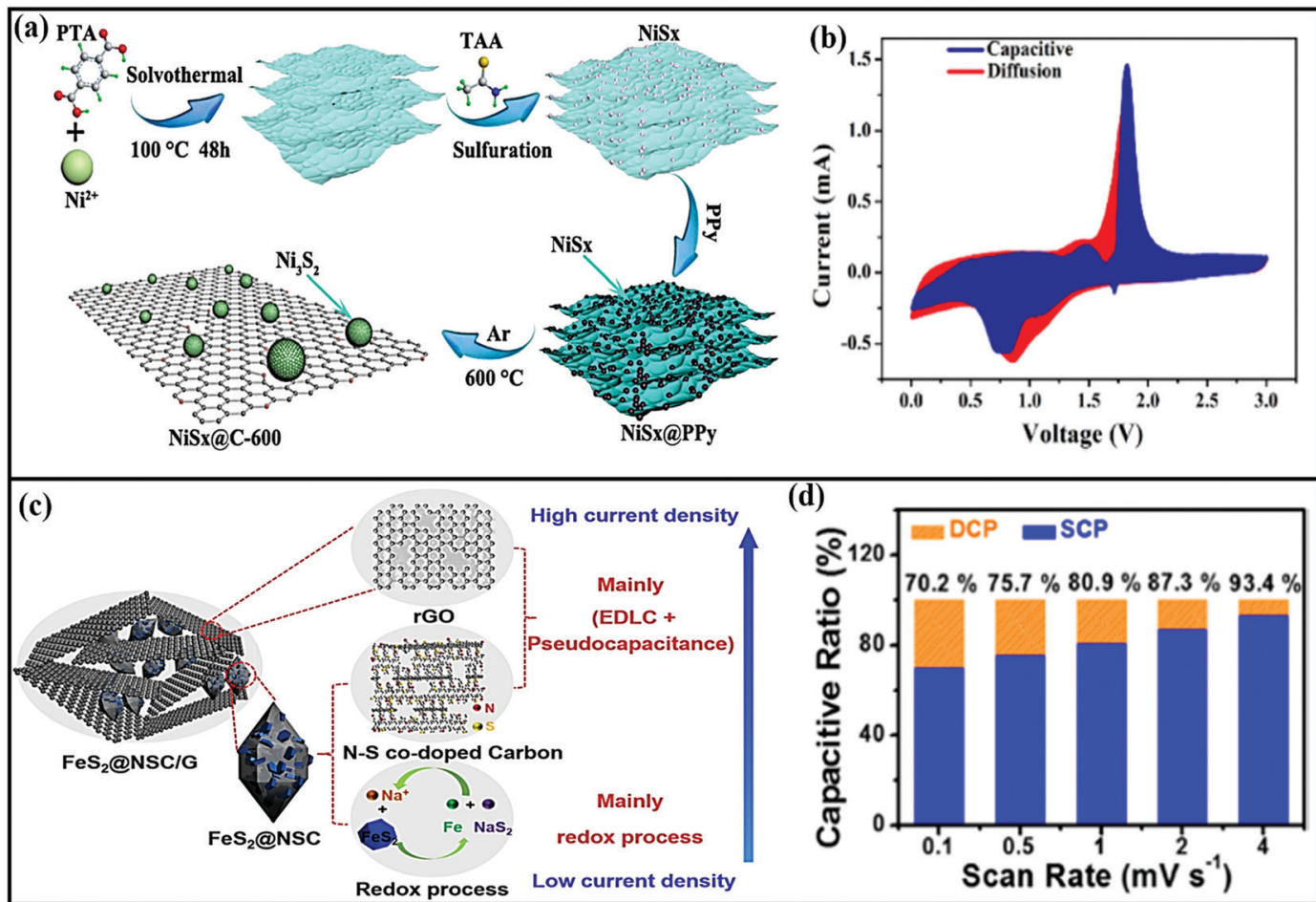

Fig. 21 (a) A schematic diagram of the fabrication of NiSx@C-600 and (b) the capacitive and diffusion contributions to charge storage at $0.6 \mathrm{mV} \mathrm{s}^{-1}$. Reproduced with permission. ${ }^{255}$ Copyright: 2019, Elsevier. (c) A schematic illustration of the FeS 2 @NSC/G sodium storage mechanisms of the three components at different current densities and (d) a bar chart of the capacitive ratios at various scan rates (from 0.1 to $4.0 \mathrm{mV} \mathrm{s}^{-1}$ ). Reproduced with permission. ${ }^{257}$ Copyright: 2018, American Chemical Society.

capability, and cycling stability when present in composite electrodes.

Liao et $a .^{308}$ demonstrated that the electrochemical performance of layered titanate negative electrodes can be significantly improved upon the insertion of PANI, which acts as conductive pillars to increase the interlayer spacing, facilitate charge transfer, and provide structural stability. A PANI-incorporating protonated titanate electrode annealed at $600{ }^{\circ} \mathrm{C}$ could form $\mathrm{TiO}_{2}$-coated polyaniline intercalated layered titanate (Fig. 22a-c), which exhibited a high specific capacity of $191 \mathrm{~mA} \mathrm{~h} \mathrm{~g}^{-1}$ at a current density of $1 \mathrm{~A} \mathrm{~g}^{-1}$, accompanied by good rate performance, with discharge capacities of 257 and $151 \mathrm{~mA} \mathrm{~h} \mathrm{~g}^{-1}$ at 0.05 and $5 \mathrm{~A} \mathrm{~g}^{-1}$, respectively (Fig. 22d). Werner et al. ${ }^{309}$ demonstrated a high-performance SIB cathode via electropolymerizing PANI thin film coated onto a carbon-coated oxygen-deficient anatase $\mathrm{TiO}_{2}$ nanotube $\left(\mathrm{TiO}_{2-x}-\mathrm{C} \mathrm{NT}\right)$ array, which was prepared via a one-step anodic oxidation process and subsequent annealing at high temperature. The high surface area of $\mathrm{TiO}_{2-x}-\mathrm{C}$ NTs and the favorable organized nanostructure caused good adhesion between the $\mathrm{TiO}_{2-x}-\mathrm{C}$ NTs and PANI, which synergistically improved the capacity, rate capability, and cycling stability of the composite cathode compare to the cathode without PANI.

Liu et al. ${ }^{310}$ demonstrated that the structural degradation of $\mathrm{CoS}_{2}$ can be significantly reduced in a rationally designed electrode via encapsulating it in hierarchical porous $\mathrm{rGO}$, followed by coating with polypyrrole thin film via a simple hydrothermal route, followed by a vapor polymerization reaction. The ternary composite showed a higher specific capacity of $554 \mathrm{~mA} \mathrm{~h} \mathrm{~g}^{-1}$ at $2.0 \mathrm{~A} \mathrm{~g}^{-1}$ (compared to $495 \mathrm{~mA} \mathrm{~h} \mathrm{~g}^{-1}$ for a $\mathrm{CoS}_{2} @ \mathrm{bGO}$ electrode) accompanied by cycling stability, with $65.8 \%$ capacity retention after 700 cycles. Wang et al. ${ }^{131}$ demonstrated the improved electrochemical performance of a $\mathrm{MoS}_{2}$ anode via encapsulating it with $\mathrm{N}$-doped porous hollow carbon spheres and coating with PPy. After an initial irreversible capacity loss, the ternary composite anode exhibited a high specific capacity of $713 \mathrm{~mA} \mathrm{~h} \mathrm{~g}^{-1}$ at a low current density of $0.1 \mathrm{Ag}^{-1}$ for 100 cycles, and it maintained a high capacity of $294 \mathrm{~mA} \mathrm{~h} \mathrm{~g}^{-1}$ at $5 \mathrm{~A} \mathrm{~g}^{-1}$ for 500 cycles.

A thin-layer coating of PEDOT or PEDOT:PSS ${ }^{311}$ conducting polymers onto Prussian blue analogs via in situ polymerization or simple overlaying has been reported to elevate the electrochemical performance of PB electrodes via favourable synergistic interactions, improving the charge transfer kinetics, preventing metal dissolution, and protecting the structure from pulverization. Benefiting from such structural reinforcement, Wang et al. ${ }^{312}$ reported high cycling stability, with $78.2 \%$ capacity retention after 1000 cycles, using a manganese hexacyanoferrate@PEDOT cathode. The unique features of PEDOT for stabilizing active electrode materials have been realized in many other cases. Jongsoon Kim and coworkers demonstrated that an ultrathin coating layer of PEDOT on a polyanionic compound, for example, $\mathrm{Na}_{2} \mathrm{FePO}_{4} \mathrm{~F}^{313}$ or $\mathrm{Na}_{2.4} \mathrm{~V}_{2}\left(\mathrm{PO}_{4}\right)_{3},{ }^{314}$ can address the poor conductivity and improve the power performance and cycling stability of devices. A partially desodiated phase, $\mathrm{Na}_{2-x} \mathrm{FePO}_{4} \mathrm{~F}$, or delithiated phase, $\mathrm{Li}_{3-x} \mathrm{~V}_{2}\left(\mathrm{PO}_{4}\right)_{3}$, can accelerate the polymerization of EDOT 


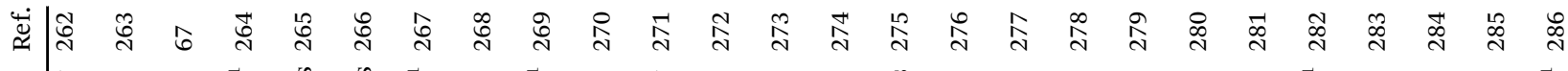

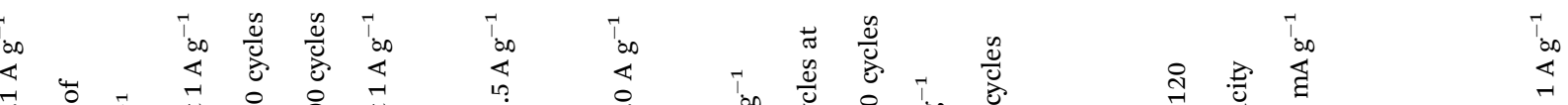

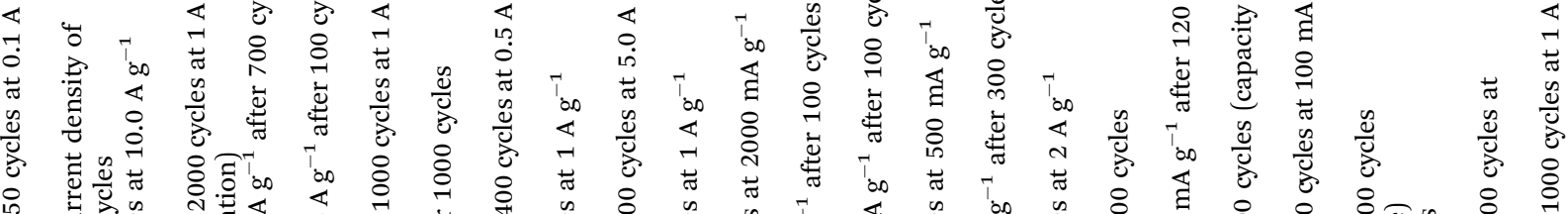

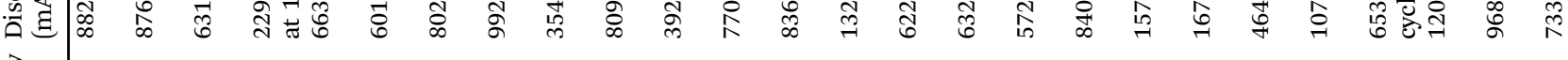

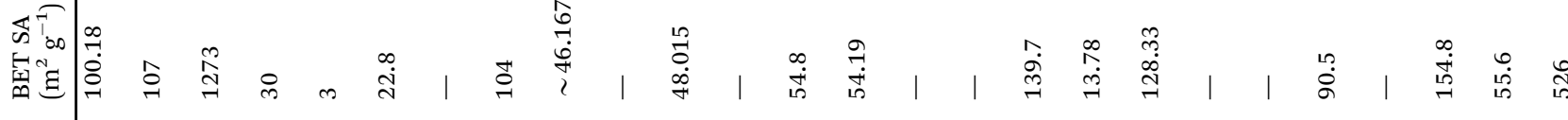<smiles>C[C@@H]1C[C@@H]1C1CC1</smiles> 


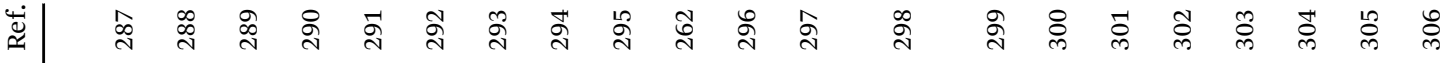

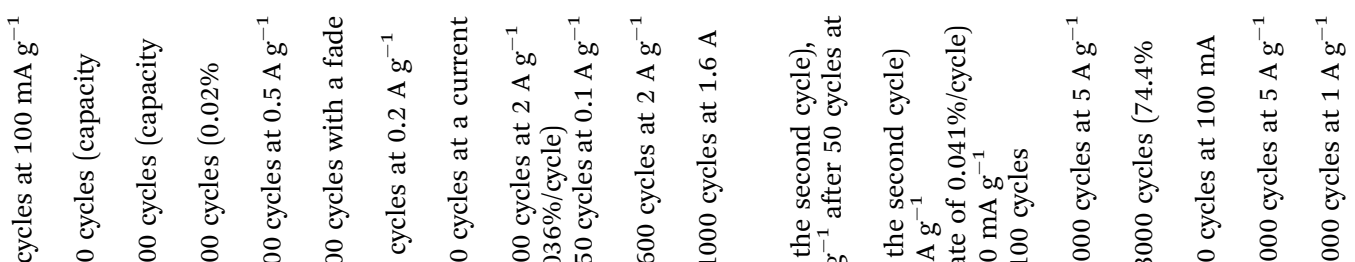

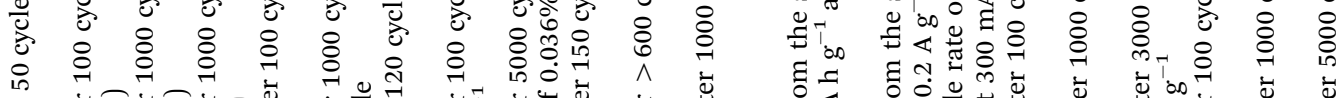
B.

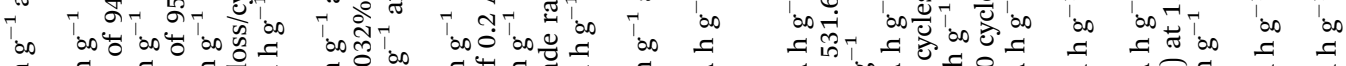

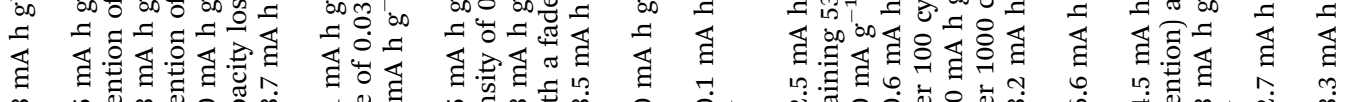

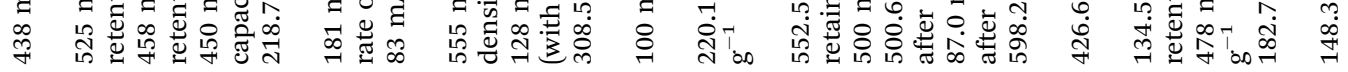

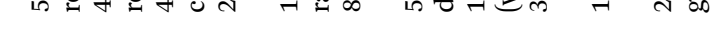

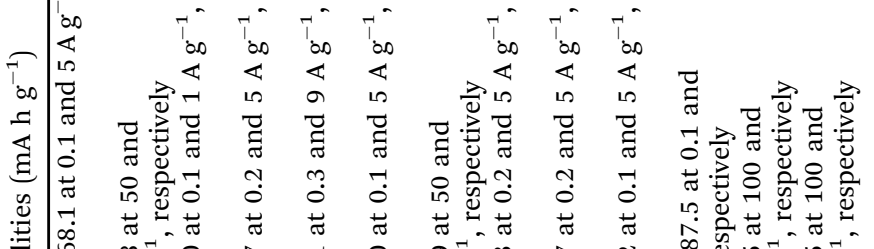

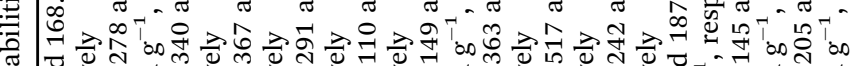

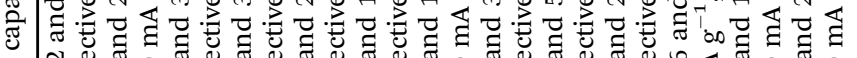

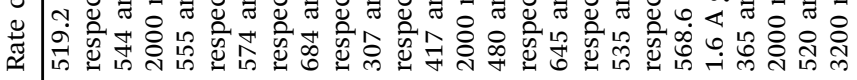

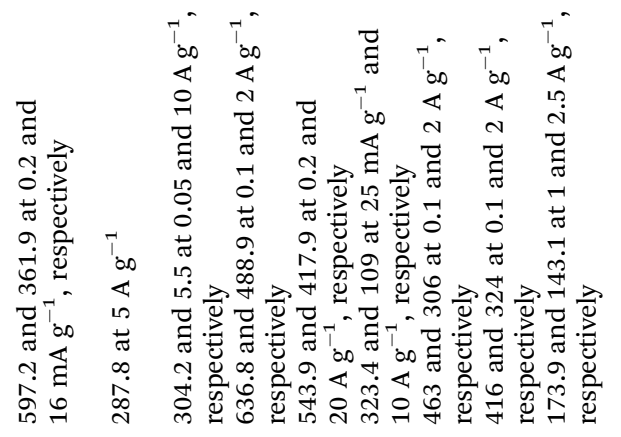

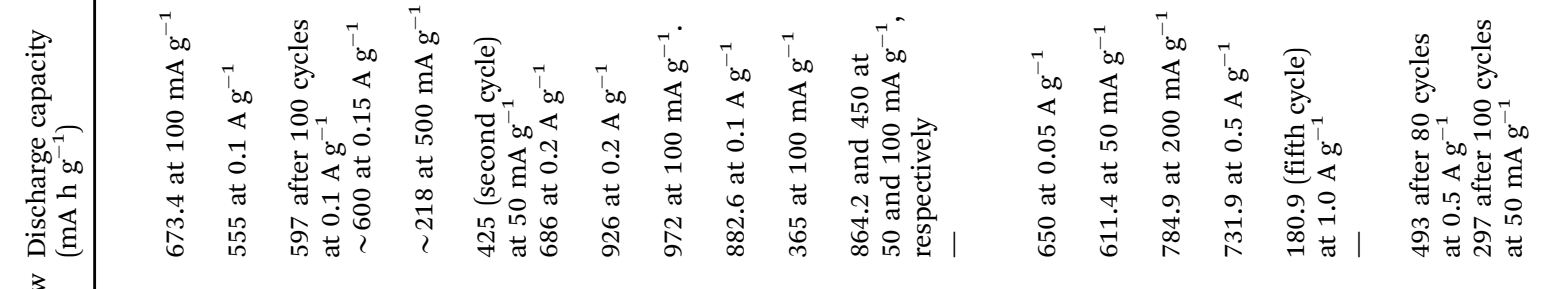

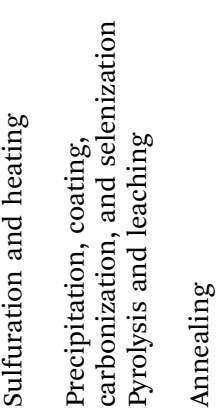

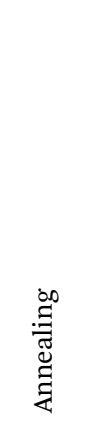
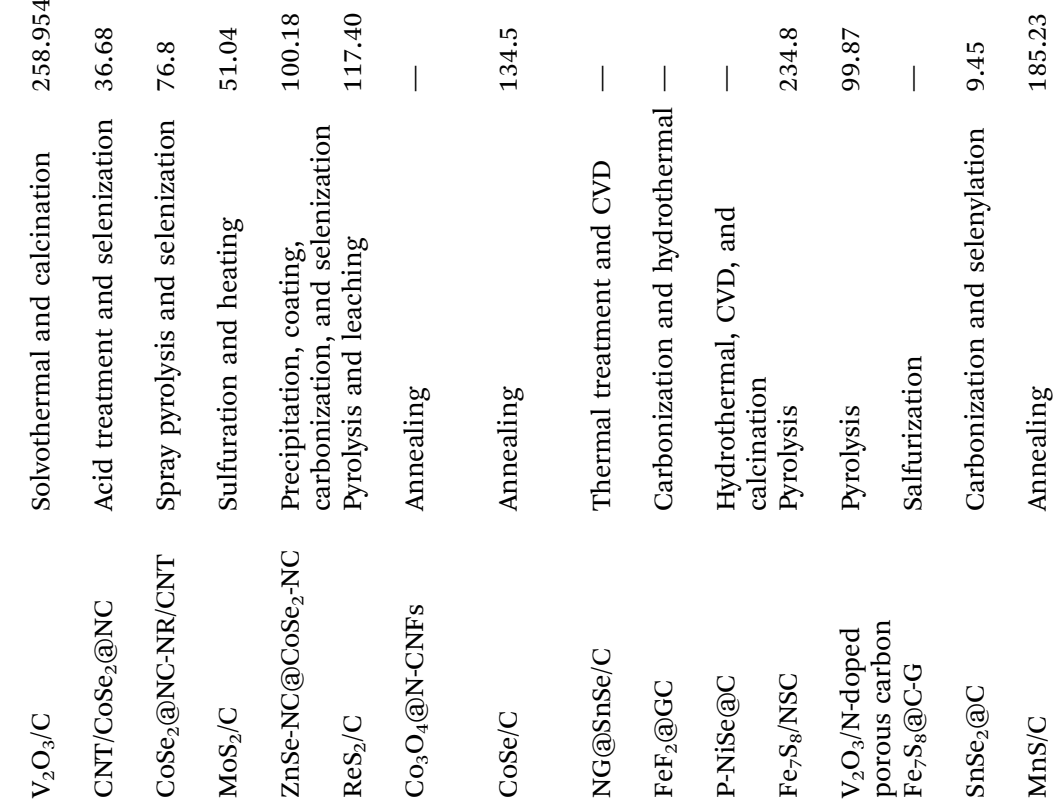

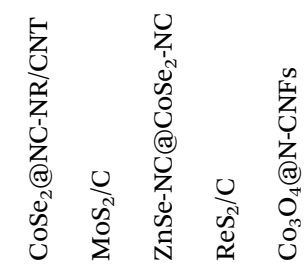

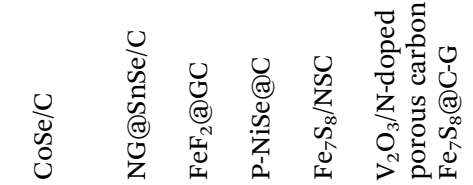

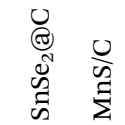


to PEDOT, forming a nanolayer PEDOT coating. The follow-up re-insertion of sodium or lithium followed by ion exchange with sodium could form $\mathrm{Na}_{2} \mathrm{FePO}_{4} \mathrm{~F}$ and $\mathrm{Na}_{2.4} \mathrm{~V}_{2}\left(\mathrm{PO}_{4}\right)_{3}$ uniformly coated with PEDOT. Notable, at a high rate (10C) $\mathrm{Na}_{2.4} \mathrm{~V}_{2}\left(\mathrm{PO}_{4}\right)_{3} /$ PEDOT and $\mathrm{Na}_{2} \mathrm{FePO}_{4} \mathrm{~F} / \mathrm{PEDOT}$ electrodes showed high specific capacities of $109.8 \mathrm{~mA} \mathrm{~h} \mathrm{~g}^{-1}$ and $76.1 \mathrm{~mA} \mathrm{~h} \mathrm{~g}^{-1}$, respectively, which were $\sim 8.5-10$ times higher than those shown by uncoated electrodes. A schematic illustration of the synthesis process of the $\mathrm{Na}_{2.4} \mathrm{~V}_{2}\left(\mathrm{PO}_{4}\right)_{3} / \mathrm{PEDOT}$ composite and electrochemical performance data are shown in Fig. 22e-g. Karthikeyan et al. ${ }^{315}$ demonstrated a cobalt-free O3-Na[Ni $\left.\mathrm{Ni}_{1 / 3} \mathrm{Mn}_{1 / 3} \mathrm{Fe}_{1 / 3}\right] \mathrm{O}_{2}$ (NNMF) cathode, which, when embedded in a PANI matrix, could be operated at a high operating voltage of $2-4.5 \mathrm{~V}$ (in contrast to $2-4.2 \mathrm{~V}$ for the NNMF cathode alone), leading to a high energy density of $567 \mathrm{~W} \mathrm{~h} \mathrm{~kg}^{-1}$ accompanied by excellent cycling stability, with $\sim 75 \%$ capacity retention after 750 cycles at $2 \mathrm{~A} \mathrm{~g}^{-1}$.

\section{Non-carbonaceous metal composites}

Similar to carbonaceous metal composites, non-carbonaceous metal composites and/or hybrids offer improved structural stability and improved electrochemical performance without sacrificing capacities. Therefore, composite routes could be an

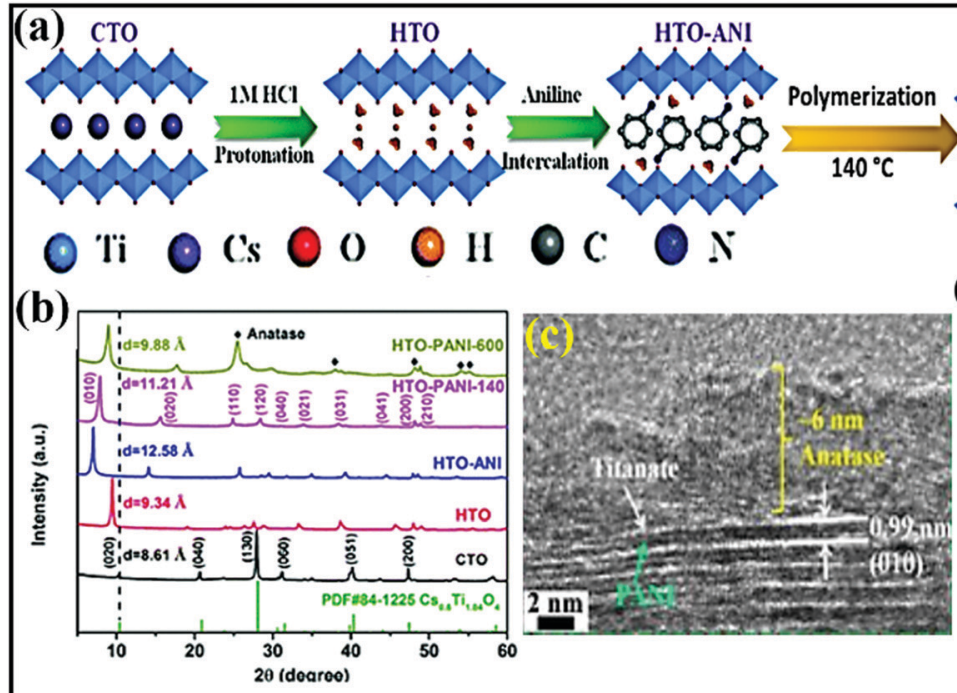

HTO-PẢNI-1+0

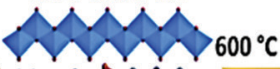

$\mathrm{TiO}_{2}$ coated

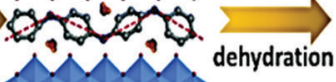
HTO-PANI-600
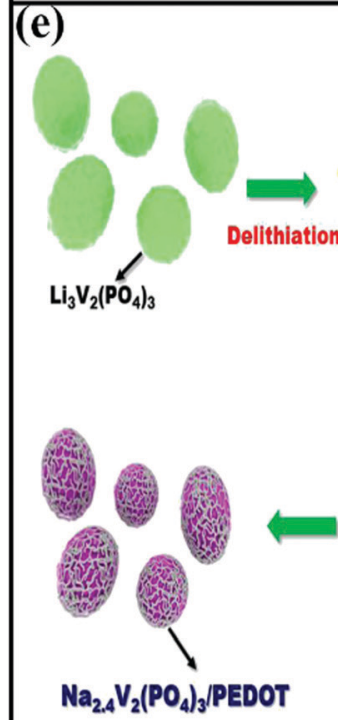
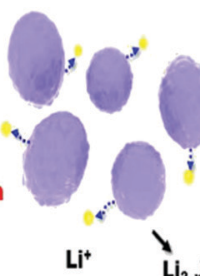

$\mathrm{Li}_{3 . \times} \mathrm{V}_{2}\left(\mathrm{PO}_{4}\right)_{3}$

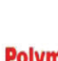

Polym
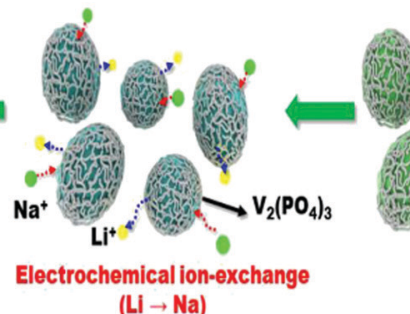

(d)

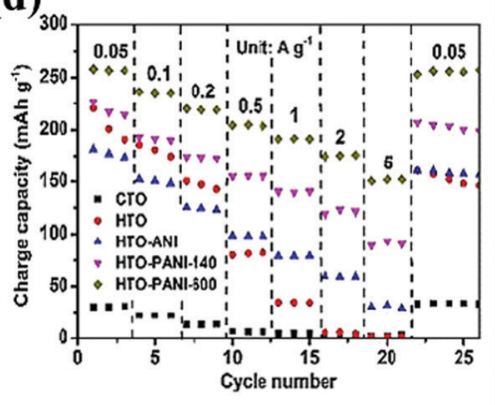

(f)

(g)
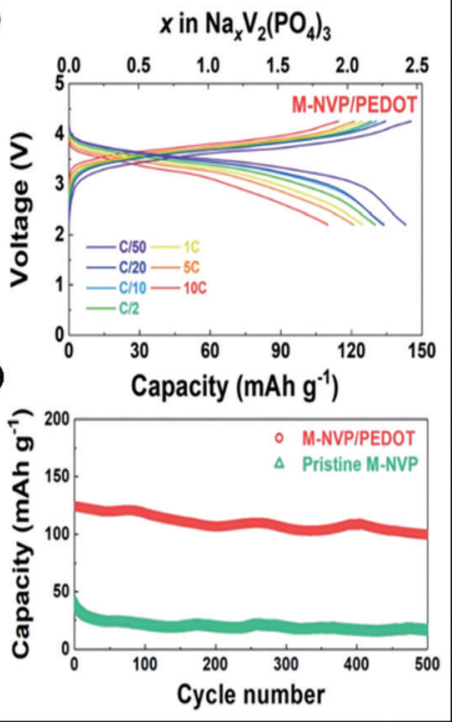

Fig. 22 (a) A schematic illustration of the synthesis of $\mathrm{TiO}_{2}$-coated polyaniline intercalated layered titanate (HTO-PANI 600) starting from layered $\mathrm{Cs}_{x} \mathrm{Ti}_{(2-x / 4)} \square_{x / 4} \mathrm{O}_{4}$ ( $\square$ stands for a vacancy) followed by an ion-exchange reaction with $\mathrm{HCl}$ to form protonated titanate (HTO), followed by ultrasonicationassisted aniline insertion into HTO (HTO-ANI), followed by in situ polymerization to form hydrated $\mathrm{HTO}$-PANI, with a subsequent dehydration step at $600{ }^{\circ} \mathrm{C}$. (b) The XRD patterns obtained from the modified layered titanates at different stages of synthesis, showing an increase in the $d$ spacing with PANI insertion. (c) A TEM image of HTO-PANI-600 and (d) a rate capability study showing the improved capacity of HTO-PANI-600 over other materials. Reproduced with permission. ${ }^{308}$ Copyright: 2020, Royal Society of Chemistry. (e) A schematic illustration of the synthesis process of the monoclinic $\mathrm{Na}_{2.4} \mathrm{~V}_{2}\left(\mathrm{PO}_{4}\right)_{3} / \mathrm{PEDOT}$ composite. (f) Charge discharge profiles at different $\mathrm{C}$ rates for the $\mathrm{Na}_{2.4} \mathrm{~V}_{2}\left(\mathrm{PO}_{4}\right)_{3} / \mathrm{PEDOT}$ cathode and (g) a comparison of the cycling stabilities of $\mathrm{Na}_{2.4} \mathrm{~V}_{2}(\mathrm{PO})_{4} /$ PEDOT and pristine $\mathrm{Na}_{2.4} \mathrm{~V}_{2}\left(\mathrm{PO}_{4}\right)_{3}$. Reproduced with permission. ${ }^{314}$ [10.1039/C8TA06238B] Copyright: 2018, Royal Society of Chemistry. 
easy way to make use of the intrinsic qualities of two or more precursors/sources via tuning the physical, chemical, and electrochemical properties. Based on works from the literature, various metal-metal composites and/or hybrids and rational design strategies adopted for the advancement of SIBs are highlighted in this section.

Nana Wang et $a .^{316}$ prepared double-walled $\mathrm{Sb} @ \mathrm{TiO}_{2}-x$ nanotubes as a composite anode via hydrolysis, calcination, and a facile reduction process, and the material showed superior high-rate performance and cycle life in SIBs and LIBs. With the advantages of a hollow structure and nanoscale size, the composite shows a maximum discharge capacity as high as $\sim 520 \mathrm{~mA} \mathrm{~h} \mathrm{~g}^{-1}$ in a fluoroethylene carbonate electrolyte, and the composite retained a capacity of $\sim 300 \mathrm{~mA} \mathrm{~h} \mathrm{~g}^{-1}$ even after 1000 cycles, which is much higher than pure $\mathrm{Sb} \operatorname{NPs}\left(\sim 20 \mathrm{~mA} \mathrm{~h} \mathrm{~g}^{-1}\right)$ and $\mathrm{TiO}_{2}-x\left(\sim 130 \mathrm{~mA} \mathrm{~h} \mathrm{~g}{ }^{-1}\right)$ at $2.64 \mathrm{~A} \mathrm{~g}^{-1}$. The advantages of the synergetic effect and distinctive interactions between $\mathrm{Sb} / \mathrm{TiO}_{2}-x$ and the 1D tubular structure morphology remain during cycling. A novel 1D yolk-shell Sb@Ti-O-P nanostructure ${ }^{317}$ was prepared via reducing the core-shell $\mathrm{Sb}_{2} \mathrm{O}_{3} @ \mathrm{TiO}_{2}$ nanorod anode $(\sim 0.8 \mathrm{Vvs}$. $\mathrm{Na} / \mathrm{Na}^{+}$) with $\mathrm{NaH}_{2} \mathrm{PO}_{2}$, and capacities of 805 and $360 \mathrm{~mA} \mathrm{~h} \mathrm{~g}{ }^{-1}$ were reported at current densities of 0.1 and $10 \mathrm{~A} \mathrm{~g}^{-1}$, respectively, which are higher than the individual components alone. Further, the composite retains a capacity of $346 \mathrm{~mA} \mathrm{~h} \mathrm{~g}^{-1}$ even at $3 \mathrm{~A} \mathrm{~g}^{-1}$ for up to 300 cycles, which corresponds to a capacity retention of $88 \%$. In this case, the authors state that the $\mathrm{Sb}$ nanorod architecture enhanced the capacity, the Ti-O-P shell stabilizes the interface between electrode and electrolyte, and the gap between the core and the shell accommodates large volume changes during the (de)sodiation process.

Dandelion-clock-inspired core-shell TiO $\mathrm{T}_{2} @ \mathrm{MoS}_{2}{ }^{318}$ was prepared via a facile solvothermal process. The novel composite provides strong structural integrity and facile electron transfer, prevents aggregation, and increases the number of active sites. As an anode material $\left(\sim 1.1 \mathrm{~V} v s\right.$. $\left.\mathrm{Na} / \mathrm{Na}^{+}\right)$with an intercalationand conversion-based mechanism, the composite showed a stable discharge capacity of $\sim 440 \mathrm{~mA} \mathrm{~h} \mathrm{~g}{ }^{-1}$ at $0.1 \mathrm{~A} \mathrm{~g}^{-1}$, and the composite showed reversible capacities of 427.3 (10th cycle) and 277.8 (170th cycle) $\mathrm{mA} \mathrm{h} \mathrm{g}{ }^{-1}$ at 0.1 and $10 \mathrm{Ag}^{-1}$, respectively. In cycling stability testing, the composite retains a capacity of $375.2 \mathrm{~mA} \mathrm{~h} \mathrm{~g}^{-1}$ even after 345 cycles, with approximately $100 \%$ capacity retention from the 6 th cycle at $0.5 \mathrm{~A} \mathrm{~g}^{-1}$. Pure $\mathrm{MoS}_{2}$ and $\mathrm{TiO}_{2}$ failed in comparison with the composite.

Shuai Liu and co-researchers ${ }^{320}$ reported a phosphorous@Ni-P core@shell (RP@Ni-P) composite with different Ni-P shell thicknesses and compositions, and their structural stabilities and electrochemical performances were analyzed. More significantly, the authors demonstrated the advantages of the core@shell composite and described how the composite is beneficial for the ion/electron transport and sodium intercalation/de-intercalation processes. Indeed, the $\mathrm{RP} @ \mathrm{Ni}-\mathrm{P}$ high-rate composite anode $\left(\sim 0.4 \mathrm{~V} v s . \mathrm{Na} / \mathrm{Na}^{+}\right)$showed a capacity as high as $1256.2 \mathrm{~mA} \mathrm{~h} \mathrm{~g}^{-1}$ after 200 cycles at $260 \mathrm{~mA} \mathrm{~g}^{-1}$, superior rate performance (delivering a capacity of $491 \mathrm{~mA} \mathrm{~h} \mathrm{~g}^{-1}$ even at a current density of $5200 \mathrm{~mA} \mathrm{~g}^{-1}$ ), and admirable cycling stability, with a capacity of $409.1 \mathrm{~mA} \mathrm{~h} \mathrm{~g}^{-1}$ after up to 2000 cycles at a current density of
$5 \mathrm{~A} \mathrm{~g}^{-1}$. Distinct core-shell $\mathrm{Sb} @ \mathrm{Co}(\mathrm{OH})_{2}$ nanosheets $^{321}$ were fabricated via the magnetron sputtering of $\mathrm{Sb}$ onto a $\mathrm{Co}(\mathrm{OH})_{2}$ substrate anchored onto stainless steel mesh. As an anode $\left(\sim 0.75 \mathrm{~V} v s . \mathrm{Na} / \mathrm{Na}^{+}\right)$, through an alloy-type mechanism, the composite reported a high discharge capacity of as high as 972.6 $\mathrm{mA} \mathrm{h} \mathrm{g}^{-1}$ at $0.2 \mathrm{~A} \mathrm{~g}^{-1}$, with high rate performance (delivering a capacity of $383.5 \mathrm{~mA} \mathrm{~h} \mathrm{~g}{ }^{-1}$ even at $30 \mathrm{~A} \mathrm{~g}^{-1}$ ). Novel core-shell $\mathrm{Sb} @ \mathrm{Co}(\mathrm{OH})_{2}$ not only facilitates ion/electron transfer but also buffers volume changes and aggregation. Subsequently, 3D Sb-Co nanocomposites ${ }^{322}$ for Na-ion and K-ion battery applications were also reported with good capacities and rate performances. The $3 \mathrm{D}$ porous architecture with a strong synergetic effect improves the overall electrochemical performance, and the incorporation of a Co element buffers volume expansion, alleviates mechanical stress, and improves the electrode kinetics.

It is well known that MXens have recently been widely reported as superior electrode materials for energy storage applications due to their high theoretical capacities, high electronic conductivities, abundant functional groups, and flexible plasticity. ${ }^{323-325}$ Therefore, rationally integrating MXens with other metal oxides can achieve unconventional functionalities with improved electrochemical performance that cannot be obtained using pristine (bare) materials. For instance, Jimei Huang et al. ${ }^{319}$ prepared novel sandwich-like $\mathrm{Na}_{0.23} \mathrm{TiO}_{2} / \mathrm{Ti}_{3} \mathrm{C}_{2}$ MXene composites (1D amorphous $\mathrm{Na}_{0.23} \mathrm{TiO}_{2}$ nanobelts grown on $2 \mathrm{D} \mathrm{Ti}_{3} \mathrm{C}_{2}$ nanosheets) via a one-step in situ transformation reaction (which consisted of etching with $\mathrm{HF}$, the partial oxidation of $\mathrm{Ti}_{3} \mathrm{C}_{2}$ layers using dissolved $\mathrm{O}_{2}$ in $\mathrm{NaOH}$, and in situ transformation to $\mathrm{Na}_{0.23} \mathrm{TiO}_{2}$ nanobelts to achieve sandwich-like $\mathrm{Na}_{0.23} \mathrm{TiO}_{2} / \mathrm{Ti}_{3} \mathrm{C}_{2} \mathrm{MXene}$ composites) (Fig. 23a and b).

As an anode material, a $\mathrm{Na}_{0.23} \mathrm{TiO}_{2} / \mathrm{Ti}_{3} \mathrm{C}_{2}$ MXene composite showed capacities of 138 and $47 \mathrm{~mA} \mathrm{~h} \mathrm{~g}^{-1}$ at 0.1 and $3 \mathrm{~A} \mathrm{~g}^{-1}$, respectively, and the composite retained a capacity of $56 \mathrm{~mA} \mathrm{~h} \mathrm{~g}$ after up to 4000 cycles, with nearly $100 \%$ capacity retention (Fig. 23c and d). The novel sandwich-like composite composed of $1 \mathrm{D}$ and $2 \mathrm{D}$ architectures facilitates the charge-transport dynamics (Fig. 23e) and effectively relieves strain on the electrode during cycling. More significantly, $\mathrm{Na}_{0.23} \mathrm{TiO}_{2}$ nanobelts with ultra-small dimensions can reduce the diffusion length and buffer volume changes, while $\mathrm{Ti}_{3} \mathrm{C}_{2}$ nanosheets were electrically connected with $\mathrm{Na}_{0.23} \mathrm{TiO}_{2}$ and supported efficient $2 \mathrm{D}$ electron transfer. A distinctive two-step hydrothermal method for the in situ growth of hybrid $\mathrm{NaT}_{8} \mathrm{O}_{13} / \mathrm{NaTiO}_{2}$ nanoribbons on $\mathrm{Ti}_{3} \mathrm{C}_{2}$ MXene $^{329}$ was reported, with the material showing good cycling stability. With an intercalation-type mechanism, the hybrid anode reported a stable voltage of $\sim 1.2 \mathrm{~V}$ and retained a capacity of $82 \mathrm{~mA} \mathrm{~h} \mathrm{~g}^{-1}$ even after 1900 cycles at $2 \mathrm{~A} \mathrm{~g}^{-1}$. In another instance, Feng Wu et al. ${ }^{326}$ reported a $3 \mathrm{D} \mathrm{VO}_{2} / \mathrm{MXene}$ flower-like hybrid architecture to overcome solubility issues, low electronic conductivity, and significant volume changes during cycling. The resultant hybrid prepared via a facile hydrothermal method (which consists of etching, exfoliation, and mixing) (Fig. 24a) exhibited superior electrochemical performance through the combined effects of MXene and $\mathrm{VO}_{2}$. A reversible capacity of $280.9 \mathrm{~mA} \mathrm{~h} \mathrm{~g}^{-1}$ at $0.1 \mathrm{~A} \mathrm{~g}^{-1}$, a voltage of $\sim 1.25 \mathrm{~V}$, and capacity 

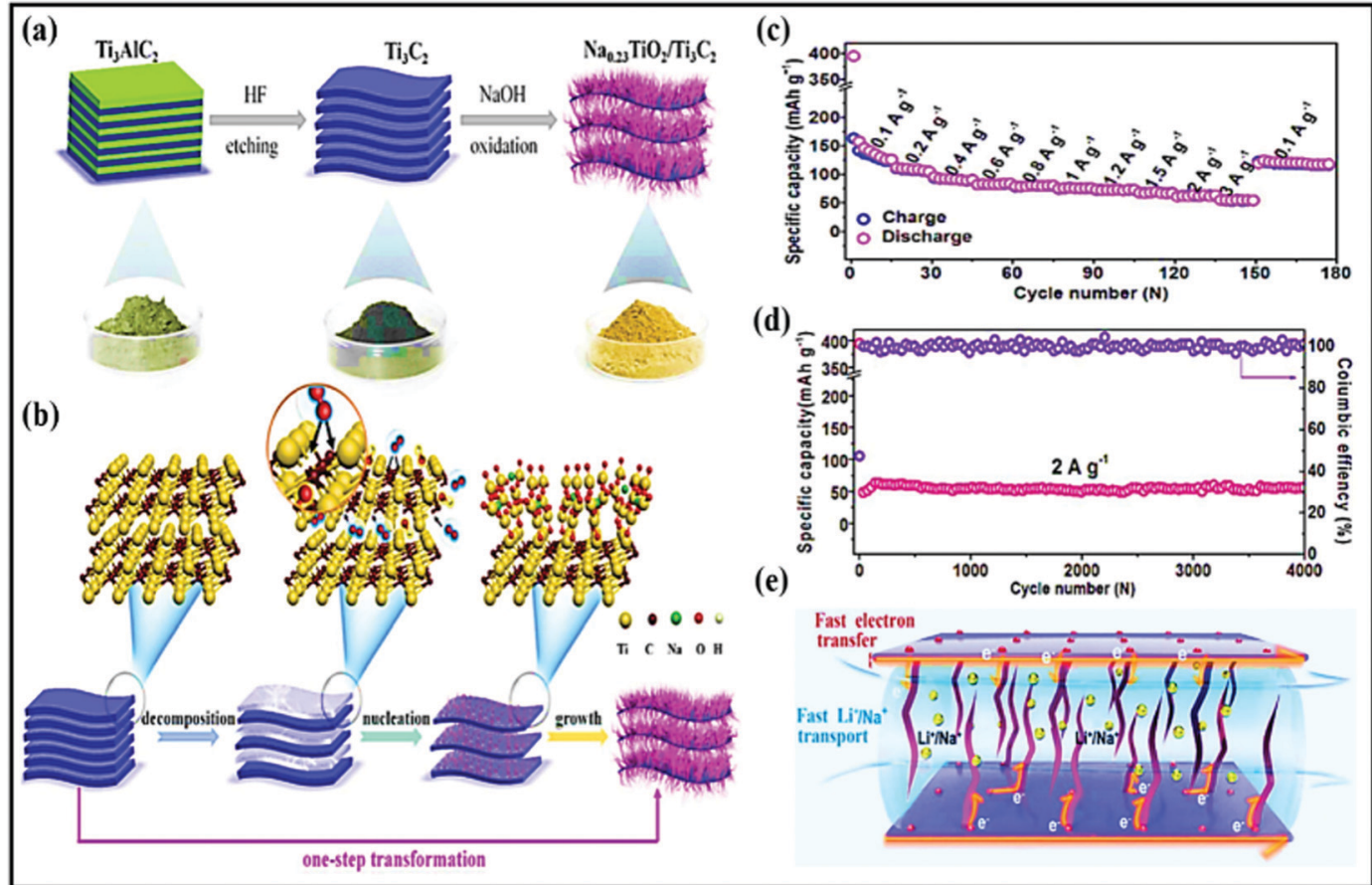

Fig. 23 (a) A schematic representation of the synthetic route to the sandwich-like $\mathrm{Na}_{0.23} \mathrm{TiO}_{2} / \mathrm{Ti}_{3} \mathrm{C}_{2}$ composite and (b) a schematic illustration of the formation mechanism of the sandwich-like $\mathrm{Na}_{0.23} \mathrm{TiO}_{2} / \mathrm{Ti}_{3} \mathrm{C}_{2}$ composite through an in situ transformation reaction. (c) The rate performance, (d) longterm cycling performance, and (e) energy-storage mechanism during the discharge process using the $\mathrm{Na}_{0.23} \mathrm{TiO}_{2} / \mathrm{Ti}_{3} \mathrm{C}_{2}$ composite. Reproduced with permission. ${ }^{319}$ Copyright: 2018, Elsevier.

retention of $141 \%$ over 200 cycles at $0.1 \mathrm{~A} \mathrm{~g}^{-1}$ (Fig. 24b) are seen, based on an intercalation-type mechanism. The high surface area and porous structure of this novel hybrid provide abundant active sites for sodium intercalation/de-intercalation. The flower-like hybrid structure also provided a high specific surface area that facilitated a greater degree of contact with the electrolyte and shortened the diffusion length via improving the electrode kinetics. Subsequently, a $2 \mathrm{D}$ phosphorene $/ \mathrm{Ti}_{3} \mathrm{C}_{2} \mathrm{~T}_{x}$ stable architecture with a fluorene hybrid interface ${ }^{327}$ (fabricated via a self-assembly process) (Fig. 24c-e) was also reported, with good sodium storage kinetics. The fluorene hybrid interface provided good mechanical support for stable and fast sodium storage. Indeed, the combined effects of 2D phosphorene nanosheets and $\mathrm{Ti}_{3} \mathrm{C}_{2} \mathrm{~T}_{x}$ improved the electrode kinetics and alleviated volume variations, thereby enhancing the cycling performance. Electrochemically, the hybrid maintained capacities of 535 and $193 \mathrm{~mA} \mathrm{~h} \mathrm{~g}^{-1}$ at 0.1 and $5 \mathrm{~A} \mathrm{~g}^{-1}$, respectively, due to the large proportion of pseudocapacitive charge storage. In terms of cycling performance, the hybrid could be repeatedly cycled up to 1000 times and it retained a capacity of $298 \mathrm{~mA} \mathrm{~h} \mathrm{~g}^{-1}$ with $88 \%$ capacity retention. Chengxiang et al. also reported a heterostructured black phosphorous $/ \mathrm{Ti}_{3} \mathrm{C}_{2}$ hybrid ${ }^{328}$ with improved storage performance. From DFT studies, they found that strong interactions between black phosphorous and $\mathrm{Ti}_{3} \mathrm{C}_{2}$ lower the binding energy to support the sodiation process. More significantly, the surface functional groups, such as $-\mathrm{O},-\mathrm{F}$, and $-\mathrm{OH}$, in $\mathrm{Ti}_{3} \mathrm{C}_{2}$ act as synergetic adsorption sites, accelerating sodiation and playing an important role in immobilizing black phosphorous (Fig. 23f-h). In a similar fashion, a $\mathrm{Bi}_{2} \mathrm{~S}_{3}$ /MXene sandwichlike stereochemical structure ${ }^{330}$ was reported with enhanced performance due to the high-capacity $\mathrm{Bi}_{2} \mathrm{~S}_{3} \mathrm{NPs}$ and the high electrical conductivity of the $\mathrm{Ti}_{3} \mathrm{C}_{2} \mathrm{~T}_{x}$ layers. As an anode material, the composite showed maximum/minimum discharge capacities of $407 / 168 \mathrm{~mA} \mathrm{~h} \mathrm{~g}^{-1}$ at $0.1 / 5 \mathrm{~A} \mathrm{~g}^{-1}$ and low capacity decay of only $\sim 0.22 \%$ per cycle for up to 250 (de)sodiation cycles. An optimized Si/TiN/Ti/Ge hybrid composite ${ }^{331}$ anode reported excellent electrochemical performance due to its novel 3D nanostructure and an effective conductive layer of TiN/Ti thin film. Theoretically, the adsorption and diffusion of sodium over the $\mathrm{Si}$ lattice was evidenced via first-principles calculations.

\section{Conclusions and future scope}

Although SIBs are considered as some of the most suitable alternatives to LIBs, their development for practical and large-scale applications has been hindered by poor electrochemical performance, mainly arising from the large size of $\mathrm{Na}^{+}$and the lack of suitable electrode materials. In this review, we have summarized recent progress relating to rationally designed nanocomposite materials (both carbonaceous and non-carbonaceous) for use as electrodes aimed at improving the electrochemical performances of SIBs (Fig. 25).

In general, large numbers of available $\mathrm{Na}^{+}$storage sites with facile solid-state $\mathrm{Na}^{+}$diffusion, sufficient electronic conductivity for facile charge transfer, and flexibility to buffer huge volume changes during cycling are the most desired properties for any electrode material for SIBs. Notably, depending on the nature of the active material (inorganic or organic), much effort has been 

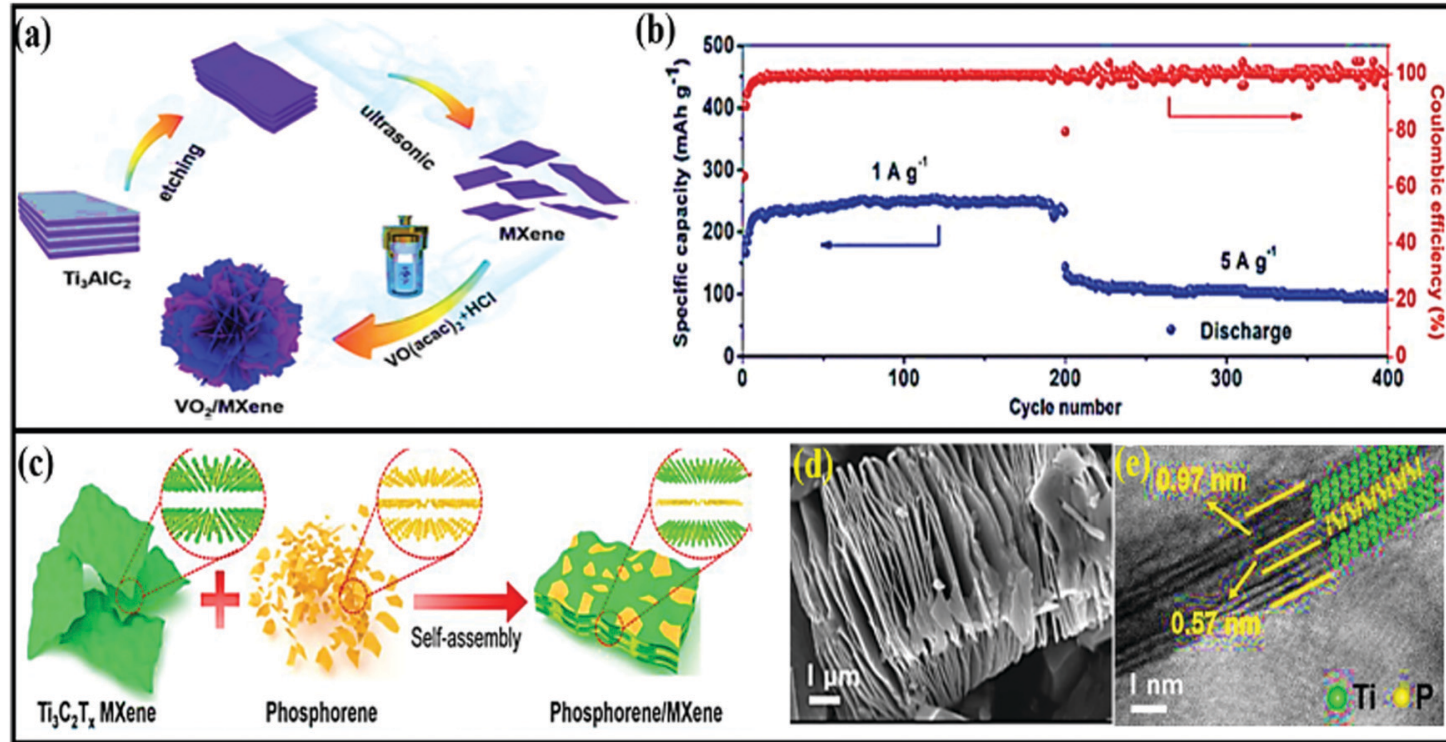

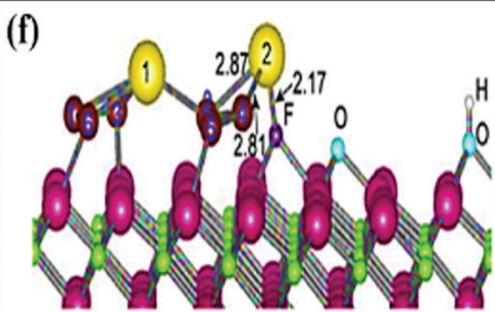

- $F$ in PDDA-BP/Ti3 $\mathrm{C}_{2}$ heterostructure $(-2.27 \mathrm{eV})$ (g)

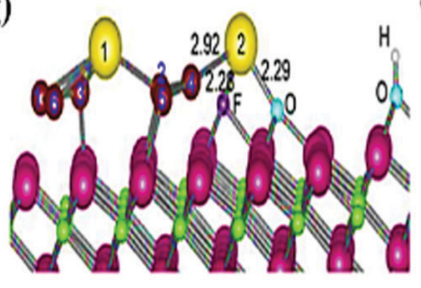

.0 in PDOA-BPTTBC2 helerostucture (-2.45 eV)

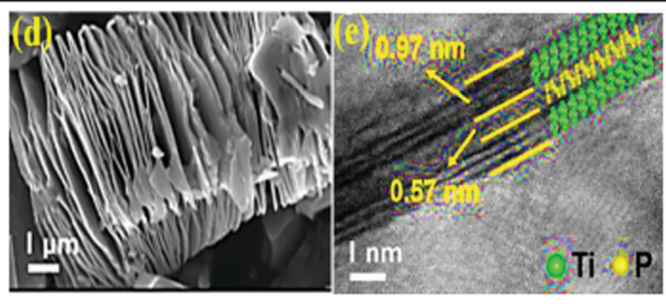

(h)

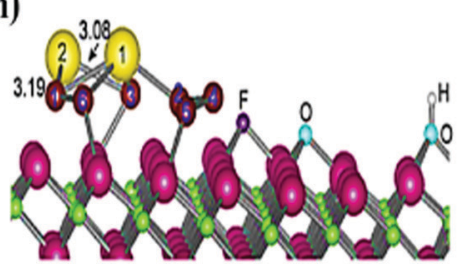

.OH in PDDA.BP/Ti3 $\mathrm{C}_{2}$ heterostructure $(-3.15 \mathrm{eV})$

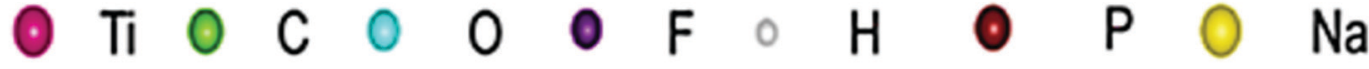

Fig. 24 (a) A schematic illustration of the synthetic process for $\mathrm{VO}_{2} / \mathrm{MXene} \mathrm{hybrids} \mathrm{and} \mathrm{(b)} \mathrm{the} \mathrm{cycling} \mathrm{performance} \mathrm{of} \mathrm{VO}_{2} / \mathrm{MX}-1$ at $c$ urrent densities of 1 and $5 \mathrm{~A} \mathrm{~g} \mathrm{~g}^{-1}$. Reproduced with permission. ${ }^{326}$ Copyright: 2019, Royal Society of Chemistry. (c) A schematic illustration of the synthesis process for phosphorene/MXene hybrid structures. (d) An SEM image of etched- $\mathrm{Ti}_{3} \mathrm{C}_{2} \mathrm{~T}_{x}$. (e) A HRTEM image of the phosphorene/MXene architecture; the inset shows the corresponding atomic structural model. Reproduced with permission. ${ }^{327}$ Copyright: 2020, American Chemical Society. The sodiation process revealed via DFT calculations: ( $\mathrm{f}-\mathrm{h}$ ) the most stable adsorption configurations for Na adsorption on top of functional heterostructure groups, such as $-\mathrm{F}$, $-\mathrm{O}$, and $-\mathrm{OH}$. Reproduced with permission. ${ }^{328}$ Copyright: 2019, Elsevier.

devoted to improving the electrochemical performance via optimizing crystal structures, ${ }^{332}$ nano-engineering, ${ }^{30}$ surface modifications, ${ }^{333}$ doping, ${ }^{344,335}$ creating vacancies, ${ }^{336}$ functionalization, extending conjugation, ${ }^{337,338}$ etc. However, it is difficult to achieve all the beneficial properties for developing reliable practical batteries based on any single state-of-the-art investigated active material, and the task-specific design of nanocomposites where the components can synergistically overcome current limitations (the poor electronic conductivities of bare active materials, poor $\mathrm{Na}^{+}$diffusion kinetics due to large sizes, and uncontrollable volume changes causing structural degradation during cycling) and obtain the aforementioned desired properties is a good approach. To summarize:

- The nanoengineering of active materials to achieve 0D, 1D, and $2 \mathrm{D}$ architectures with simultaneous composite formation with other active materials or conductive matrices has been found to be one of the most effective approaches for obtaining desired electrode performances in SIBs. Such engineered architectures not only increase the active surface area that is accessible to electrolytes for charge storage but, also, the open framework structures in such short-range ordered materials and enhanced interfacial connections can increase solid-state ion diffusion.

- Nanocomposites involving two or more active materials with engineered heterostructures (0D-2D, 0D-3D, 2D-2D, 1D-3D, etc.) can synergistically boost the electrochemical performance, resulting in improved electronic and kinetic properties. Engineered architectures, such as yolk-shell, core-shell with a hollow interior, and robust shell, are highly effective at stabilizing electrode architectures during cycling and improving the cycling stability.

- Connecting nanostructured active materials through porous conductive networks with high surface areas, carbonaceous materials (either synthesizing them in situ along with the active materials from soluble carbon precursors following postprocessing or using engineered carbon substrates and directly anchoring the nanostructure active material to them) can not only maintain a conductive network throughout the material for facile charge transfer but they can also provide flexibility to buffer the effects of volume changes during cycling, prevent the 


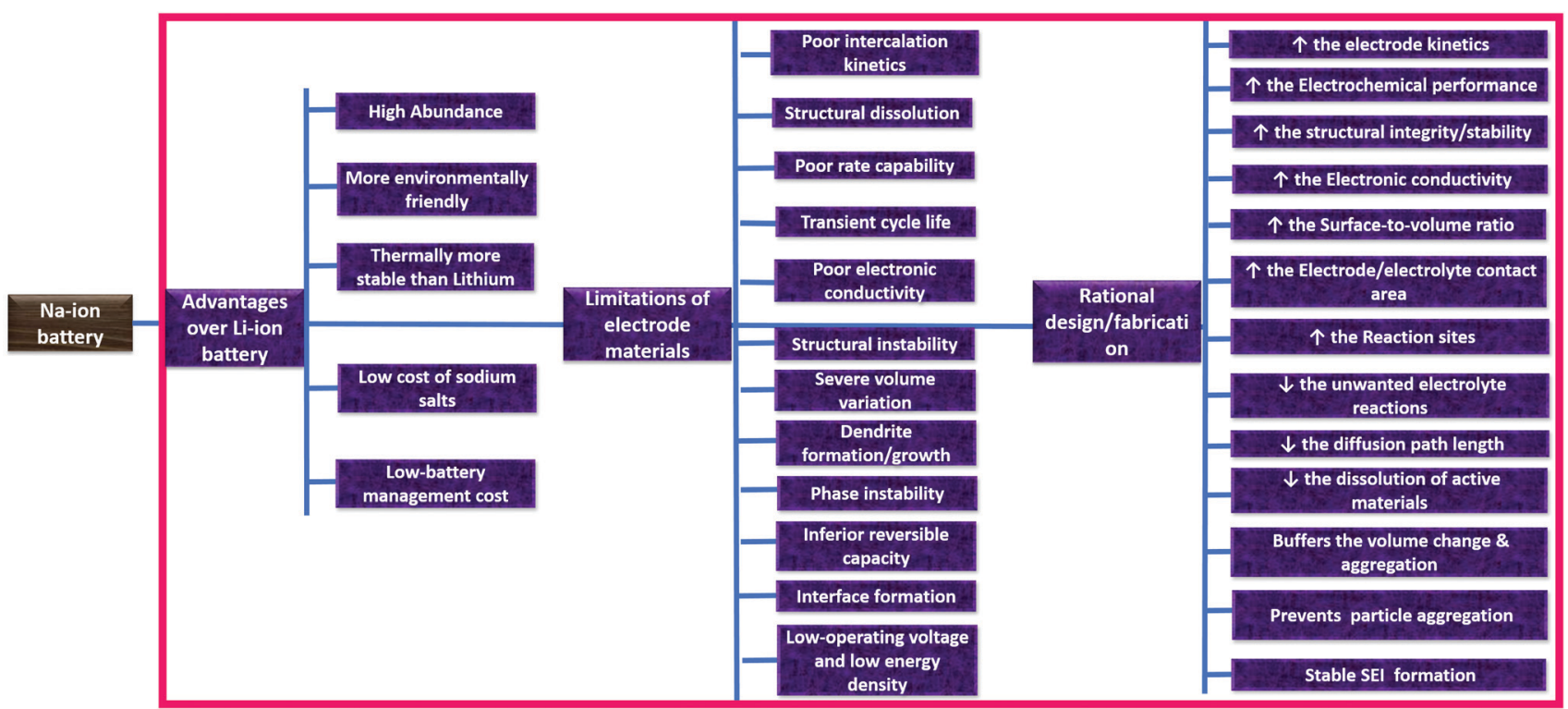

Fig. 25 An overview of the advantages and limitations of Na-ion battery electrode materials and the merits of rational design/fabrication aimed at obtaining high electrochemical performance.

agglomeration of particles, and maintain the structural integrity. Such porous nanocomposites also offer a significant capacitive contribution to the total charge storage.

- In the case of organic-material-based nanocomposite hybrids, the organic compounds are mostly physically adsorbed on carbon matrices through $\pi-\pi$ interactions $\mathrm{s}^{21,187,189,202,220}$ or chemically bonded to the carbon matrix. ${ }^{187,189,339,340}$ Therefore, the resulting heterogeneous (modified/rationally designed) hybrid structures exhibit unique structural and physicochemical properties different from the bulk forms. Such carbonaceous nanocomposite organic electrodes show reduced charge transfer resistance ${ }^{21,193}$ and increased electrode/electrolyte contact areas, ${ }^{202}$ prevent the dissolution of the active organic compound through stable chemical or non-covalent $\pi-\pi$ stacking interactions, ${ }^{187,341}$ improve the electron transportation kinetics and diffusion properties, ${ }^{191,202,207}$ etc.

- MOF-Derived composite materials fabricated via the simple pyrolysis of parent MOFs can produce well-defined metal compound (metals or metal oxides/sulfides/selenides/phosphides depending on the pyrolysis condition) NPs embedded in porous carbon matrix architectures. Such nanoarchitectures, with kinetically favorable large interstitial sites with ordered porosity, high conductivity, and high surface areas, are favorable for (de)sodiation when used as SIB electrodes. ${ }^{250}$

However, although the rational design of electrodes may boost the electrochemical performance, many challenges still remain. The performances of oxide-based materials in LIBs are quite outstanding, while the Na-storage performances are far from satisfactory, with low capacities and inferior cycling stabilities. It is a significant challenge to develop electrode materials with large interstitial spaces within their crystallographic structures that can host $\mathrm{Na}$ ions and achieve satisfactory electrochemical performance. Also, conversion- and alloying-based materials exhibit huge irreversible capacity losses. Furthermore, nanostructured materials exhibit high surface areas and low densities, accelerating electrolyte degradation and inevitably affecting the volumetric energy densities of these systems. Moreover, the unstable SEI layers formed during the first cycles induce the continuous consumption and trapping of $\mathrm{Na}$ ions during cycling with consequent low Coulombic efficiencies and quick capacity fading.

Based on the comprehensive analysis of rationally designed composite materials given in this review and the existing challenges, some possible future research directions are proposed for building reliable electrodes for use in SIBs.

- The rational design of layered electrode materials with chemical pre-intercalation or pillaring with foreign ions and molecules to improve the interlayer distance is a promising approach for improving $\mathrm{Na}^{+}$diffusion coefficients, and it needs to be investigated in-depth and extensively.

- Robust core-shell or yolk-shell architectures can alleviate the cycling stability limitations of SIBs and require extensive investigation. In addition, compact void-free universal film formation strategies should be developed to enhance the volumetric energy densities of such electrodes.

- The structures and morphologies of parent MOFs and the transformation process greatly influence the structural, morphological, and compositional features and, in turn, the electrochemical performances of the derived products; in-depth analysis is required to develop synergistic interactions efficiently.

- A high-surface-area electrode often results in higher levels of electrolyte degradation; thus, the surface area should also be optimized. Along with the rational design of electrodes, presodiation strategies should be adopted (especially for anodes) to overcome the loss of Na ions during SEI formation, which is a major cause of the initial low Coulombic efficiencies of SIBs.

- Mechanistic understanding of sodium ion transport and storage in nanocomposite electrodes and solid electrolyte interphase formation in SIBs is still at an early stage. Deep investigations 
of the specific electrochemical changes occurring in nanocomposite electrodes during cycling via different in situ techniques, like XRD, TEM, XAS, Raman spectroscopy, etc., and computational studies to correlate structural changes and the electrochemical performances of SIBs are needed for the future design of nanocomposite electrodes.

- The rational design of nanocomposite electrodes often involves multistep processes, which need to be reduced, and processes should be made cost-effective and compatible with industrial mass production. Moreover, even more complex nanocomposites with desired architectures and compositions need to be fabricated and tested for $\mathrm{Na}^{+}$storage. In addition, more comprehensive studies (surface functionalities and reactions, electrode/electrolyte interfacial reactions and kinetics, defect analysis) are required to achieve high electrochemical performance.

- The behaviors of nanocomposite electrodes in high voltage aqueous electrolytes (water-in-salt electrolytes) and solid-state electrolytes have not been well explored. Considering the high safety of such electrolytes, detailed comprehensive studies of the structures at the interfaces and the $\mathrm{Na}^{+}$transport and storage mechanisms should be carried out.

- Sodium-based dual-ion batteries also represent a promising and cost-effective technology; however, they have been relatively less explored, with challenges mainly arising due to the unavailability of suitable cathode materials and the degradation of conventional carbonate-based electrolytes at high voltages. ${ }^{342,343}$ Significant research should also be focused on designing sodiumbased dual-ion batteries with high-performance electrodes with facile anion intercalation pathways, high structural integrity, and high voltage electrolyte combinations.

- Finally, computer simulations should be carried out for the rational design of future electrode materials to determine the most promising atomic configurations and interactions before attempting laboratory synthesis.

\section{Conflicts of interest}

There are no conflicts to declare.

\section{Acknowledgements}

D. G. thanks SERB DST, India (ECR/2018/001039) for the research grant. D. G. and S. K. N. thank DST-Technology Mission Division, India (Ref No. DST/TMD/HFC/2K18/124(G)). S. K. N. thanks DST-Government of India, NANOMISSION PROJECT (SR/NM/NT1073/2016) for financial support. S. K. N. thanks Talent Attraction Programme funded by the Community of Madrid Spain (2017-T1/ AMB5610) for financial support.

\section{References}

1 T. Kim, W. Song, D.-Y. Son, L. K. Ono and Y. Qi, J. Mater. Chem. A, 2019, 7, 2942-2964.

2 R. Marom, S. F. Amalraj, N. Leifer, D. Jacob and D. Aurbach, J. Mater. Chem., 2011, 21, 9938-9954.
3 S. Goriparti, E. Miele, F. De Angelis, E. Di Fabrizio, R. Proietti Zaccaria and C. Capiglia, J. Power Sources, 2014, 257, 421-443.

4 M. Armand and J. M. Tarascon, Nature, 2008, 451, 652-657.

5 Z. Guo, S. Zhao, T. Li, D. Su, S. Guo and G. Wang, Adv. Energy Mater., 2020, 10, 1903591.

6 D. Chen, M. Lu, D. Cai, H. Yang and W. Han, J. Energy Chem., 2021, 54, 712-726.

7 W. Zhang, J. Yin, W. Wang, Z. Bayhan and H. N. Alshareef, Nano Energy, 2021, 83, DOI: 10.1016/j.nanoen.2021.105792.

8 K. Zhang, K. O. Kirlikovali, J. M. Suh, J.-W. Choi, H. W. Jang, R. S. Varma, O. K. Farha and M. Shokouhimehr, ACS Appl. Energy Mater., 2020, 3, 6019-6035.

9 N. Wu, W. Yao, X. Song, G. Zhang, B. Chen, J. Yang and Y. Tang, Adv. Energy Mater., 2019, 9, 1803865.

10 R. Nagaraj, S. Pakhira, K. Aruchamy, P. Yadav, D. Mondal, K. Dharmalingm, N. Sanna Kotrappanavar and D. Ghosh, ACS Appl. Energy Mater., 2020, 3, 3425-3434.

11 J.-Y. Hwang, S.-T. Myung and Y.-K. Sun, Chem. Soc. Rev., 2017, 46, 3529-3614.

12 Z. Dai, U. Mani, H. T. Tan and Q. Yan, Small Methods, 2017, 1, 1700098.

13 N. Yabuuchi, K. Kubota, M. Dahbi and S. Komaba, Chem. Rev., 2014, 114, 11636-11682.

14 Y. Zhang, X. Xia, B. Liu, S. Deng, D. Xie, Q. Liu, Y. Wang, J. Wu, X. Wang and J. Tu, Adv. Energy Mater., 2019, 9, 1803342.

15 L. Yu, L. P. Wang, H. Liao, J. Wang, Z. Feng, O. Lev, J. S. C. Loo, M. T. Sougrati and Z. J. Xu, Small, 2018, 14, 1703338.

16 A. Eftekhari and D.-W. Kim, J. Power Sources, 2018, 395, 336-348.

17 A. Eguia-Barrio, E. Castillo-Martínez, F. Klein, R. Pinedo, L. Lezama, J. Janek, P. Adelhelm and T. Rojo, J. Power Sources, 2017, 367, 130-137.

18 J.-H. Kim and D. K. Kim, J. Korean Ceram. Soc., 2018, 55, 307-324.

19 C. Wang, Y. Xu, Y. Fang, M. Zhou, L. Liang, S. Singh, H. Zhao, A. Schober and Y. Lei, J. Am. Chem. Soc., 2015, 137, 3124-3130.

20 A. Sabir, T. Zia, M. Usman, M. Shafiq, R. U. Khan and K. I. Jacob, Self-standing Substrates, 2020, ch. 12, pp. 353-368, DOI: 10.1007/978-3-030-29522-6_12.

21 M. Chen, C. Yang, Z. Xu, Y. Tang, J. Jiang, P. Liu, Y. Su and D. Wu, RSC Adv., 2016, 6, 13666-13669.

22 Q. Ni, Y. Bai, F. Wu and C. Wu, Adv. Sci., 2017, 4, 1600275.

23 C. Yang, S. Xin, L. Mai and Y. You, Adv. Energy Mater., 2020, 11, 2000974.

24 Z. Hu, Q. Liu, S.-L. Chou and S.-X. Dou, Adv. Mater., 2017, 29, 1700606.

25 R. Mukherjee, R. Krishnan, T.-M. Lu and N. Koratkar, Nano Energy, 2012, 1, 518-533.

26 C. Cai and Y. Wang, Materials, 2009, 2, 1205-1238.

27 P. Roy and S. K. Srivastava, J. Mater. Chem. A, 2015, 3, 2454-2484.

28 R. Puttaswamy, R. Nagaraj, P. Kulkarni, H. K. Beere, S. N. Upadhyay, R. G. Balakrishna, N. Sanna Kotrappanavar, S. Pakhira and D. Ghosh, ACS Sustainable Chem. Eng., 2021, 9, 3985-3995. 
29 J. Xie, L. Liu, J. Xia, Y. Zhang, M. Li, Y. Ouyang, S. Nie and X. Wang, Nano-Micro Lett., 2017, 10, 1-12.

30 Y. Fang, X.-Y. Yu and X. W. Lou, Matter, 2019, 1, 90-114.

31 W. Wang, W. Li, S. Wang, Z. Miao, H. K. Liu and S. Chou, J. Mater. Chem. A, 2018, 6, 6183-6205.

32 Y. Wang, Y. Liu, Y. Liu, Q. Shen, C. Chen, F. Qiu, P. Li, L. Jiao and X. Qu, J. Energy Chem., 2021, 54, 225-241.

33 X. Zhang, J. Zhou, C. Liu, X. Chen and H. Song, J. Mater. Chem. A, 2016, 4, 8837-8843.

34 Y. Lu, N. Zhang, S. Jiang, Y. Zhang, M. Zhou, Z. Tao, L. A. Archer and J. Chen, Nano Lett., 2017, 17, 3668-3674.

35 X. Chang, X. Zhou, X. Ou, C. S. Lee, J. Zhou and Y. Tang, Adv. Energy Mater., 2019, 9, 1902672.

36 B. Wang, T. Ruan, Y. Chen, F. Jin, L. Peng, Y. Zhou, D. Wang and S. Dou, Energy Storage Mater., 2020, 24, 22-51.

37 Y. Zhao, L. P. Wang, M. T. Sougrati, Z. Feng, Y. Leconte, A. Fisher, M. Srinivasan and Z. Xu, Adv. Energy Mater., 2017, 7, 1601424.

38 L. Ji, W. Zhou, V. Chabot, A. Yu and X. Xiao, ACS Appl. Mater. Interfaces, 2015, 7, 24895-24901.

39 T. Jin, Q. Han and L. Jiao, Adv. Mater., 2019, 32, 1806304.

40 L. N. Zhao, T. Zhang, H. L. Zhao and Y. L. Hou, Mater. Today Nano, 2020, 10, 100072.

41 T. Jin, H. Li, K. Zhu, P.-F. Wang, P. Liu and L. Jiao, Chem. Soc. Rev., 2020, 49, 2342-2377.

42 M. Tang, H. Li, E. Wang and C. Wang, Chin. Chem. Lett., 2018, 29, 232-244.

43 H. Wang, C.-J. Yao, H.-J. Nie, K.-Z. Wang, Y.-W. Zhong, P. Chen, S. Mei and Q. Zhang, J. Mater. Chem. A, 2020, 8, 11906-11922.

44 K. Amin, L. Mao and Z. Wei, Macromol. Rapid Commun., 2019, 40, 1800565.

45 M. Luo, H. Yu, F. Hu, T. Liu, X. Cheng, R. Zheng, Y. Bai, M. Shui and J. Shu, Chem. Eng. J., 2020, 380, 122557.

46 R. Zhao, Z. Liang, R. Zou and Q. Xu, Joule, 2018, 2, 2235-2259.

47 H. B. Wu and X. W. Lou, Sci. Adv., 2017, 3, eaap9252.

48 T. Chen, X. Liu, L. Niu, Y. Gong, C. Li, S. Xu and L. Pan, Inorg. Chem. Front., 2020, 7, 567-582.

49 S. Qi, B. Xu, V. T. Tiong, J. Hu and J. Ma, Chem. Eng. J., 2020, 379, 122261.

50 Y. Fang, J. Zhang, L. Xiao, X. Ai, Y. Cao and H. Yang, Adv. Sci., 2017, 4, 1600392.

51 A. Beda, C. Villevieille, P.-L. Taberna, P. Simon and C. Matei Ghimbeu, J. Mater. Chem. A, 2020, 8, 5558-5571.

52 E. Irisarri, A. Ponrouch and M. R. Palacin, J. Electrochem. Soc., 2015, 162, A2476-A2482.

53 H.-G. Wang, W. Li, D.-P. Liu, X.-L. Feng, J. Wang, X.-Y. Yang, X.-b. Zhang, Y. Zhu and Y. Zhang, Adv. Mater., 2017, 29, 1703012.

54 Y. Liang, W.-H. Lai, Z. Miao and S.-L. Chou, Small, 2018, 14, 1702514.

55 K. C. Wasalathilake, H. Li, L. Xu and C. Yan, J. Energy Chem., 2020, 42, 91-107.

56 H. Ming, H. Zhou, X. Zhu, S. Zhang, P. Zhao, M. Li, L. Wang and J. Ming, Energy Technol., 2018, 6, 766-772.
57 Y. Zhao, F. Wang, C. Wang, S. Wang, C. Wang, Z. Zhao, L. Duan, Y. Liu, Y. Wu, W. Li and D. Zhao, Nano Energy, 2019, 56, 426-433.

58 L. Wang, Z. Wei, M. Mao, H. Wang, Y. Li and J. Ma, Energy Storage Mater., 2019, 16, 434-454.

59 G. D. Moon, Nanomaterials, 2020, 10, 675.

60 Y. Zhang, C. Wang, H. Hou, G. Zou and X. Ji, Adv. Energy Mater., 2017, 7, 1600173.

61 S. Qiu, L. Xiao, X. Ai, H. Yang and Y. Cao, ACS Appl. Mater. Interfaces, 2016, 9, 345-353.

62 S. Li, Z. Wang, J. Liu, L. Yang, Y. Guo, L. Cheng, M. Lei and W. Wang, ACS Appl. Mater. Interfaces, 2016, 8, 19438-19445.

63 Q. Chen, S. Sun, T. Zhai, M. Yang, X. Zhao and H. Xia, Adv. Energy Mater., 2018, 8, 1800054.

64 Y. Wu, J. Meng, Q. Li, C. Niu, X. Wang, W. Yang, W. Li and L. Mai, Nano Res., 2017, 10, 2364-2376.

65 B. Chen, H. Qin, K. Li, B. Zhang, E. Liu, N. Zhao, C. Shi and C. He, Nano Energy, 2019, 66, 104133.

66 Z. Zhang, Y. Huang, X. Liu, X. Wang and P. Liu, Electrochim. Acta, 2020, 342, 136104.

67 Y. Zhao, Q. Fu, D. Wang, Q. Pang, Y. Gao, A. Missiul, R. Nemausat, A. Sarapulova, H. Ehrenberg, Y. Wei and G. Chen, Energy Storage Mater., 2019, 18, 51-58.

68 M. Chen, Z. Zhang, L. Si, R. Wang and J. Cai, ACS Appl. Mater. Interfaces, 2019, 11, 35050-35059.

69 Z. Liu, T. Lu, T. Song, X.-Y. Yu, X. W. Lou and U. Paik, Energy Environ. Sci., 2017, 10, 1576-1580.

70 Y.-X. Wang, J. Yang, S.-L. Chou, H. K. Liu, W.-x. Zhang, D. Zhao and S. X. Dou, Nat. Commun., 2015, 6, 8689.

71 H. Kong, Y. Wu, W. Hong, C. Yan, Y. Zhao and G. Chen, Energy Storage Mater., 2020, 24, 610-617.

72 S. H. Choi, Y. N. Ko, J.-K. Lee and Y. C. Kang, Adv. Funct. Mater., 2015, 25, 1780-1788.

73 E. Pan, Y. Jin, C. Zhao, M. Jia, Q. Chang, M. Jia, L. Wang and X. He, ACS Appl. Energy Mater., 2019, 2, 1756-1764.

74 Z. Kong, X. Liu, T. Wang, A. Fu, Y. Li, P. Guo, Y.-G. Guo, H. Li and X. S. Zhao, Appl. Surf. Sci., 2019, 479, 198-208.

75 Y. Wang, D. Kong, S. Huang, Y. Shi, M. Ding, Y. Von Lim, T. Xu, F. Chen, X. Li and H. Y. Yang, J. Mater. Chem. A, 2018, 6, 10813-10824.

76 X. Xie, T. Makaryan, M. Zhao, K. L. Van Aken, Y. Gogotsi and G. Wang, Adv. Energy Mater., 2016, 6, 1502161.

77 D. Zhang, L. Liu, T. Aihaiti, X. Xu and S. Ding, ChemistrySelect, 2017, 2, 5283-5287.

78 D. Sun, X. Zhu, B. Luo, Y. Zhang, Y. Tang, H. Wang and L. Wang, Adv. Energy Mater., 2018, 8, 1801197.

79 X. Lin, X. Cui, H. Yan, J. Lei, P. Xu, J. Fan, R. Yuan, M. Zheng and Q. Dong, ACS Sustainable Chem. Eng., 2019, 7, 15729-15738.

80 L. Yang, Y.-E. Zhu, J. Sheng, F. Li, B. Tang, Y. Zhang and Z. Zhou, Small, 2017, 13, 1702588.

81 M. Liu, P. Zhang, Z. Qu, Y. Yan, C. Lai, T. Liu and S. Zhang, Nat. Commun., 2019, 10, 3917.

82 S. Chen, Y. Pang, J. Liang and S. Ding, J. Mater. Chem. A, 2018, 6, 13164-13170. 
83 C. Chen, Y. Yang, X. Tang, R. Qiu, S. Wang, G. Cao and M. Zhang, Small, 2019, 15, 1804740.

84 P. Senguttuvan, G. Rousse, V. Seznec, J.-M. Tarascon and M. R. Palacín, Chem. Mater., 2011, 23, 4109-4111.

85 Y. Chen, X. Hu, B. Evanko, X. Sun, X. Li, T. Hou, S. Cai, C. Zheng, W. Hu and G. D. Stucky, Nano Energy, 2018, 46, 117-127.

86 S. Tan, Y. Jiang, Q. Wei, Q. Huang, Y. Dai, F. Xiong, Q. Li, Q. An, X. Xu, Z. Zhu, X. Bai and L. Mai, Adv. Mater., 2018, 30, 1707122.

87 P. Ge, S. Li, L. Xu, K. Zou, X. Gao, X. Cao, G. Zou, H. Hou and X. Ji, Adv. Energy Mater., 2019, 9, 1803035.

88 Z. Wei, L. Wang, M. Zhuo, W. Ni, H. Wang and J. Ma, J. Mater. Chem. A, 2018, 6, 12185-12214.

89 X. Ou, C. Yang, X. Xiong, F. Zheng, Q. Pan, C. Jin, M. Liu and K. Huang, Adv. Funct. Mater., 2017, 27, 1606242.

90 Y. Huang, Z. Wang, Y. Jiang, S. Li, Z. Li, H. Zhang, F. Wu, M. Xie, L. Li and R. Chen, Nano Energy, 2018, 53, 524-535.

91 X. Wang, D. Kong, Z. X. Huang, Y. Wang and H. Y. Yang, Small, 2017, 13, 1603980.

92 Z. Zhang, Y. Fu, X. Yang, Y. Qu and Z. Zhang, ChemNanoMat, 2015, 1, 409-414.

93 X. Wang, H.-M. Kim, Y. Xiao and Y.-K. Sun, J. Mater. Chem. A, 2016, 4, 14915-14931.

94 Q. Xia, W. Li, Z. Miao, S. Chou and H. Liu, Nano Res., 2017, 10, 4055-4081.

95 W. Zhang, M. Dahbi, S. Amagasa, Y. Yamada and S. Komaba, Electrochem. Commun., 2016, 69, 11-14.

96 L. Liu, Q. Li, Z. Wang, J. Yan and Y. Chen, Funct. Mater. Lett., 2018, 11, 1830001.

97 M. Walter, M. I. Bodnarchuk, K. V. Kravchyk and M. V. Kovalenko, Chimia, 2015, 69, 724-728.

98 Q. Li, Z. Li, Z. Zhang, C. Li, J. Ma, C. Wang, X. Ge, S. Dong and L. Yin, Adv. Energy Mater., 2016, 6, 1600376.

99 Y. Xu, B. Peng and F. M. Mulder, Adv. Energy Mater., 2018, 8, 1701847.

100 C. Chen, H. Xu, T. Zhou, Z. Guo, L. Chen, M. Yan, L. Mai, P. Hu, S. Cheng, Y. Huang and J. Xie, Adv. Energy Mater., 2016, 6, 1600322.

101 L. Wang, X. Bi and S. Yang, Adv. Mater., 2016, 28, 7672-7679.

102 B. Luo, Y. Hu, X. Zhu, T. Qiu, L. Zhi, M. Xiao, H. Zhang, M. Zou, A. Cao and L. Wang, J. Mater. Chem. A, 2018, 6, 1462-1472.

103 B. Qu, C. Ma, G. Ji, C. Xu, J. Xu, Y. S. Meng, T. Wang and J. Y. Lee, Adv. Mater., 2014, 26, 3854-3859.

104 Y. Liu, H. Kang, L. Jiao, C. Chen, K. Cao, Y. Wang and H. Yuan, Nanoscale, 2015, 7, 1325-1332.

105 C. Masquelier and L. Croguennec, Chem. Rev., 2013, 113, 6552-6591.

106 B. Senthilkumar, C. Murugesan, L. Sharma, S. Lochab and P. Barpanda, Small Methods, 2018, 3, 1800253.

107 P. Rangaswamy, G. S. Suresh and M. K. Mahadevan, ChemistrySelect, 2016, 1, 1472-1483.

108 R. Puttaswamy, G. S. Suresh, K. M. Mahadevan and Y. Arthoba Nayaka, ChemistrySelect, 2018, 3, 3056-3069.

109 J.-c. Zheng, Y.-d. Han, B. Zhang, C. Shen, L. Ming and J.-f. Zhang, ACS Appl. Mater. Interfaces, 2014, 6, 13520-13526.
110 Y. Fang, L. Xiao, J. Qian, Y. Cao, X. Ai, Y. Huang and H. Yang, Adv. Energy Mater., 2016, 6, 1502197.

111 B. Zhao, B. Lin, S. Zhang and C. Deng, Nanoscale, 2015, 7, 18552-18560.

112 P. Lei, K. Liu, X. Wan, D. Luo and X. Xiang, Chem. Commun., 2019, 55, 509-512.

113 Y. Liu, N. Zhang, F. Wang, X. Liu, L. Jiao and L.-Z. Fan, Adv. Funct. Mater., 2018, 28, 1801917.

114 X. Ma, Z. Pan, X. Wu and P. K. Shen, Chem. Eng. J., 2019, 365, 132-141.

115 Y. Xu, Q. Wei, C. Xu, Q. Li, Q. An, P. Zhang, J. Sheng, L. Zhou and L. Mai, Adv. Energy Mater., 2016, 6, 1600389.

116 X. Rui, W. Sun, C. Wu, Y. Yu and Q. Yan, Adv. Mater., 2015, 27, 6670-6676.

117 L. Ke, J. Dong, B. Lin, T. Yu, H. Wang, S. Zhang and C. Deng, Nanoscale, 2017, 9, 4183-4190.

118 G. Yang, B. Ding, J. Wang, P. Nie, H. Dou and X. Zhang, Nanoscale, 2016, 8, 8495-8499.

119 Y. Liu, S. Xu, S. Zhang, J. Zhang, J. Fan and Y. Zhou, J. Mater. Chem. A, 2015, 3, 5501-5508.

120 W. Wang, X. Liu, Q. Xu, H. Liu, Y.-G. Wang, Y. Xia, Y. Cao and X. Ai, J. Mater. Chem. A, 2018, 6, 4354-4364.

121 Y. Liu, R. Rajagopalan, E. Wang, M. Chen, W. Hua, B. Zhong, Y. Zhong, Z. Wu and X. Guo, ACS Sustainable Chem. Eng., 2018, 6, 16105-16112.

122 Y. Meng, Q. Li, T. Yu, S. Zhang and C. Deng, CrystEngComm, 2016, 18, 1645-1654.

123 M. Chen, D. Cortie, Z. Hu, H. Jin, S. Wang, Q. Gu, W. Hua, E. Wang, W. Lai, L. Chen, S.-L. Chou, X.-L. Wang and S.-X. Dou, Adv. Energy Mater., 2018, 8, 1800944.

124 S. Li, X. Song, X. Kuai, W. Zhu, K. Tian, X. Li, M. Chen, S. Chou, J. Zhao and L. Gao, J. Mater. Chem. A, 2019, 7, 14656-14669.

125 T. Yu, B. Lin, Q. Li, X. Wang, W. Qu, S. Zhang and C. Deng, Phys. Chem. Chem. Phys., 2016, 18, 26933-26941.

126 J. Sun, H.-W. Lee, M. Pasta, H. Yuan, G. Zheng, Y. Sun, Y. Li and Y. Cui, Nat. Nanotechnol., 2015, 10, 980-985.

127 J. H. Choi, S.-K. Park and Y. C. Kang, Small, 2019, 15, 1803043.

128 G. Li, D. Luo, X. Wang, M. H. Seo, S. Hemmati, A. Yu and Z. Chen, Adv. Funct. Mater., 2017, 27, 1702562.

129 Y. Li, Y. Liang, F. C. Robles Hernandez, H. Deog Yoo, Q. An and Y. Yao, Nano Energy, 2015, 15, 453-461.

130 X. Xie, Z. Ao, D. Su, J. Zhang and G. Wang, Adv. Funct. Mater., 2015, 25, 1393-1403.

131 G. Wang, X. Bi, H. Yue, R. Jin, Q. Wang, S. Gao and J. Lu, Nano Energy, 2019, 60, 362-370.

132 Y. Wang, K. Wang, C. Zhang, J. Zhu, J. Xu and T. Liu, Small, 2019, 15, 1903816.

133 P. Li, J. Y. Jeong, B. Jin, K. Zhang and J. H. Park, Adv. Energy Mater., 2018, 8, 1703300.

134 J. K. Kim, S.-K. Park, J.-S. Park and Y. C. Kang, J. Mater. Chem. A, 2019, 7, 2636-2645.

135 Y. Pang, S. Zhang, L. Liu, J. Liang, Z. Sun, Y. Wang, C. Xiao, D. Ding and S. Ding, J. Mater. Chem. A, 2017, 5, 17963-17972.

136 M. Lin, M. Deng, C. Zhou, Y. Shu, L. Yang, L. Ouyang, Q. Gao and M. Zhu, Electrochim. Acta, 2019, 309, 25-33. 
137 Y. Zhang, P. Zhu, L. Huang, J. Xie, S. Zhang, G. Cao and X. Zhao, Adv. Funct. Mater., 2015, 25, 481-489.

138 J. K. Kim, K. E. Lim, W. J. Hwang, Y. C. Kang and S. K. Park, ChemSusChem, 2019, 13, 1546-1555.

139 Z. Li, J. Ding, H. Wang, K. Cui, T. Stephenson, D. Karpuzov and D. Mitlin, Nano Energy, 2015, 15, 369-378.

140 H. Gao, T. Zhou, Y. Zheng, Y. Liu, J. Chen, H. Liu and Z. Guo, Adv. Energy Mater., 2016, 6, 1601037.

141 J. Zhou, Z. Jiang, S. Niu, S. Zhu, J. Zhou, Y. Zhu, J. Liang, D. Han, K. Xu, L. Zhu, X. Liu, G. Wang and Y. Qian, Chem, 2018, 4, 372-385.

142 C. Zhang, X. Wang, Q. Liang, X. Liu, Q. Weng, J. Liu, Y. Yang, Z. Dai, K. Ding, Y. Bando, J. Tang and D. Golberg, Nano Lett., 2016, 16, 2054-2060.

143 Y. Liu, A. Zhang, C. Shen, Q. Liu, X. Cao, Y. Ma, L. Chen, C. Lau, T.-C. Chen, F. Wei and C. Zhou, ACS Nano, 2017, 11, 5530-5537.

144 X. Liang, C. Chang, W. Guo, X. Jiang, C. Xiong and X. Pu, ChemElectroChem, 2019, 6, 5721-5727.

145 S. Hao, H. Li, Z. Zhao and X. Wang, ChemElectroChem, 2019, 6, 5712-5720.

146 X. Xie, M.-Q. Zhao, B. Anasori, K. Maleski, C. E. Ren, J. Li, B. W. Byles, E. Pomerantseva, G. Wang and Y. Gogotsi, Nano Energy, 2016, 26, 513-523.

147 Y. Ding, P. Zeng and Z. Fang, J. Power Sources, 2020, 450, 227688.

148 X. Liu, M. Gao, H. Yang, X. Zhong and Y. Yu, Nano Res., 2017, 10, 4360-4367.

149 S. H. Choi and Y. C. Kang, Nanoscale, 2015, 7, 3965-3970.

150 G. D. Park and Y. C. Kang, Chem. - Eur. J., 2016, 22, 4140-4146.

151 C. Wu, P. Kopold, Y.-L. Ding, P. A. van Aken, J. Maier and Y. Yu, ACS Nano, 2015, 9, 6610-6618.

152 S. Liu, Z. Luo, J. Guo, A. Pan, Z. Cai and S. Liang, Electrochem. Commun., 2017, 81, 10-13.

153 Z. Li, J. Zhang, Y. Lu and X. W. Lou, Sci. Adv., 2018, 4, eaat1687.

154 D. Li, J. Zhou, X. Chen and H. Song, ACS Appl. Mater. Interfaces, 2016, 8, 30899-30907.

155 Y. Zhang, L. Fan, P. Wang, Y. Yin, X. Zhang, N. Zhang and K. Sun, Nanoscale, 2017, 9, 17694-17698.

156 Y. Ding, W. Wang, M. Bi, J. Guo and Z. Fang, Electrochim. Acta, 2019, 313, 331-340.

157 Q. Guo, Y. Ma, T. Chen, Q. Xia, M. Yang, H. Xia and Y. Yu, ACS Nano, 2017, 11, 12658-12667.

158 M. Wang, Z. Yang, J. Wang, W. Li, L. Gu and Y. Yu, Small, 2015, 11, 5381-5387.

159 Z. Tong, S. Liu, Y. Zhou, J. Zhao, Y. Wu, Y. Wang and Y. Li, Energy Storage Mater., 2018, 13, 223-232.

160 P. Sennu, N. Arun, S. Madhavi, V. Aravindan and Y.-S. Lee, J. Power Sources, 2019, 414, 96-102.

161 Y. Zhong, X. Xia, S. Deng, J. Zhan, R. Fang, Y. Xia, X. Wang, Q. Zhang and J. Tu, Adv. Energy Mater., 2018, 8, 1701110.

162 L. Zeng, B. Kang, F. Luo, Y. Fang, C. Zheng, J. Liu, R. Liu, X. Li, Q. Chen, M. Wei and Q. Qian, Chem. - Eur. J., 2019, 25, 13411-13421.
163 J. Li, L. Wang, L. Li, C. Lv, I. V. Zatovsky and W. Han, ACS Appl. Mater. Interfaces, 2019, 11, 8072-8080.

164 R. Guo, D. Li, C. Lv, Y. Wang, H. Zhang, Y. Xia, D. Yang and X. Zhao, Electrochim. Acta, 2019, 299, 72-79.

165 D. Li, D. Yang, X. Yang, Y. Wang, Z. Guo, Y. Xia, S. Sun and S. Guo, Angew. Chem., Int. Ed., 2016, 55, 15925-15928.

166 D. Xie, X.-h. Xia, W.-j. Tang, Y. Zhong, Y.-d. Wang, D.h. Wang, X.-l. Wang and J.-p. Tu, J. Mater. Chem. A, 2017, 5, $7578-7585$.

167 Y. Zhang, C. Lv, X. Wang, S. Chen, D. Li, Z. Peng and D. Yang, ACS Appl. Mater. Interfaces, 2018, 10, 40531-40539.

168 H. Liu, C. Lv, S. Chen, X. Song, B. Liu, J. Sun, H. Zhang, D. Yang, X. She and X. Zhao, J. Alloys Compd., 2019, 795, 54-59.

169 D. Li, Y. Sun, S. Chen, J. Yao, Y. Zhang, Y. Xia and D. Yang, ACS Appl. Mater. Interfaces, 2018, 10, 17175-17182.

170 K. Chen, G. Li, Y. Wang, W. Chen and L. Mi, Green Energy Environ., 2020, 5, 50-58.

171 Q. Li, B. Lin, S. Zhang and C. Deng, J. Mater. Chem. A, 2016, 4, 5719-5729.

172 L. Cao, X. Gao, B. Zhang, X. Ou, J. Zhang and W.-B. Luo, ACS Nano, 2020, 14, 3610-3620.

173 Y. Huang, Z. Wang, Y. Jiang, S. Li, M. Wang, Y. Ye, F. Wu, M. Xie, L. Li and R. Chen, Adv. Sci., 2018, 5, 1800613.

174 Y. Zhang, P. Wang, Y. Yin, X. Zhang, L. Fan, N. Zhang and K. Sun, Chem. Eng. J., 2019, 356, 1042-1051.

175 Y. Fang, D. Luan, Y. Chen, S. Gao and X. W. Lou, Angew. Chem., Int. Ed., 2020, 59, 7178-7183.

176 Y. Lin, Z. Qiu, D. Li, S. Ullah, Y. Hai, H. Xin, W. Liao, B. Yang, H. Fan, J. Xu and C. Zhu, Energy Storage Mater., 2018, 11, 67-74.

177 G. Fang, Z. Wu, J. Zhou, C. Zhu, X. Cao, T. Lin, Y. Chen, C. Wang, A. Pan and S. Liang, Adv. Energy Mater., 2018, 8, 1703155.

178 L. Huang, X. Cao, A. Pan, J. Chen, X. Kong, Y. Yang, S. Liang and G. Cao, Sci. China Mater., 2019, 62, 1857-1867.

179 K. Zhu, X. Wang, J. Liu, S. Li, H. Wang, L. Yang, S. Liu and T. Xie, ACS Sustainable Chem. Eng., 2017, 5, 8025-8034.

180 Y. Su, Y. Liu, P. Liu, D. Wu, X. Zhuang, F. Zhang and X. Feng, Angew. Chem., Int. Ed., 2015, 54, 1812-1816.

181 T. Sun, Z.-j. Li, H.-g. Wang, D. Bao, F.-l. Meng and X.-b. Zhang, Angew. Chem., Int. Ed., 2016, 55, 10662-10666.

182 K. A. See, S. Hug, K. Schwinghammer, M. A. Lumley, Y. Zheng, J. M. Nolt, G. D. Stucky, F. Wudl, B. V. Lotsch and R. Seshadri, Chem. Mater., 2015, 27, 3821-3829.

183 S. Sun, Y. Chen and J. Yu, J. Phys. Chem. C, 2015, 119, 25770-25777.

184 K. Hernández-Burgos, S. E. Burkhardt, G. G. RodríguezCalero, R. G. Hennig and H. D. Abruña, J. Phys. Chem. C, 2014, 118, 6046-6051.

185 Y. Sun, Y. Sun, Q. Pan, G. Li, B. Han, D. Zeng, Y. Zhang and H. Cheng, Chem. Commun., 2016, 52, 3000-3002.

186 T. Ma, Q. Zhao, J. Wang, Z. Pan and J. Chen, Angew. Chem., 2016, 128, 6538-6542.

187 G. Yang, Y. Zhang, Y. Huang, M. I. Shakir and Y. Xu, Phys. Chem. Chem. Phys., 2016, 18, 31361-31377. 
188 S. Lee, G. Kwon, K. Ku, K. Yoon, S.-K. Jung, H.-D. Lim and K. Kang, Adv. Mater., 2018, 30, 1704682.

189 M. Lee, J. Hong, H. Kim, H.-D. Lim, S. B. Cho, K. Kang and C. B. Park, Adv. Mater., 2014, 26, 2558-2565.

190 A. Wild, M. Strumpf, B. Häupler, M. D. Hager and U. S. Schubert, Adv. Energy Mater., 2017, 7, 1601415.

191 W. Ai, W. Zhou, Z. Du, C. Sun, J. Yang, Y. Chen, Z. Sun, S. Feng, J. Zhao, X. Dong, W. Huang and T. Yu, Adv. Funct. Mater., 2017, 27, 1603603.

192 T. Suga, H. Konishi and H. Nishide, Chem. Commun., 2007, 17, 1730-1732.

193 J.-K. Kim, Y. Kim, S. Park, H. Ko and Y. Kim, Energy Environ. Sci., 2016, 9, 1264-1269.

194 Y. Zhang, J. Wang and S. N. Riduan, J. Mater. Chem. A, 2016, 4, 14902-14914.

195 C. Wang, C. Jiang, Y. Xu, L. Liang, M. Zhou, J. Jiang, S. Singh, H. Zhao, A. Schober and Y. Lei, Adv. Mater., 2016, 28, 9182-9187.

196 D. Wu, Y. Huang and X. Hu, Chem. Commun., 2016, 52, 11207-11210.

197 Y. Morita, S. Nishida, T. Murata, M. Moriguchi, A. Ueda, M. Satoh, K. Arifuku, K. Sato and T. Takui, Nat. Mater., 2011, 10, 947-951.

198 Z. Zhu, M. Hong, D. Guo, J. Shi, Z. Tao and J. Chen, J. Am. Chem. Soc., 2014, 136, 16461-16464.

199 D. Chen, A.-J. Avestro, Z. Chen, J. Sun, S. Wang, M. Xiao, Z. Erno, M. M. Algaradah, M. S. Nassar, K. Amine, Y. Meng and J. F. Stoddart, Adv. Mater., 2015, 27, 2907-2912.

200 Y. Ishii, K. Tashiro, K. Hosoe, A. Al-zubaidi and S. Kawasaki, Phys. Chem. Chem. Phys., 2016, 18, 10411-10418.

201 Y. Xu, M. Zhou and Y. Lei, Mater. Today, 2018, 21, 60-78.

202 Z. Zhu and J. Chen, J. Electrochem. Soc., 2015, 162, A2393-A2405.

203 J. Wang, K. Tee, Y. Lee, S. N. Riduan and Y. Zhang, J. Mater. Chem. A, 2018, 6, 2752-2757.

204 Y. Lu, Q. Zhao, L. Miao, Z. Tao, Z. Niu and J. Chen, J. Phys. Chem. C, 2017, 121, 14498-14506.

205 Y. Lu, Q. Zhang, L. Li, Z. Niu and J. Chen, Chem, 2018, 4, 2786-2813.

206 B. Häupler, A. Wild and U. S. Schubert, Adv. Energy Mater., 2015, 5, 1402034.

207 Q. Zhao, Y. Lu and J. Chen, Adv. Energy Mater., 2017, 7, 1601792.

208 C. Yuan, Q. Wu, Q. Li, Q. Duan, Y. Li and H.-g. Wang, ACS Sustainable Chem. Eng., 2018, 6, 8392-8399.

209 G. Zhou, L. Mo, C. Zhou, Y. Wu, F. Lai, Y. Lv, J. Ma, Y.-E. Miao and T. Liu, Chem. Eng. J., 2021, 420, 127597.

210 C. Yuan, Q. Wu, Q. Shao, Q. Li, B. Gao, Q. Duan and H.-g. Wang, J. Colloid Interface Sci., 2018, 517, 72-79.

211 A. Li, Z. Feng, Y. Sun, L. Shang and L. Xu, J. Power Sources, 2017, 343, 424-430.

212 Y. Liang, P. Zhang, S. Yang, Z. Tao and J. Chen, Adv. Energy Mater., 2013, 3, 600-605.

213 B. Häupler, T. Hagemann, C. Friebe, A. Wild and U. S. Schubert, ACS Appl. Mater. Interfaces, 2015, 7, 3473-3479.

214 X. Chen, Y. Wu, Z. Huang, X. Yang, W. Li, L. C. Yu, R. Zeng, Y. Luo and S.-L. Chou, J. Mater. Chem. A, 2016, 4, 18409-18415.
215 C. Guo, K. Zhang, Q. Zhao, L. Pei and J. Chen, Chem. Commun., 2015, 51, 10244-10247.

216 S. Zheng, J. Hu and W. Huang, Inorg. Chem. Front., 2017, 4, 1806-1812.

217 T. Cao, W. Lv, S.-W. Zhang, J. Zhang, Q. Lin, X. Chen, Y. He, F.-Y. Kang and Q.-H. Yang, Chem. - Eur. J., 2017, 23, 16586-16592.

218 B. E. Gurkan, Z. Qiang, Y.-M. Chen, Y. Zhu and B. D. Vogt, J. Electrochem. Soc., 2017, 164, H5093-H5099.

219 L. Zhong, Y. Lu, H. Li, Z. Tao and J. Chen, ACS Sustainable Chem. Eng., 2018, 6, 7761-7768.

220 H. Wang, P. Hu, J. Yang, G. Gong, L. Guo and X. Chen, Adv. Mater., 2015, 27, 2348-2354.

221 Z. Song and H. Zhou, Energy Environ. Sci., 2013, 6, 2280-2301. 222 M. Armand, S. Grugeon, H. Vezin, S. Laruelle, P. Ribière, P. Poizot and J. M. Tarascon, Nat. Mater., 2009, 8, 120-125.

223 W. Deng, J. Qian, Y. Cao, X. Ai and H. Yang, Small, 2016, 12, 583-587.

224 C. Luo, Y. Zhu, Y. Xu, Y. Liu, T. Gao, J. Wang and C. Wang, J. Power Sources, 2014, 250, 372-378.

225 D. Wu, K. Luo, S. Du and X. Hu, J. Power Sources, 2018, 398, 99-105.

226 T. Liu, B. Lee, B. G. Kim, M. J. Lee, J. Park and S. W. Lee, Small, 2018, 14, 1801236.

227 T. Liu, K. C. Kim, B. Lee, Z. Chen, S. Noda, S. S. Jang and S. W. Lee, Energy Environ. Sci., 2017, 10, 205-215.

228 Y. Huang, K. Li, J. Liu, X. Zhong, X. Duan, I. Shakir and Y. Xu, J. Mater. Chem. A, 2017, 5, 2710-2716.

229 J. Manuel, X. Zhao, K.-K. Cho, J.-K. Kim and J.-H. Ahn, ACS Sustainable Chem. Eng., 2018, 6, 8159-8166.

230 K. Zhang, Y. Hu, L. Wang, M. J. Monteiro and Z. Jia, ACS Appl. Mater. Interfaces, 2017, 9, 34900-34908.

231 Y.-H. Wang, M.-K. Hung, C.-H. Lin, H.-C. Lin and J.-T. Lee, Chem. Commun., 2011, 47, 1249-1251.

232 X. Xu, H. Zeng, D. Han, K. Qiao, W. Xing, M. J. Rood and Z. Yan, ACS Appl. Mater. Interfaces, 2018, 10, 37172-37180.

233 Q. Deng, S. Feng, C. Tian, Y. Ding, R. Yang, Y. Yan and Y. Xu, J. Electroanal. Chem., 2018, 827, 145-150.

234 W. Xiong, W. Huang, M. Zhang, P. Hu, H. Cui and Q. Zhang, Chem. Mater., 2019, 31, 8069-8075.

235 N. Liu, Y. Liu, Y. Zhao, Y. Liu, Q. Lan, J. Qin, Z. Song and H. Zhan, ACS Appl. Mater. Interfaces, 2019, 11, 46726-46734.

236 Y. Chen, H. Li, M. Tang, S. Zhuo, Y. Wu, E. Wang, S. Wang, C. Wang and W. Hu, J. Mater. Chem. A, 2019, 7, 20891-20898.

237 L. Zhu, G. Ding, J. Liu, Z. Liu, L. Xie and X. Cao, Int. J. Energy Res., 2019, 1-11.

238 B. Yan, L. Wang, W. Huang, S. Zheng, P. Hu and Y. Du, Inorg. Chem. Front., 2019, 6, 1977-1985.

239 H. Ha, S. Nam, S.-H. Jeong and S. Hyun, J. Mech. Sci. Technol., 2019, 33, 3865-3870.

240 P.-Y. Zhao, B.-J. Yu, S. Sun, Y. Guo, Z.-Z. Chang, Q. Li and C.-Y. Wang, Electrochim. Acta, 2017, 232, 348-356.

241 Y. Wang, K. Kretschmer, J. Zhang, A. K. Mondal, X. Guo and G. Wang, RSC Adv., 2016, 6, 57098-57102.

242 D. Wu, G. Zhang, D. Lu, L. Ma, Z. Xu, X. Xi, R. Liu, P. Liu and Y. Su, J. Mater. Chem. A, 2018, 6, 13613-13618. 
243 Y. Huang, G. Jiang, J. Xiong, C. Yang, Q. Ai, H. Wu and S. Yuan, Appl. Surf. Sci., 2020, 499, 143849.

244 T. Huang, D. Lu, L. Ma, X. Xi, R. Liu and D. Wu, Chem. Eng. J., 2018, 349, 66-71.

245 Y. Li, Y. Xu, W. Yang, W. Shen, H. Xue and H. Pang, Small, 2018, 14, 1704435.

246 C. Janiak and J. K. Vieth, New J. Chem., 2010, 34, 2366-2388.

247 Y. Zhao, Z. Song, X. Li, Q. Sun, N. Cheng, S. Lawes and X. Sun, Energy Storage Mater., 2016, 2, 35-62.

248 G. Zou, H. Hou, P. Ge, Z. Huang, G. Zhao, D. Yin and X. Ji, Small, 2018, 14, 1702648.

249 Z. Liang, R. Zhao, T. Qiu, R. Zou and Q. Xu, EnergyChem, 2019, 1, 100001.

250 Y. Xue, S. Zheng, H. Xue and H. Pang, J. Mater. Chem. A, 2019, 7, 7301-7327.

251 H. Zhang, X. Liu, Y. Wu, C. Guan, A. K. Cheetham and J. Wang, Chem. Commun., 2018, 54, 5268-5288.

252 X. Xu, J. Liu, J. Liu, L. Ouyang, R. Hu, H. Wang, L. Yang and M. Zhu, Adv. Funct. Mater., 2018, 28, 1707573.

253 Y. Wang, C. Wang, Y. Wang, H. Liu and Z. Huang, J. Mater. Chem. A, 2016, 4, 5428-5435.

254 Y. Chen, X. Li, K. Park, W. Lu, C. Wang, W. Xue, F. Yang, J. Zhou, L. Suo, T. Lin, H. Huang, J. Li and J. B. Goodenough, Chem, 2017, 3, 152-163.

255 W. Shuang, H. Huang, L. Kong, M. Zhong, A. Li, D. Wang, Y. Xu and X.-H. Bu, Nano Energy, 2019, 62, 154-163.

256 S. Liu, D. Li, G. Zhang, D. Sun, J. Zhou and H. Song, ACS Appl. Mater. Interfaces, 2018, 10, 34193-34201.

257 M. Shao, Y. Cheng, T. Zhang, S. Li, W. Zhang, B. Zheng, J. Wu, W.-W. Xiong, F. Huo and J. Lu, ACS Appl. Mater. Interfaces, 2018, 10, 33097-33104.

258 A. Y. Kim, M. K. Kim, K. Cho, J.-Y. Woo, Y. Lee, S.-H. Han, D. Byun, W. Choi and J. K. Lee, ACS Appl. Mater. Interfaces, 2016, 8, 19514-19523.

259 R. Bi, C. Zeng, H. Huang, X. Wang and L. Zhang, J. Mater. Chem. A, 2018, 6, 14077-14082.

260 X. Liu, F. Zou, K. Liu, Z. Qiang, C. J. Taubert, P. Ustriyana, B. D. Vogt and Y. Zhu, J. Mater. Chem. A, 2017, 5, 11781-11787.

261 C. Li, Q. Hu, Y. Li, H. Zhou, Z. Lv, X. Yang, L. Liu and H. Guo, Sci. Rep., 2016, 6, 25556.

262 X. Hu, X. Liu, K. Chen, G. Wang and H. Wang, J. Mater. Chem. A, 2019, 7, 11016-11037.

263 W. Zhang, Z. Yue, Q. Wang, X. Zeng, C. Fu, Q. Li, X. Li, L. Fang and L. Li, Chem. Eng. J., 2020, 380, 122548.

264 W. Kang, Y. Zhang, L. Fan, L. Zhang, F. Dai, R. Wang and D. Sun, ACS Appl. Mater. Interfaces, 2017, 9, 10602-10609.

265 X. Yang, S. Wang, D. Y. W. Yu and A. L. Rogach, Nano Energy, 2019, 58, 392-398.

266 S.-K. Park, J. K. Kim and Y. C. Kang, Chem. Eng. J., 2017, 328, 546-555.

267 X. Wu, H. Zhao, J. Xu, Z. Zhang, W. Sheng, S. Dai, T. Xu, S. Zhang, X. Wang, Y. Wang and X. Li, Appl. Surf. Sci., 2019, 492, 504-512.

268 F. Zou, Y.-M. Chen, K. Liu, Z. Yu, W. Liang, S. M. Bhaway, M. Gao and Y. Zhu, ACS Nano, 2015, 10, 377-386.
269 L. Wang, Z. Han, Q. Zhao, X. Yao, Y. Zhu, X. Ma, S. Wu and C. Cao, J. Mater. Chem. A, 2020, 8, 8612-8619.

270 Y. Yao, J. Zheng, Z. Gong, Z. Ding, J. Zhang, W. Yu, D. A. M. Bengono, H. Li, B. Zhang and H. Tong, J. Alloys Compd., 2019, 790, 288-295.

271 Y. Zhang, Y. Wu, W. Zhong, F. Xiao, M. Kashif Aslam, X. Zhang and M. Xu, ChemSusChem, 2021, 14, 1336-1343.

272 D. Cao, W. Fan, W. Kang, Y. Wang, K. Sun, J. Zhao, Z. Xiao and D. Sun, Mater. Today Energy, 2019, 12, 53-61.

273 X. Liu, Y. Liu, M. Feng and L.-Z. Fan, J. Mater. Chem. A, 2018, 6, 23621-23627.

274 Z. Xu, Y. Huang, C. Chen, L. Ding, Y. Zhu, Z. Zhang and Z. Guang, Ceram. Int., 2020, 46, 4532-4542.

275 E. Pan, Y. Jin, C. Zhao, Q. Chang and M. Jia, Ionics, 2018, 24, 3281-3285.

276 A. Jin, M.-J. Kim, K.-S. Lee, S.-H. Yu and Y.-E. Sung, Nano Res., 2019, 12, 695-700.

277 R. Zhang, J. Xu, M. Jia, E. Pan, C. Zhou and M. Jia, J. Alloys Compd., 2019, 781, 450-459.

278 Y. Wang, W. Kang, D. Cao, M. Zhang, Z. Kang, Z. Xiao, R. Wang and D. Sun, J. Mater. Chem. A, 2018, 6, 4776-4782.

279 Y. Wang, Q. Deng, W. Xue, Z. Jian, R. Zhao and J. Wang, J. Mater. Sci., 2018, 53, 6785-6795.

280 S. Dong, C. Li, X. Ge, Z. Li, X. Miao and L. Yin, ACS Nano, 2017, 11, 6474-6482.

281 X. Xie, K. Huang, X. Wu, N. Wu, Y. Xu, S. Zhang and C. Zhang, Carbon, 2020, 169, 1-8.

282 K. Wang, W. Ye, W. Yin, W. Chai, Y. Rui and B. Tang, Electrochim. Acta, 2019, 322, 134790.

283 W. Ren, H. Zhang, C. Guan and C. Cheng, Adv. Funct. Mater., 2017, 27, 1702116.

284 Z. Zhang, Y. An, X. Xu, C. Dong, J. Feng, L. Ci and S. Xiong, Chem. Commun., 2016, 52, 12810-12812.

285 Z. Li, L. Zhang, X. Ge, C. Li, S. Dong, C. Wang and L. Yin, Nano Energy, 2017, 32, 494-502.

286 G. Zou, H. Hou, G. Zhao, P. Ge, D. Yin and X. Ji, J. Mater. Chem. A, 2018, 6, 4839-4847.

287 T. Xu, J. Zhao, L. Li, J. Mao, J. Xu and H. Zhao, New J. Chem., 2020, 44, 13141-13147.

288 S. Zhang, X. Li, B. Ding, H. Li, X. Liu and Q. Xu, J. Alloys Compd., 2020, 822, 153624.

289 Y. Huang, X. Zhu, D. Cai, Z. Cui, Q. Wang and H. Zhan, J. Energy Chem., 2021, 59, 473-481.

290 W. Li, S. Hu, X. Luo, Z. Li, X. Sun, M. Li, F. Liu and Y. Yu, Adv. Mater., 2017, 29, 1605820.

291 Y. V. Kaneti, J. Zhang, Y.-B. He, Z. Wang, S. Tanaka, M. S. A. Hossain, Z.-Z. Pan, B. Xiang, Q.-H. Yang and Y. Yamauchi, J. Mater. Chem. A, 2017, 5, 15356-15366.

292 Y. Cai, G. Fang, J. Zhou, S. Liu, Z. Luo, A. Pan, G. Cao and S. Liang, Nano Res., 2017, 11, 449-463.

293 S. H. Yang, S.-K. Park and Y. C. Kang, Chem. Eng. J., 2019, 370, 1008-1018.

294 S.-K. Park and Y. C. Kang, ACS Appl. Mater. Interfaces, 2018, 10, 17203-17213.

295 Y. Cai, H. Yang, J. Zhou, Z. Luo, G. Fang, S. Liu, A. Pan and S. Liang, Chem. Eng. J., 2017, 327, 522-529. 
296 Y. Von Lim, S. Huang, Q. Wu, Y. Zhang, D. Kong, Y. Wang, T. Xu, Y. Shi, Q. Ge, L. K. Ang and H. Y. Yang, Nano Energy, 2019, 61, 626-636.

297 L. Li, Q. Wang, X. Zhang, L. Fang, X. Li and W. Zhang, Appl. Surf. Sci., 2020, 508, 145295.

298 Y. Zhang, A. Pan, L. Ding, Z. Zhou, Y. Wang, S. Niu, S. Liang and G. Cao, ACS Appl. Mater. Interfaces, 2017, 9, 3624-3633.

299 C. Lu, Z. Li, Z. Xia, H. Ci, J. Cai, Y. Song, L. Yu, W. Yin, S. Dou, J. Sun and Z. Liu, Nano Res., 2019, 12, 3051-3058.

300 A. Y. Maulana, C. M. Futalan and J. Kim, J. Alloys Compd., 2020, 840, 155719.

301 C. Su, Q. Ru, S. Cheng, Y. Gao, F. Chen, L. Zhao and F. C.-C. Ling, Composites, Part B, 2019, 179, 107538.

302 L. Chen, L. Han, X. Liu, Y. Li and M. Wei, Chem. - Eur. J., 2020, 27, 2104-2111.

303 L. Kong, M. Zhong, Y. Liu, W. Xu and X.-H. Bu, J. Power Sources, 2018, 405, 37-44.

304 W. Huang, H. Sun, H. Shangguan, X. Cao, X. Xiao, F. Shen, K. Mølhave, L. Ci, P. Si and J. Zhang, Nanoscale, 2018, 10, 7851-7859.

305 F. Zhang, Y. Shen, M. Shao, Y. Zhang, B. Zheng, J. Wu, W. Zhang, A. Zhu, F. Huo and S. Li, ACS Appl. Mater. Interfaces, 2019, 12, 2346-2353.

306 X. Gao, X. Zhang, J. Jiang and J. Chen, Mater. Lett., 2018, 228, 42-45.

307 G. A. Snook, P. Kao and A. S. Best, J. Power Sources, 2011, 196, 1-12.

308 J. Liao, Q. Hu, J. Mu, F. Chen, X. He, F. Chen, Z. Wen and C. Chen, Chem. Commun., 2020, 56, 8392-8395.

309 D. Werner, C. Griesser, D. Stock, U. J. Griesser, J. KunzeLiebhäuser and E. Portenkirchner, ACS Appl. Energy Mater., 2020, 3, 3477-3487.

310 X. Liu, H. Ma, H. Xu, Z. Tan, Q. Liu, Y. Wang, H. Shu and D. Wang, J. Solid State Electrochem., 2019, 24, 81-91.

311 D. S. Kim, H. Yoo, M.-S. Park and H. Kim, J. Alloys Compd., 2019, 791, 385-390.

312 X. Wang, B. Wang, Y. Tang, B. B. Xu, C. Liang, M. Yan and Y. Jiang, J. Mater. Chem. A, 2020, 8, 3222-3227.

313 W. Ko, J.-K. Yoo, H. Park, Y. Lee, H. Kim, Y. Oh, S.-T. Myung and J. Kim, J. Power Sources, 2019, 432, 1-7.

314 Y. Lee, J.-K. Yoo, Y. Oh, H. Park, W. Go, S.-T. Myung and J. Kim, J. Mater. Chem. A, 2018, 6, 17571-17578.

315 K. Kaliyappan, Z. Bai and Z. Chen, J. Phys. Chem. C, 2019, 123, 11464-11475.

316 N. Wang, Z. Bai, Y. Qian and J. Yang, Adv. Mater., 2016, 28, 4126-4133.

317 N. Wang, Z. Bai, Y. Qian and J. Yang, ACS Appl. Mater. Interfaces, 2016, 9, 447-454.

318 Y.-L. Bai, X.-Y. Wu, Y.-S. Liu, C. Ma, X. Wei, K.-X. Wang and J.-S. Chen, J. Alloys Compd., 2020, 815, 152386.

319 J. Huang, R. Meng, L. Zu, Z. Wang, N. Feng, Z. Yang, Y. Yu and J. Yang, Nano Energy, 2018, 46, 20-28.
320 S. Liu, J. Feng, X. Bian, J. Liu, H. Xu and Y. An, Energy Environ. Sci., 2017, 10, 1222-1233.

321 Y. Zhang, H. Gao, J. Niu, W. Ma, Y. Shi, M. Song, Z. Peng and Z. Zhang, ACS Nano, 2018, 12, 11678-11688.

322 Y. Zhang, M. Li, F. Huang, Y. Li, Y. Xu, F. Wang, Q. Yao, H. Zhou and J. Deng, Appl. Surf. Sci., 2020, 499, 143907.

323 S. Sun, C. Liao, A. M. Hafez, H. Zhu and S. Wu, Chem. Eng. J., 2018, 338, 27-45.

324 L. Verger, V. Natu, M. Carey and M. W. Barsoum, Trends Chem., 2019, 1, 656-669.

325 H. Tang, Q. Hu, M. Zheng, Y. Chi, X. Qin, H. Pang and Q. Xu, Prog. Nat. Sci.: Mater. Int., 2018, 28, 133-147.

326 F. Wu, Y. Jiang, Z. Ye, Y. Huang, Z. Wang, S. Li, Y. Mei, M. Xie, L. Li and R. Chen, J. Mater. Chem. A, 2019, 7, 1315-1322.

327 X. Guo, W. Zhang, J. Zhang, D. Zhou, X. Tang, X. Xu, B. Li, H. Liu and G. Wang, ACS Nano, 2020, 14, 3651-3659.

328 R. Zhao, Z. Qian, Z. Liu, D. Zhao, X. Hui, G. Jiang, C. Wang and L. Yin, Nano Energy, 2019, 65, 104037.

329 X. Sun, K. Tan, Y. Liu, J. Zhang, L. Hou and C. Yuan, Chin. Chem. Lett., 2020, 31, 2254-2258.

330 Q. Yang, W. Gao, W. Zhong, M. Tao, Y. Qi, S.-j. Bao and M. Xu, New J. Chem., 2020, 44, 3072-3077.

331 C. Yue, Y. Yu, S. Sun, X. He, B. Chen, W. Lin, B. Xu, M. Zheng, S. Wu, J. Li, J. Kang and L. Lin, Adv. Funct. Mater., 2015, 25, 1386-1392.

332 R. Chen, Y. Huang, M. Xie, Q. Zhang, X. Zhang, L. Li and F. Wu, ACS Appl. Mater. Interfaces, 2016, 8, 16078-16086.

333 A. Lahiri, M. Olschewski, R. Gustus, N. Borisenko and F. Endres, Phys. Chem. Chem. Phys., 2016, 18, 14782-14786.

334 H. Usui, S. Yoshioka, K. Wasada, M. Shimizu and H. Sakaguchi, ACS Appl. Mater. Interfaces, 2015, 7, 6567-6573.

335 T. Wu, J. Sun, Z. Q. Jeremy Yap, M. Ke, C. Y. H. Lim and L. Lu, Mater. Des., 2020, 186, 108287.

336 Y. Zhang, L. Tao, C. Xie, D. Wang, Y. Zou, R. Chen, Y. Wang, C. Jia and S. Wang, Adv. Mater., 2020, 32, 1905923.

337 T. Sun, J. Xie, W. Guo, D. S. Li and Q. Zhang, Adv. Energy Mater., 2020, 10, 1904199.

338 X. Yin, S. Sarkar, S. Shi, Q. A. Huang, H. Zhao, L. Yan, Y. Zhao and J. Zhang, Adv. Funct. Mater., 2020, 30, 1908445.

339 V. Georgakilas, M. Otyepka, A. B. Bourlinos, V. Chandra, N. Kim, K. C. Kemp, P. Hobza, R. Zboril and K. S. Kim, Chem. Rev., 2012, 112, 6156-6214.

340 Q. Zhao, J. Wang, C. Chen, T. Ma and J. Chen, Nano Res., 2017, 10, 4245-4255.

341 H. Wu, K. Wang, Y. Meng, K. Lu and Z. Wei, J. Mater. Chem. A, 2013, 1, 6366-6372.

342 G. Zhang, X. Ou, C. Cui, J. Ma, J. Yang and Y. Tang, Adv. Funct. Mater., 2019, 29, 1806722.

343 D. Xie, M. Zhang, Y. Wu, L. Xiang and Y. Tang, Adv. Funct. Mater., 2019, 30, 1906770. 